International Scientific-Technical and Production Journal

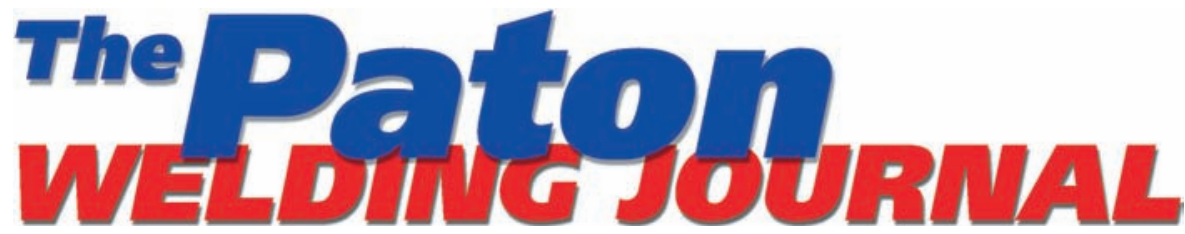

\section{EDITORIAL BOARD \\ Editor-in-Chief B.E. Paton}

Scientists of PWI, Kyiv S.I. Kuchuk-Yatsenko (vice-chief ed.), V.N. Lipodaev (vice-chief ed.)

Yu.S. Borisov, G.M. Grigorenko A.T. Zelnichenko, V.V. Knysh,

I.V. Krivtsun, Yu.N. Lankin, L.M. Lobanov, V.D. Poznyakov, I.A. Ryabtsev, K.A. Yushchenko

Scientists of Ukrainian Universities V.V. Dmitrik, NTU «KhPI», Kharkov V.V. Kvasnitsky, NTUU «KPI», Kyiv E.P. Chvertko, NTUU «KPI», Kyiv

Foreign Scientists

N.P. Alyoshin

N.E. Bauman MSTU, Moscow, Russia Guan Qiao

Beijing Aeronautical Institute, China

M. Zinigrad

Ariel University, Israel V.I. Lysak

Volgograd STU, Russia Ya. Pilarczyk

Welding Institute, Gliwice, Poland U. Reisgen

Welding and Joining Institute, Aachen, Germany G.A. Turichin

St. Petersburg SPU, Russia

Founders

E.O. Paton Electric Welding Institute, NASU

International Association «Welding» Publisher

International Association «Welding» Translators

A.A. Fomin, O.S. Kurochko, I.N. Kutianova Editor

N.G. Khomenko

Electron galley

D.I. Sereda, T.Yu. Snegiryova Address

E.O. Paton Electric Welding Institute,

International Association «Welding»

11 Kazimir Malevich Str. (former Bozhenko Str.), 03150, Kyiv, Ukraine

Tel.: (38044) 20060 16, 2008277

Fax: (38044) 20082 77, 2008145

E-mail: journal@paton.kiev.ua

www.patonpublishinghouse.com

State Registration Certificate

KV 4790 of 09.01 .2001

ISSN 0957-798X

DOI: http://dx.doi.org/10.15407/tpwj Subscriptions

$\$ 348,12$ issues per year

air postage and packaging included. Back issues available.

All rights reserved.

This publication and each of the articles contained herein are protected by copyright.

Permission to reproduce material contained in this journal must be obtained in writing from the Publisher.

\section{CONTENTS}

\section{SCIENTIFIC AND TECHNICAL}

Golovko V.V. Possibilities of nanomodification of dendrite structure of

weld metal

Rejdemejster A.G., Kalashnik V.A., Knysh V.V. and Solovej S.A. Fatigue resistance of welded elements of freight cars of a new design made from steels of S345 and S390 strength grade

Saraev Yu.N., Lunev A.G., Kiselev A.S., Gordynets A.S. and Trigub M.V.

Complex for investigation of arc welding processes

\section{INDUSTRIAL}

Nesterenkov V.M., Orsa Yu.V., Khripko K.S. and Makhnenko O.V.

Technology for EBW of aircraft structures of titanium alloys

Akhonin S.V., Belous V.Yu. and Selin R.V. Effect of thermal cycle of TIG welding on structure and properties of pseudo- $\beta$-titanium alloys

Markov I.B., Petrik I.A., Seliverstov A.G. and Marchenko Yu.A. Repair of large-sized blades of the fan of gas-turbine engine

Babinets A.A., Ryabtsev I.A. and Panfilov A.I. Materials for individual armour protection (Review)

Razmyshlyaev A.D., Vydmysh P.A. and Ageeva M.V. Procedure for determination of induction of controlling magnetic field in pool zone during arc welding

\section{INFORMATION}

Professor Jan Pilarczyk

Interview with A.I. Panfilov — Director of Welding Department

of «Steel Work» LLC 


\title{
POSSIBILITIES OF NANOMODIFICATION OF DENDRITE STRUCTURE OF WELD METAL
}

\author{
V.V. GOLOVKO \\ E.O. Paton Electric Welding Institute of the NAS of Ukraine \\ 11 Kazimir Malevich Str., 03150, Kyiv, Ukraine. E-mail: office@paton.kiev.ua
}

\begin{abstract}
Possibility of application of refractory disperse compounds for nanomodification of weld metal was shown. The results of calculation of the optimum size of modifier particles for weld pool conditions are given. Effect of the refractory particles on the parameters of weld metal primary structure was determined. Increase of dendrite size, noted as a result of addition into a weld pool of titanium carbide and zirconium oxide compounds, is accompanied by change of relationship between content of upper and lower bainite preserving fraction of martensite and xenomorphic ferrite. Indices of ductility as well as toughness of weld metal increase as a result. 14 Ref., 4 Tables, 3 Figures.
\end{abstract}

Keywords : fusion welding; weld metal modification, nanodisperse particles, particle size, dendrite size, microstructure, mechanical properties

Rolled steel continues to be the main material in manufacture of welded metal structures and in the closest time will keep its position in this sphere. Continuous growth of the requirements to safety and workability of structures in combination with the necessity to reduce costs on their manufacture have promoted intensive growth of application of innovative solutions in steel rolling production. Modern low-alloy high-strength steels have submicron or micron structure, that provides their high service properties, however, the practice showed that complication of rolled stock production technology promotes increase of amount of problems appearing in its welding.

Formation of weld metal structure starts in the process of solidification of the weld pool from the boundaries of partially fused grains of the base metal, but heredity principle is violated in this process. Thus, for example, welding of metal with grain size up to $10 \mu \mathrm{m}$ forms the weld, in which grain size can reach $100 \mu \mathrm{m}$ and more. Such nonconformity is related with the fact that a steel billet in process of rolling is subjected to complex thermomechanical treatment with different mode of reheating and cycle of applied forces for the purpose of production of fine structure. The weld is formed as cast metal, which is not subjected to such treatment, therefore, other technological means are necessary for refinement of its structure. Traditionally, technologies of alloying, microalloying and modification are used for refinement of weld metal structure in addition to variation of welding mode parameters. These technologies, which has appeared at the end of 1950th and entered to the market of rolling of high-strength low-alloy steels, have been de-

(C) V.V. GOLOVKO, 2018 veloped and improved till the recent time, however, up to the moment they have exhausted their potential. The practice showed that increase of alloying level results in decrease of ductility and toughness indices of metal, and rise of content of modifiers can lead to grain boundary embrittlement. Further development requires application of new technologies of formation of weld metal fine structure.

Traditionally, the modification processes, which are well studied and described in details (for example in monograph [1]) and widely used in practice, are applied for these purposes. Improvement of resolution capability of the equipment used for metallographic investigations, promoted increase of number of publications in the field of nanomaterials and nanotechnologies, including nanomodification [2-5].

Modification processes allow changing size and shape of primary crystals and carried in the recent years investigations showed that [6-10] application of nanotechnologies, which is based on peculiarities of physical-chemical and surface properties of powder materials, can have significant modifying effect due to high specific surface of nanomaterials and high energy activity of the nanoparticles.

Proceeding from the differences of hydrodynamic situation in the weld pool from the metallic melt in steel casting, the main possibilities of effect on formation of dendrite structure of weld metal are related with presence of high-speed convective flows close to a solidification front, thermocapillary movement in interdendritic space and value of interphase tension at the boundary of growing dendrite with metallic melt. If the first two factors can be effect by variation of the parameters of welding modes, than the latter to signif- 
Table 1. Time of dissociation of inclusions, $\mathrm{s}$

\begin{tabular}{|c|c|c|c|c|c|c|c|c|c|c|}
\hline \multirow{2}{*}{ Inoculant } & \multicolumn{10}{|c|}{ Size of inclusions, $\mu \mathrm{m}$} \\
\cline { 2 - 26 } & 1.0 & 2.0 & 5.0 & 10 & 20 & 40 & 80 & 120 & 160 & 200 \\
\hline $\mathrm{TiC}$ & 0.05 & 0.21 & 1.34 & 5.35 & 21.40 & 85.61 & 342.46 .8 & 770.53 & 2140.4 \\
\hline $\mathrm{TiN}$ & 0.01 & 0.06 & 0.35 & 1.40 & 5.60 & 22.40 & 89.61 & 201.62 & 360.1 \\
\hline $\mathrm{TiO}_{2}$ & 0.03 & 0.13 & 0.83 & 3.33 & 13.32 & 53.29 & 213.15 & 479.59 & 852.6 & 1332.3 \\
\hline
\end{tabular}

icant extent depends on presence of the surface-active refractory compounds in a layer of metallic melt before growing dendrite front. In order to increase the efficiency of such effect the size of refractory particles should correspond to the size of growing dendrite tip. Process of pool solidification in welding of low-alloy high-strength steels provokes formation of dendrites of 30-40 $\mu \mathrm{m}$ size, on surface of which appear new centers of growth initiation (branches of second order) of around $10 \mu \mathrm{m}$ size [11] . Efficiency of addition into the weld pool (inoculation) of the refractory particles depends on their size, since too small particles, due to high intensity of their dissociation in the melt, can have no effect on metal solidification, but too big are able to behave themselves as coarse nonmetallic inclusions [5]. In order to choose the optimum inoculant size it is necessary to determine probable time of existence of the disperse particles in the metal melt, i.e. the time during which they can have effect on formation of weld solidification structure.

Let's use procedure proposed in work [12] for calculations. In welding of low-alloy steels significant attention should be paid on effect of nonmetallic inclusions containing titanium compounds on structure and properties of weld metal. In this connection, let's consider the possibility of application of some refractory compounds of titanium as disperse inoculants. Their physical-chemical characteristics presented below and they were used for thermodynamic calculations.

\section{Physical-chemical characteristics}

Density, $\cdot 10^{3}, \mathrm{~kg} / \mathrm{m}^{3}$ :

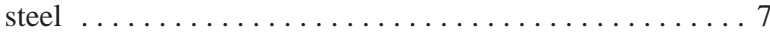

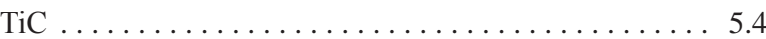

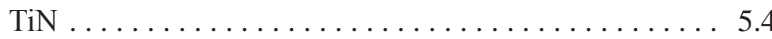

$\mathrm{TiO}_{2} \ldots \ldots \ldots \ldots \ldots \ldots \ldots \ldots \ldots \ldots .4 .25$

Content in weld metal, wt.\% $\left(\mathrm{kg} / \mathrm{m}^{3}\right)$ :

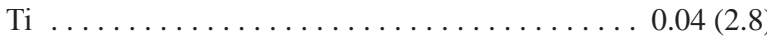

C ............................. $0.07(4.9)$

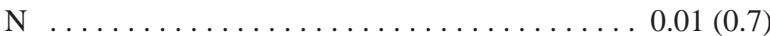

$\mathrm{O} \ldots \ldots \ldots \ldots \ldots \ldots \ldots \ldots \ldots . .06(4.2)$

Coefficient of diffusion in steel, $\cdot 10^{-9} \mathrm{~m}^{2} / \mathrm{s}$ :

Ti ............................. 8

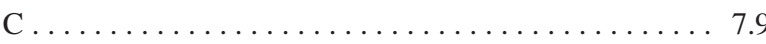

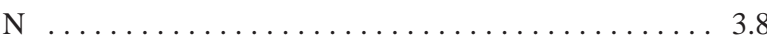

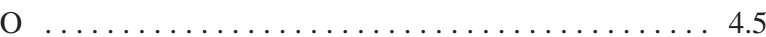

Equilibrium constant of dissociation reaction at $1873 \mathrm{~K}$ :

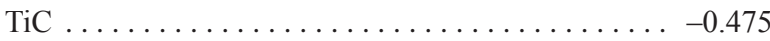

TiN . . . . . . . . . . . . . . . . . . . . . . . . . . . 2.515

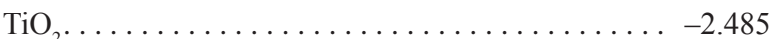

Coefficient of activity in weld metal:

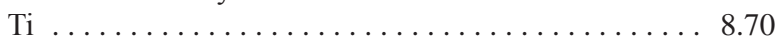

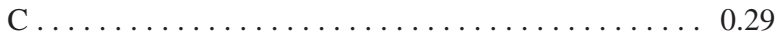

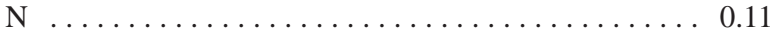

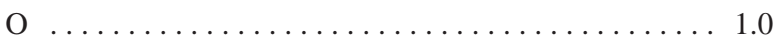

Thermodynamic calculations were carried out following the scheme, in accordance with which a transition layer, containing $[i]_{\text {suf }}$ elements present in inclusion content, is formed around a refractory inclusion of radius $r_{0}$ located in steel melt.

Time of complete dissociation $t$ is calculated from the expression

$$
t=\frac{r_{0}^{2} A_{i} \rho_{B}}{2 A_{B} D_{i}\left([i]_{\text {sur }}-[i]_{0}\right)},
$$

where $A_{i}$ and $A_{\text {inc }}$ are the atomic weights of element present in the inclusion and the inclusion itself; $[i]_{0}$ and $D_{i}$ are the content of element in metallic melt and coefficient of its diffusion in this melt; $\rho_{\text {inc }}$ is the inclusion density.

Based on the data, provided in the literature [13], time of existence of the weld pool depending on parameters of welding mode can lie in the limits from 2 to $15 \mathrm{~s}$. Table 1 shows the results of calculation of time necessary for complete dissociation of inoculants in steel melt without mixing.

Presence of the intensive flows of molten metal in the weld pool, rate of which can be an order higher than the welding rate [13], significantly increase rate of particles dissociation. The calculation estimations, carried on procedure [12], show that activity of dissociation processes in this case can rise by two orders in comparison with stationary conditions.

Proceeding from the received results of carried data calculations, it can be concluded that, first of all, to preserve the inoculants as active centers of effect on weld pool metal solidification processes it is reasonable to add them in form of disperse particles of refractory crystalline compounds of not less than $0.2 \mathrm{~mm}(200 \mu \mathrm{m})$ size; secondly, application of TiN for these purposes does not allow achievement of determined purposes since inclusions of up to $50 \mu \mathrm{m}$ size are virtually completely dissolved in steel melt and presence of coarser inclusions in the weld metal structure can promote decrease of level of their ductility and toughness indices. 

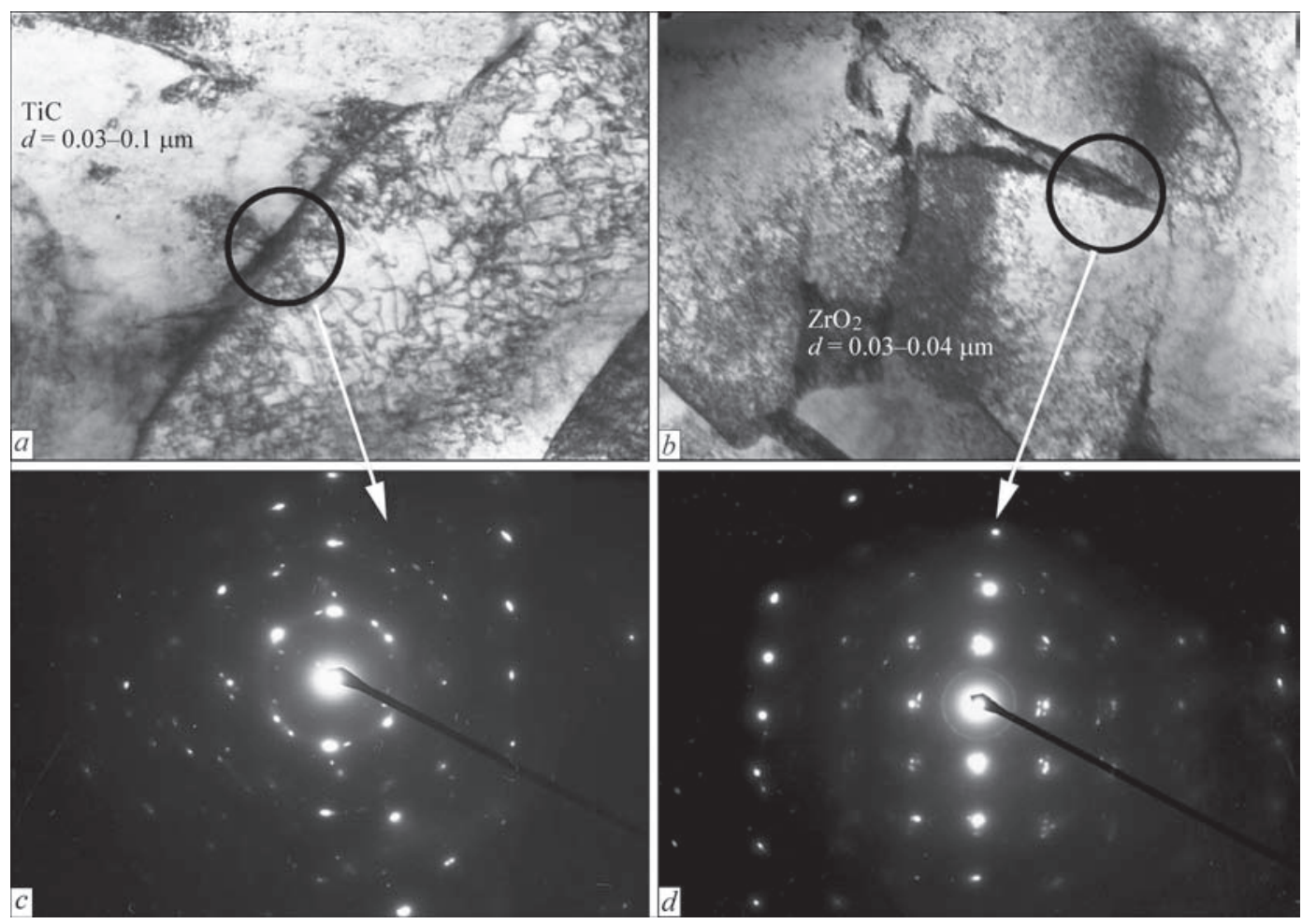

Figure 1. Fine structure of weld metal of $12 \mathrm{GN} 2 \mathrm{KhM}$ type, containing inclusions of TiC $(a, \times 37000), \mathrm{ZrO}_{2}(b, \times 20000)$; $c, d-$ diffraction pattern of areas with inclusions

In the process of growth of solid phase at interphase boundary in the metallic melt there is a layer of metal with increased content of liquation elements, which determines energy of interphase interaction at «liquid-solid» boundary, and, thus, value of overcooling and solidification rate, in accordance with expression

$$
\Delta T=\frac{\sigma_{1-\mathrm{s}} T_{1}}{r \rho q_{\mathrm{S}}},
$$

where $\sigma_{1-\mathrm{s}}$ is the value of interpahse tension at «liquid-solid» boundary; $T_{1}$ is the liquidus temperature of metallic melt; $r$ - is the critical radius of solid phase nucleus; $\rho$ and $q_{\mathrm{s}}$ are the density and specific heat of metal solidification.

Contact of the refractory inclusion with the boundary of growing dendrite changes the composition of boundary layer due to saturation with the products of inclusion dissociation that can be described by expression

$$
\Delta T=\frac{m C_{0}(1-k)}{k D},
$$

where $m$ is the tangent of inclination angle of alloy liquidus line; $C_{0}$ is the initial content of impurity in the melt; $k$ and $D$ are the coefficients of distribution and diffusion of impurity in the melt.

Varying the value of interphase tension at «liquidsolid» boundary, the inclusions can effect the rate of growth and morphology of dendrites in the solidifying metal, and the closer the dimensions of centers of dendrite and non-metallic inclusion initiation, the more noticeable this effect will be.

Figure 1 shows the samples of weld metal structure, received in arc welding of high-strength low-alloy steel with addition into the weld pool of refractory nonmetallic inclusions. The investigations were carried out with the samples of deposited metal received without addition of nanomodifiers (weld NM-0) as well as with addition of refractory compounds of titanium carbide (weld $\mathrm{TiC}$ ) and zirconium oxide (weld $\mathrm{ZrO}_{2}$ ). The particles of zirconium oxide and titanium carbide of $200 \mu \mathrm{m}$ size were added through a fluxcored wire core, which were supplied into the weld pool in form of filler. Metallographic examinations using transmission electron microscopy ${ }^{*}$, made on JEM-200CX device (JEOL Company) at accelerating voltage of $200 \mathrm{kV}$ showed that the added disperse inclusions do not have complete dissociation in the liquid metal and locate at the boundaries of secondary structure grains. When adding disperse refractory compounds of not more than $200 \mu \mathrm{m}$ size in the weld pool corresponding compounds of 30-100 nm size were revealed at the boundaries of secondary structure grains. It indicates sufficiently high resistance of these inclusions in liquid as well as solid steel solutions.

To clear up the problem of possible effect of these inclusions on the dendrite structure, the primary struc-

${ }^{*}$ The examinations were carried out by Dr. L.I. Markashova. 

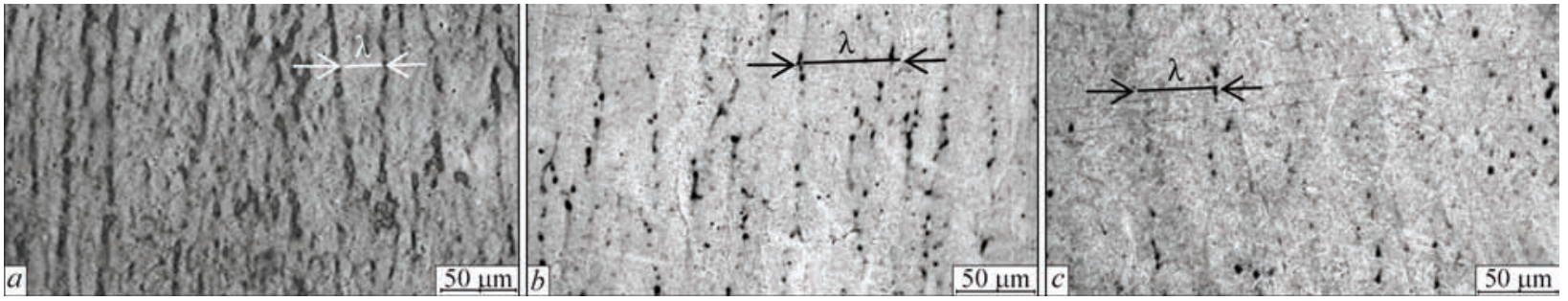

Figure 2. Dendrite structure of weld metal: $a-\mathrm{NM}-0 ; b-\mathrm{TiC} ; c-\mathrm{ZrO}_{2}(\lambda-$ size of columnar dendrites $)$
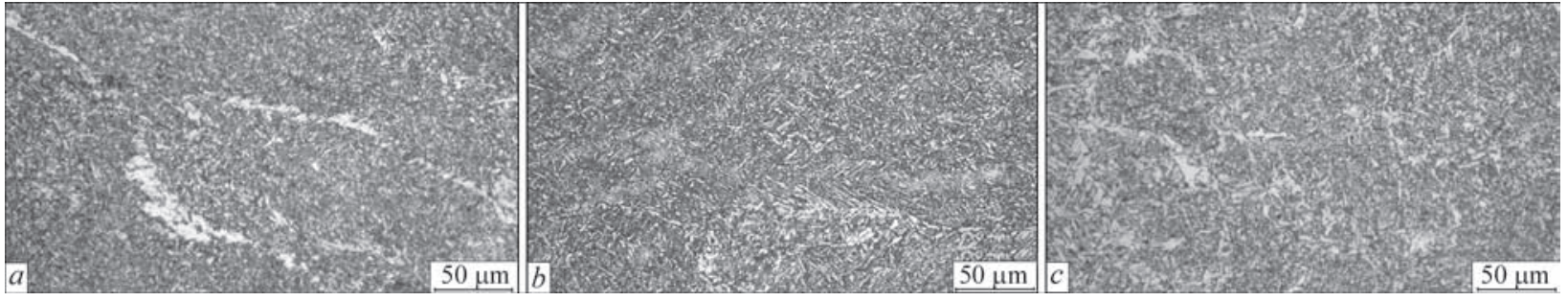

Figure 3. Secondary structure of weld metal: $a-\mathrm{NM}-0 ; b-\mathrm{ZrO}_{2}$

ture of weld metal was examined on polished samples, etched in boiling saturated sodium picrate solution $\left(\mathrm{C}_{6} \mathrm{H}_{2}\left(\mathrm{NO}_{2}\right)_{3} \mathrm{ONa}\right)$ in water. A microstructure of the last pass of metal of multipass weld (cast structure) was examined. The samples were cut out in a direction normal to longitudinal weld axis, in such a way that dendrites, which grew in the direction of the highest thermal gradient in the weld pool, were observed on section surface. The dimensions of columnar dendrites (dimensions $\lambda$ on Figure 2 ) were determined during examination of the primary structure on the images, received by method of optical metallography*, which were made on optical microscope NEOPHOT 30.

The analysis results showed that presence in the weld pool of nanosize refractory compounds have modifying effect on dendrite sizes. If in the initial metal (weld NM-0) the averaged width of dendrites made $25 \mu \mathrm{m}$, than as a result in addition of nanosize titanium carbide compounds (weld $\mathrm{TiC}$ ) and zirconi- um oxide (weld $\mathrm{ZrO}_{2}$ ) this index rose to 44 and $37 \mu \mathrm{m}$ level, respectively.

Change of dendrite morphology effected formation of secondary structure (Figure 3, Table 2) and level of mechanical properties of weld metal (Table 3 ). It can be seen from data presented in Tables 2-4 that addition of nanomodifiers has virtually no effect on chemical composition of the weld metal, but content of their structural constituents significantly changed at that.

Increase of dendrite size, noted as a result of addition of titanium carbide and zirconium oxide compounds into the weld pool is accompanied by change

Table 2. Content of main structural constituents of weld metal

\begin{tabular}{|c|c|c|c|c|}
\hline \multirow{2}{*}{ Weld } & \multicolumn{4}{|c|}{ Portion of constituents in weld microstructure, \% } \\
\cline { 2 - 5 } & $\mathrm{Bl}$ & $\mathrm{Bu}$ & $\mathrm{M}$ & $\mathrm{F}$ \\
\hline $\mathrm{NM}-0$ & 25 & 60 & 10 & 5 \\
\hline $\mathrm{ZrO}_{2}$ & 65 & 20 & 10 & 5 \\
\hline $\mathrm{TiC}$ & 50 & 30 & 10 & 10 \\
\hline
\end{tabular}

Table 3. Mechanical properties of weld metal

\begin{tabular}{|c|c|c|c|c|c|c|c|c|}
\hline \multirow{2}{*}{ Weld } & \multicolumn{2}{|c|}{$\sigma_{\mathrm{t}}$} & \multicolumn{2}{c|}{$\sigma_{0.2}$} & \multicolumn{2}{c|}{$\kappa$} & \multicolumn{4}{c|}{$K C V, \mathrm{~J} / \mathrm{cm}^{2}$ at $T,{ }^{\circ} \mathrm{C}$} \\
\cline { 2 - 12 } & \multicolumn{2}{|c|}{$\mathrm{MPa}$} & \multicolumn{2}{|c|}{$\%$} & 20 & 0 & -20 & -40 \\
\hline $\mathrm{NM}-0$ & 788 & 739 & 11,4 & 35 & 60 & 58 & 57 & 52 \\
\hline $\mathrm{ZrO}_{2}$ & 645 & 556 & 21 & 60 & 116 & 96 & 98 & 82 \\
\hline $\mathrm{TiC}$ & 728 & 665 & 19 & 61 & 82 & 72 & 63 & 52 \\
\hline
\end{tabular}

Table 4. Composition of weld metal

\begin{tabular}{|c|c|c|c|c|c|c|c|c|c|c|}
\hline Weld & $\mathrm{C}$ & $\mathrm{Si}$ & $\mathrm{Mn}$ & $\mathrm{S}$ & $\mathrm{P}$ & $\mathrm{Ni}$ & $\mathrm{Mo}$ & $\mathrm{Al}$ & $\mathrm{Ti}$ & $\mathrm{Zr}$ \\
\hline $\mathrm{NM}-0$ & 0.050 & 0.290 & 1.32 & 0.024 & 0.014 & 2.19 & 0.27 & 0.039 & 0.019 & $\mathrm{H} / \mathrm{o}$ \\
\hline $\mathrm{ZrO}_{2}$ & 0.053 & 0.138 & 0.94 & 0.020 & 0.024 & 1.55 & 0.23 & 0.021 & 0.005 & 0.06 \\
\hline $\mathrm{TiC}$ & 0.046 & 0.340 & 1.39 & 0.021 & 0.019 & 1.70 & 0.24 & 0.033 & 0.011 & $\mathrm{H} / \mathrm{o}$ \\
\hline
\end{tabular}

${ }^{*}$ The examinations were carried out by Cand. of Tech. Sci. D.Yu. Ermolenko. 
of relationship between content of upper $\left(\mathrm{B}_{\mathrm{u}}\right)$ and lower bainite $\left(B_{1}\right)$ at preservation of portion of martensite (M) and xenomorphic ferrite (F). It results in rise of ductility as well as toughness indices of the weld metal (Table 3).

Present paper does not consider the problems related with technology of addition of the modifiers into the weld pool, selection of their type, size and composition. These problems are referred to further investigations. This paper reflects the possibilities of application of refractory disperse compounds for nanomodification of weld metal.

1. Goldshtejn, Ya.E., Mizin, V.G. (1986) Modification and microalloying of cast iron and steel. Moscow, Metallurgiya [in Russian].

2. Hashimoto, M. (2005) Advances in nano-level materials characterization technology. Nippon Steel Technical Report, 91(1), 2-6.

3. Suito, H., Ohta, H., Morioka, S. (2006) Refinement of solidification microstructure and austenite grain by inclusion particles. ISIJ Int., 46(6), 840-846.

4. Davydov, S.V. (2006) Nanomodificator as a tool of genetic engineering of structural state of cast iron melt. In: Proc. of Casting Council No. 1 on Modification as an Effective Method for Improvement of Quality of Cast Irons and Steels. Chelyabinsk, Chelyabinsky Dom Pechati [in Russian].
5. Ryabtsev, I.A., Kondratiev, I.A., Gadzyra, N.F. et al. (2009) Effect of ultra-dispersed carbides contained in flux-cored wires on properties of heat-resistant deposited metal. The Paton Welding J., 6, 10-13.

6. Saburov, V.P., Eremin, E.N., Cherpanov, A.N., Minnekhanov, G.N. (2002) Modification of steels and alloys by disperse inoculants. Omsk, Izd. OmGTU [in Russian].

7. Bolshakov, V.I., Kalinin, A.V. (2016) Particularities of structure formation of modified Si-Mn steels. Stroitelstvo, Materialovedenie, Mashinostroenie, 89, 24-29 [in Russian].

8. Borisenko, V.E., Tolochko, N.K. (2008) Nanomaterials and nanotechnologies. Minsk, Tsentr BRU [in Russian].

9. Golovin, Yu.I. (2003) Introduction to nanotechnology. Moscow, Mashinostroenie [in Russian].

10. Bolshakov, V.I., Tushinsky, L.I. (2010) Structural theory of hardening of structural steels and other materials. Dniepropetrovsk, Svidler [in Russian].

11. Vanovsek, W., Bernhard, C., Fiedler, M., Posch, G. (2012) Influence of aluminum content on the characterization of microstructure and inclusions in high-strength steel welds. Weld. World, 57(1), 73-83.

12. Cherepanov, A.N., Afonin, Yu.V., Malikov, A.G., Orishich, A.M. (2008) About application of refractory compounds in laser welding and treatment of metals and alloys. Tyazholoe Mashinostroenie, 4/2, 25-26 [in Russian].

13. Grigoryan, V.A., Stomakhin, A.Ya., Ponomarenko, A.G. et al. (1989) Physicochemical calculations of electric steelmaking processes. Moscow, Metallurgiya [in Russian].

14. Erokhin, A.A. (1973) Principles of fusion welding. Physicochemical fundamentals. Moscow, Mashinostroenie [in Russian].

Received 05.07.2018 


\title{
FATIGUE RESISTANCE OF WELDED ELEMENTS OF FREIGHT CARS OF A NEW DESIGN MADE FROM STEELS OF S345 AND S390 STRENGTH GRADE
}

\author{
A.G. REJDEMEJSTER ${ }^{1}$, V.A. KALASHNIK ${ }^{1}$, V.V. KNYSH ${ }^{2}$ and S.A. SOLOVEJ ${ }^{2}$ \\ ${ }^{1}$ Acad. V. Lazaryan Dnipropetrovsk National University of Railway Transport \\ 2 Lazaryan Str., 49010, Dnepr, Ukraine. E-mail: dnuzl@diit.edu.ua \\ ${ }^{2}$ E.O. Paton Electric Welding Institute of the NAS of Ukraine \\ 11 Kazimir Malevich Str., 03150, Kyiv, Ukraine. E-mail: office@paton.kiev.ua
}

\begin{abstract}
The paper presents the results of experimental-calculation studies of fatigue resistance of full-scale samples of the bolster assembly and side wall rack sealing assembly of a gondola car of 12-4106-01 model. It is found that their operating life is determined by fatigue resistance of welded joints of structural elements of the assemblies. Their fatigue strength is equal from 12.1 MPa (side wall rack sealing assembly) up to 33.6 MPa (bolster assembly). Sections of fatigue cracks initiation, regularities of their propagation and fatigue limit of the structure were established. As shown by calculation of the car body stressed state, the fatigue limit values ensure operation for 34.1 and 57.0 years for the bolster assembly and side wall rack sealing assembly, respectively, before appearance of the fatigue crack. 9 Ref., 2 Tables, 8 Figures.
\end{abstract}

Ke y words: welded elements of freight cars, bolster assembly, side wall rack sealing assembly, fatigue resistance, stressed state

The most damaged elements of gondola cars in operation are the assemblies of joining the elements of the frame and racks of the side walls. Reduction of loading of these assemblies creating the preconditions for extending the service life and reducing the cost of car repair is a priority in development of the new generation rolling stock. In this connection, PJSC «Dneprovagonmash» developed 12-4106-01 model of gondola car with side wall racks of a tubular design, which envisages increase of the strength of the latter. Figure 1 gives the general view of the assembly.

Strength characteristics of car elements were improved also due to application of steels of strength grades C345 (racks) and C390 (bolster assembly).

Owing to modification of the design and application of materials with improved strength characteristics, the specified service life was extended up to 32 years that should be confirmed by the results of the work on residual life assessment.

Such problems were earlier considered in papers [1-4]. The problem of investigation of fatigue strength of side wall rack sealing is considered for the first time in [4], and work [1] shows that the existing norms for fatigue strength assessment do not fully reflect the real service conditions and defines the ways of further development of calculation-experimental assessment of fatigue strength of freight car bodies. Works [2, 3] give the results of investigations of fa- tigue strength of side wall rack sealing with improved strength characteristics for gondola cars with axle loads of 23.5 and $25 \mathrm{tf}$.

Acad. V. Lazaryan Dnepropetrovsk National University of Railway Transport (DNURT), by the request of PJSC «Dneprovagonmash», performed a package of work on assessment of the residual life of assem-

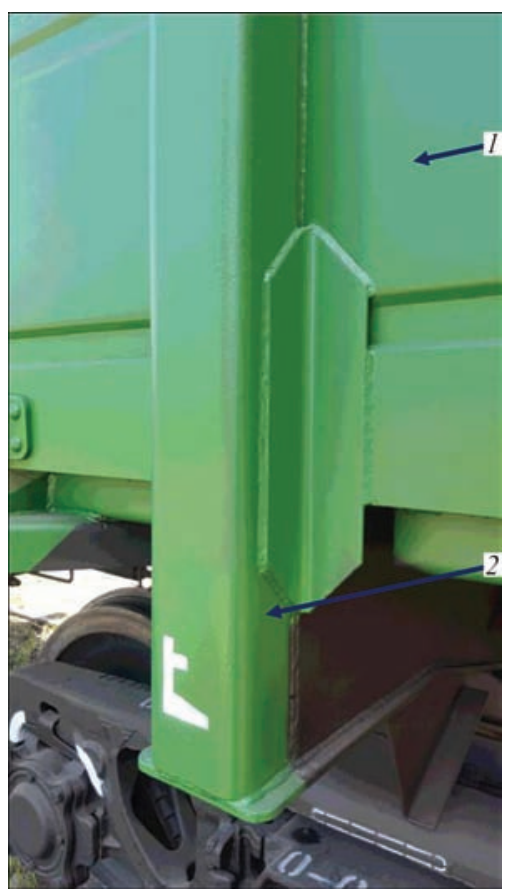

Figure 1. Side wall rack sealing assembly (1) of a gondola car of 12-4106-01 model (2) 


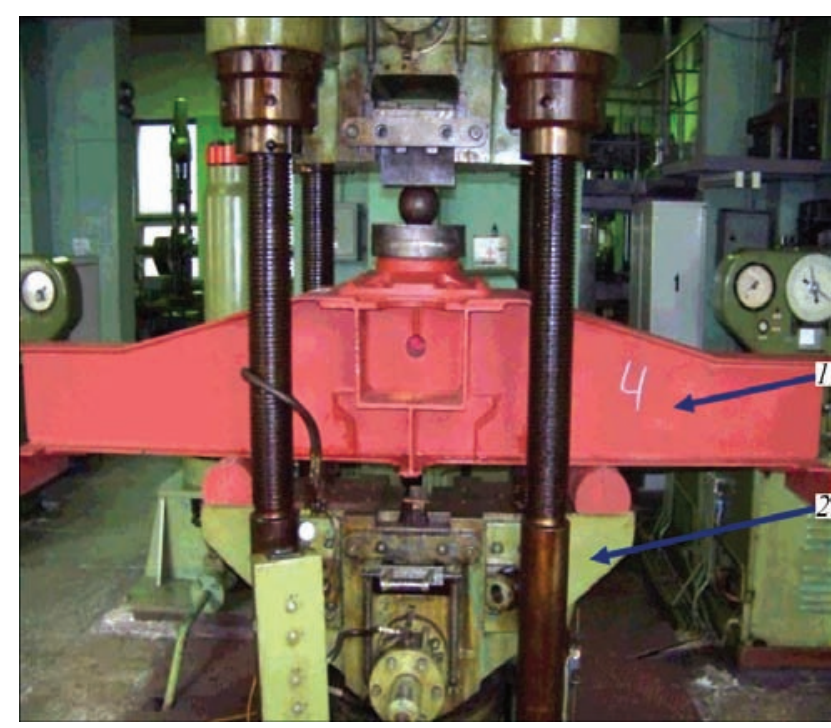

Figure 2. Sample of bolster assembly No.4 (1) in testing machine ZDM-200pu (2)

blies, including bench testing of full-scale samples of the gondola car for evaluation of the stress-strain state and fatigue resistance, as well as calculation-experimental assessment of the assembly residual life.

Service life of the assembly up to initiation of fatigue damage, in keeping with the acting normative documentation [5-8], is assessed by Palmgren-Miner hypothesis, in the assumption that the fatigue curve consists of two sections with values $m_{1}$ and $m_{2}=2 m_{1}$ 1, divided by point $N_{0}=10^{7}$ (number of basic cycles). Stresses $\sigma_{a, N}$, the structure fatigue limit, correspond to this point.

The objective of experimental research conducted at PWI consisted in revealing the structure sections with the worst fatigue resistance values and deter-

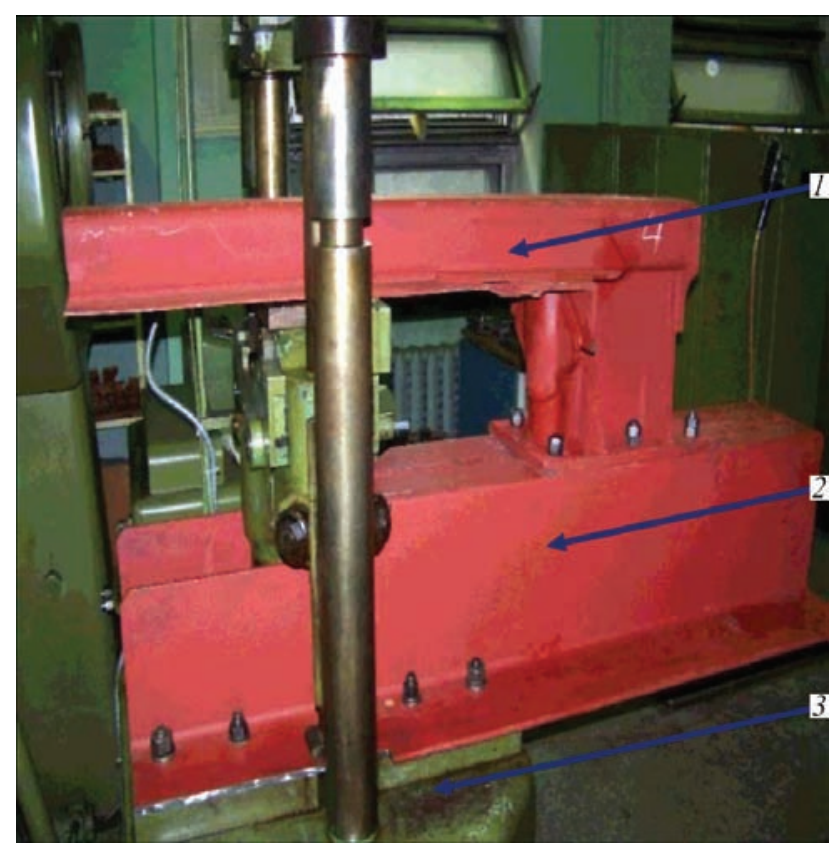

Figure 3. Sample of side wall rack sealing assembly No.4 (1) installed on a platform, (2) in testing machine ZDM-10pu (3) mination of the value of fatigue limit $\sigma_{a},{ }_{N}$ for them. The sequence of experimental research performance is set forth in [9]. Because of the limited volume of experimental data, the fatigue curve was not plotted, assuming the value of index $m_{1}=3$ recommended in normative documentation [5].

Four full-scale samples of the bolster assembly and side wall rack sealing assembly each were prepared. Three samples of each kind were subjected to fatigue testing to fracture. Strain measurement was performed in the remaining sample for validation of finite-element models of the assemblies. Sample positioning in hydropulsating machines ZDM-200pu (bolster assembly) and ZDM-10pu (side wall rack sealing assembly) is shown in Figures 2, 3. Testing was conducted at sinusoidal alternating loading cycle. Maximum and minimum loads were set so that fracture (loss of load-carrying capacity) of the sample occurred under the conditions of elastic stress-strain state in the region of high-cycle fatigue (up to $5 \mathrm{mln}$ loading cycles). As average cycle stresses are not taken into account in normative documentation [5, 7] at assessment of fatigue resistance, the values of loading cycle asymmetry (ratio of the smallest to the largest load) of the bolster assembly and side wall rack sealing assembly differed (were assigned proceeding from testing machine capabilities). Loading frequency of the bolster assembly and side wall rack sealing assembly was equal to 5.5 and $7.0 \mathrm{~Hz}$, respectively, and was assigned proceeding from technical characteristics of ZDM-200pu and ZMD-10pu testing machines.

During testing, the number of loading cycles up to appearance of cracks, their location and size, as well as number of cycles to sample fracture were recorded.

As the process of fatigue crack initiation and propagation in all the three samples of the bolster assembly was identical, the kinetics of fatigue fracture of just bolster assembly No.4 is given below as an example. Sample of bolster assembly No.4 was tested at cyclic loading $\left(P_{\text {min }}=98.1 \mathrm{kN}\right.$ and $\left.P_{\text {max }}=883 \mathrm{kN}\right)$ with the frequency of $5.5 \mathrm{~Hz}$. The distance between the supports was $1400 \mathrm{~mm}$. The following was found at 797 thou cycles: crack at the top of the coverplate on the vertical plate near the center sill (crack T5) $20 \mathrm{~mm}$ long and crack between the vertical plate of the body bolster and web of Z-shaped center sill (crack T6) $25 \mathrm{~mm}$ long (Figure 4). After 1029 thou cycles a crack was found in the lower horizontal plate of the body bolster at the center sill I-beam (crack T7) $35 \mathrm{~mm}$ long. After operating for 1126 thou cycles of stress alternation, the length of crack $\mathrm{T} 5$ of $20 \mathrm{~mm}$ remained unchanged, crack T6 propagated up to $35 \mathrm{~mm}$, and 


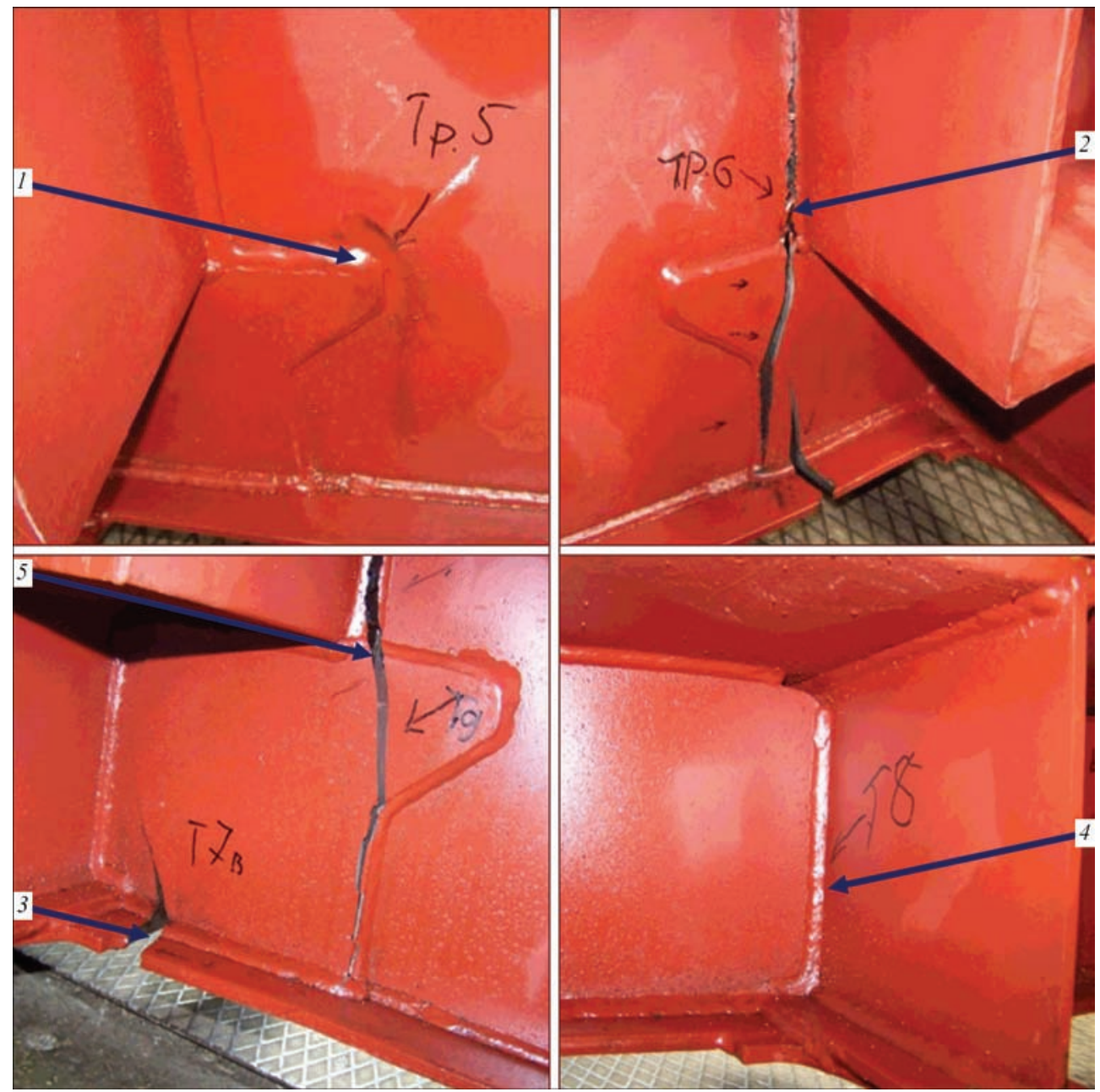

Figure 4. Cracks in bolster assembly (sample No.4): 1 - crack T5; 2 - T6; 3 - T7; 4 - T8; 5 - T9 from crack T6 on the other side from center sill

T7 started propagating both in the vertical (along the bolster assembly side wall) up to $10 \mathrm{~mm}$, and in the horizontal direction (along the lower chord) - up to $55 \mathrm{~mm}$. At 1282 thou cycles T7 crack along the vertical propagated up to $40 \mathrm{~mm}$, and along the horizontal - up to $90 \mathrm{~mm}$. A new crack was also revealed between the center sill I-beam (crack T8) $55 \mathrm{~mm}$ long. After 1458 thou cycles, the length of crack T5 of $20 \mathrm{~mm}$ remained unchanged, T6 propagated in the base material of the vertical plate of body bolster up to $45 \mathrm{~mm}$, T7 grew in the vertical direction up to $80 \mathrm{~mm}$, and up to $130 \mathrm{~mm}$ in the horizontal direction, crack T8 grew up to $180 \mathrm{~mm}$. After testing for 2346 thou cycles, a crack was found between the vertical plate of body bolster and web of Z-shaped center sill (crack T9) $50 \mathrm{~mm}$ long (from the opposite side of T6). After testing for 2815 thou cycles, the length of crack T5 was equal to $22 \mathrm{~mm}$, T6 $-150 \mathrm{~mm}$; T7 reached the length of $150 \mathrm{~mm}$, both along the vertical and the horizontal, T8 $-180 \mathrm{~mm}, \mathrm{~T} 9-120 \mathrm{~mm}$. The process of active fracture of the bolster assembly started after 2971 thou loading cycles: crack T6 grew up to $250 \mathrm{~mm}$, and crack T9 - up to $180 \mathrm{~mm}$. At 2995 thou cycles crack T6 reached the length of $320 \mathrm{~mm}$, and T9 was $300 \mathrm{~mm}$ ), and at 3031 thou cycles the sample failed.

As the process of fatigue crack initiation and propagation was identical in all the three samples of side wall rack sealing, kinetics of fatigue fracture of just sealing of the rack of side wall No.4 is given below as an example. Sample of sealing of the rack of side wall No.4 was tested at cyclic loading $\left(P_{\min }=41.2 \mathrm{kN}\right.$ and $P_{\max }=68.7 \mathrm{kN}$ ) with the frequency of $7.0 \mathrm{~Hz}$. At 325 thou loading cycles fatigue cracks $\mathrm{T} 1$ and $\mathrm{T} 2$ were found in the joint of the cross-beam (coverplate over the upper flange) with the lower chord $18 \mathrm{~mm}$ and $15 \mathrm{~mm}$ long, respectively, as well as crack T3 in the joint of the reinforcing angle bar and lower chord $10 \mathrm{~mm}$ long (Figure 5). Furtheron, at 931 thou loading cycles crack T1 grew up to $25 \mathrm{~mm}, \mathrm{~T} 2$ up to $50 \mathrm{~mm}$, and length of crack T3 did not change. At 1550 thou loading cycles, coalescence of cracks $\mathrm{T} 1$ and $\mathrm{T} 2 \mathrm{oc}-$ curred, their total length being $110 \mathrm{~mm}$, crack T3 grew up to $22 \mathrm{~mm}$, and new fatigue cracks were found: T4 and $\mathrm{T} 6$ in the joint of the rack of side wall and lower chord (from two sides), of 10 and $38 \mathrm{~mm}$ length, re- 

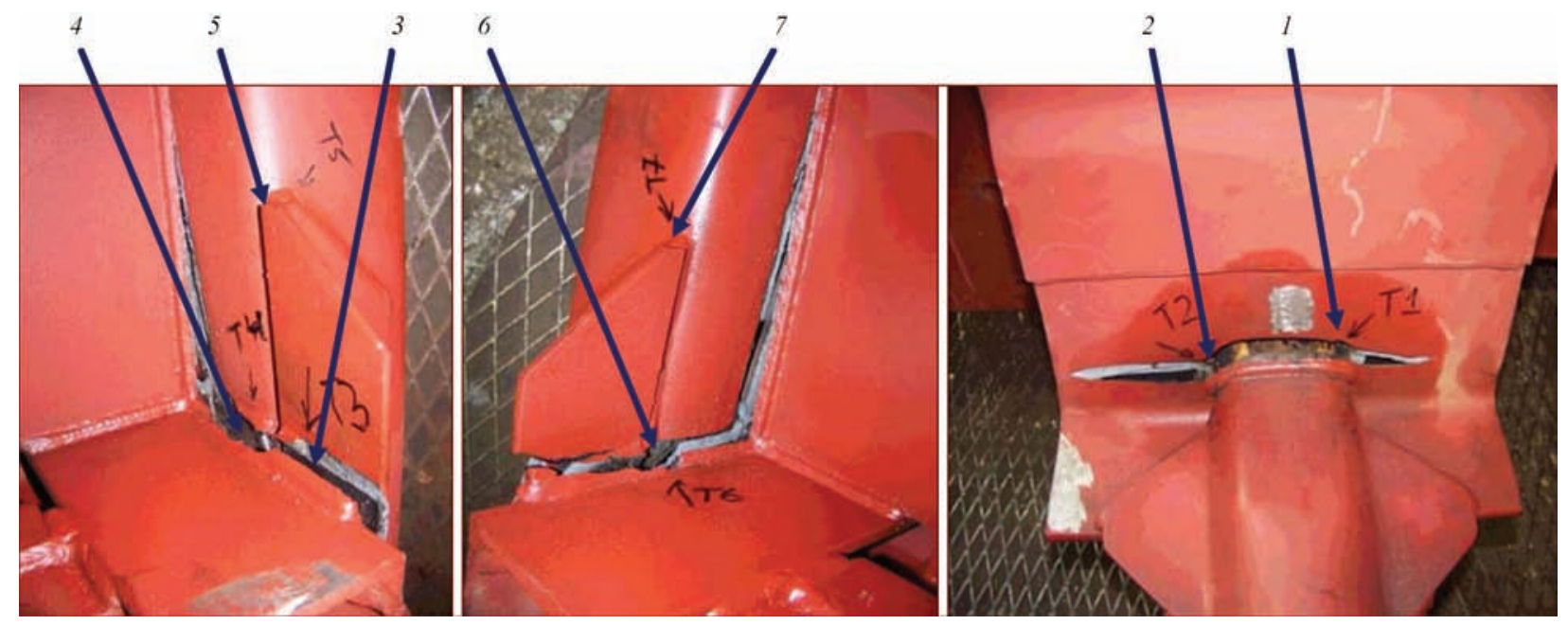

Figure 5. Cracks in the side wall rack sealing assembly (sample No.4): 1,2 — in the joint of the cross-beam (coverplate over the upper flange) and the lower chord (cracks T1 and T2, respectively); 3 - in the joint of reinforcing angle bar of side wall rack and the lower chord (crack T3); 4, 6 — in the joint of side wall rack and lower chord (cracks T4 and T6, respectively); 5, 7 - on top of the reinforcing angle bar of side wall rack (cracks T5 and T7, respectively)

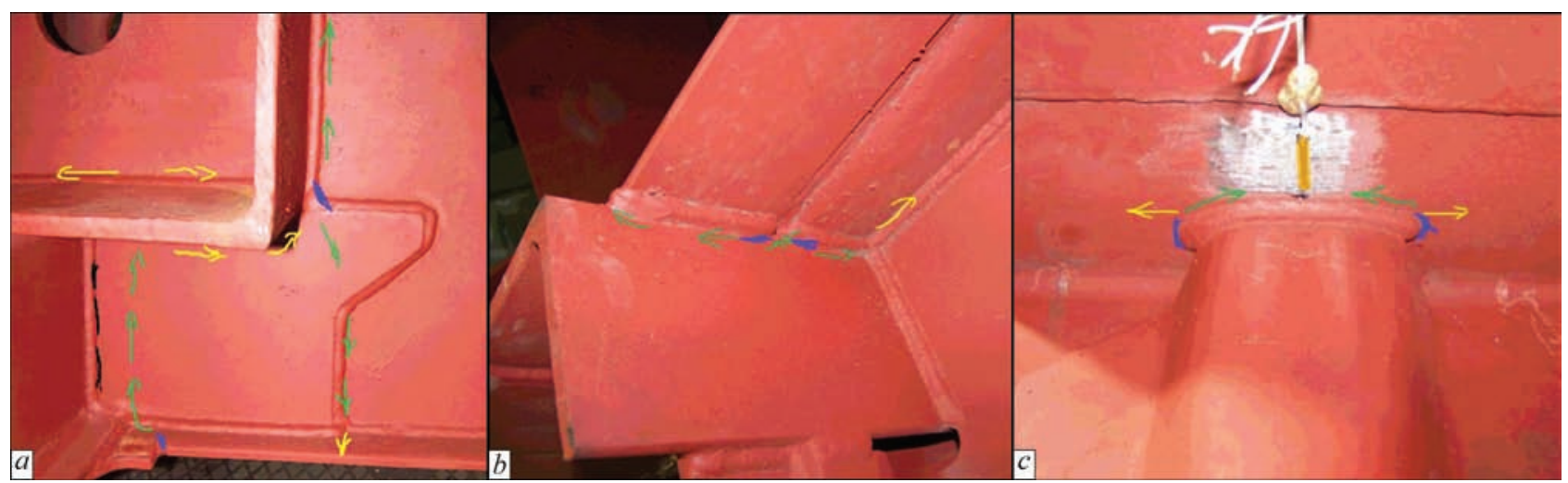

Figure 6. Crack propagation: $a$ — in bolster assembly; $b, c$ — in side wall rack sealing assembly

spectively; cracks T5 and T7 on top of the reinforcing angle bar of side wall rack of 7 and $10 \mathrm{~mm}$ length, respectively. After 2227 thou loading cycles, the length of crack T1 + T2 still was $110 \mathrm{~mm}, \mathrm{~T} 3$ crack grew up to $25 \mathrm{~mm}$, T4 - up to $14 \mathrm{~mm}$, T5 - up to $10 \mathrm{~mm}$, T6 - up to $70 \mathrm{~mm}$ and $\mathrm{T} 7$ - up to $10 \mathrm{~mm}$. At 2414 thou loading cycles, $\mathrm{T} 1+\mathrm{T} 2$ crack propagated up to $120 \mathrm{~mm}, \mathrm{~T} 3$ crack merged with crack T4 (total length of $52 \mathrm{~mm}$ ), T5 crack propagated up to $10 \mathrm{~mm}$, T6 - up to $85 \mathrm{~mm}$ and $\mathrm{T} 7$ - up to $12 \mathrm{~mm}$. After 2793 thou loading cycles, length of crack T1 + T2 still

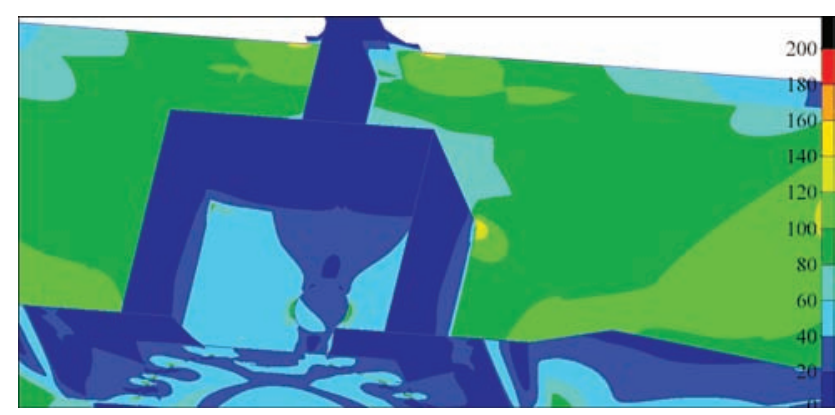

Figure 7. Stresses in bolster assembly from applied working load $P=883 \mathrm{kN}, \mathrm{MPa}$ was $120 \mathrm{~mm}$, crack $\mathrm{T} 3+\mathrm{T} 4$ propagated up to $55 \mathrm{~mm}$, T5 - up to $10 \mathrm{~mm}, \mathrm{~T} 6$ - up to $115 \mathrm{~mm}$, and T7 - up to $15 \mathrm{~mm}$. At 3351 thou loading cycles, crack T1 + T2 grew up to $125 \mathrm{~mm}$, crack T3 + T4 - up to $66 \mathrm{~mm}$, crack T5 - up to $10 \mathrm{~mm}, \mathrm{~T} 6$ - up to $130 \mathrm{~mm}$ and T7 - up to $15 \mathrm{~mm}$. At 3872 thou loading cycles the sample failed.

The generalized pattern of crack propagation and fracture is shown in Figure 6. Crack initiation sites are designated by blue marks. The cracks first propagate along the weld (green arrows). Having reached its boundary, they move over to the adjacent weld or to the base metal (yellows arrows). Black color in Figure $6, a$ shows a crack, which initiates at the initial testing stage, breaks the weld between the small I-beam of the center sill and bolster beam, and after that its propagation stops. It does not lead to loss of the sample load-carrying capacity. Further analysis was conducted for points of crack initiation (lower and upper blue marks in Figure 6). Table 1 gives the test results (cycle number to crack initiation and to sample fracture). 

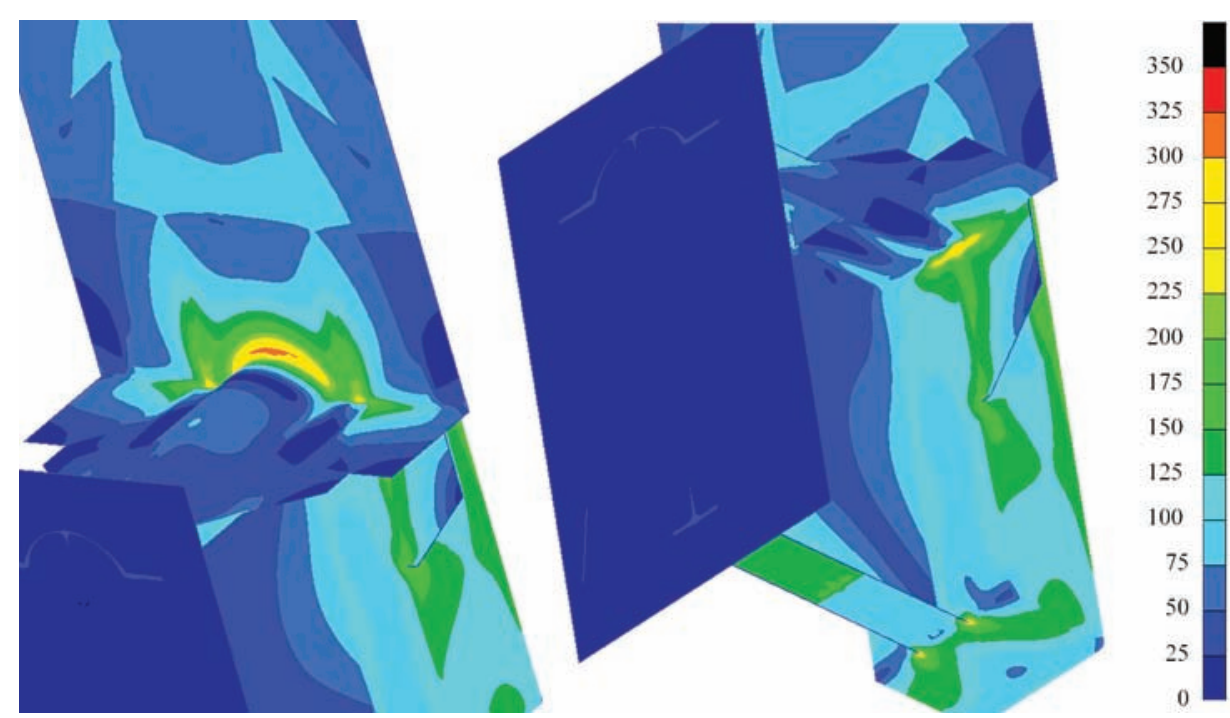

Figure 8. Stresses in side wall rack sealing assembly from applied working load $P=68.73 \mathrm{kN}, \mathrm{MPa}$

Table 1. Results of fatigue testing of assemblies of a gondola car of 12-4106-01 model

\begin{tabular}{|c|c|c|c|c|}
\hline \multirow{2}{*}{$\begin{array}{l}\text { Sample } \\
\text { number }\end{array}$} & \multicolumn{2}{|c|}{$\begin{array}{l}\text { Loading cycle parameters, } \\
\text { kN }\end{array}$} & \multicolumn{2}{|c|}{$\begin{array}{l}\text { Cyclic fatigue life, } \\
\text { thou cycles }\end{array}$} \\
\hline & $P_{\text {max }}$ & $P_{\min }$ & $\begin{array}{l}\text { Up to crack } \\
\text { initiation } \\
\text { (point) }\end{array}$ & $\begin{array}{l}\text { Up to sample } \\
\text { fracture }\end{array}$ \\
\hline \multicolumn{5}{|c|}{ Bolster assembly } \\
\hline \multirow{2}{*}{2} & \multirow{2}{*}{903} & \multirow{2}{*}{98.1} & $679(1)$ & \multirow{2}{*}{6432} \\
\hline & & & $975(2)$ & \\
\hline \multirow{2}{*}{3} & \multirow{2}{*}{903} & \multirow{2}{*}{98.1} & $771(1)$ & \multirow{2}{*}{3327} \\
\hline & & & $1820(2)$ & \\
\hline \multirow{2}{*}{4} & \multirow{2}{*}{883} & \multirow{2}{*}{98.1} & $1029(1)$ & \multirow{2}{*}{3031} \\
\hline & & & $797(2)$ & \\
\hline \multicolumn{5}{|c|}{ Side wall rack sealing assembly } \\
\hline \multirow{2}{*}{1} & \multirow{2}{*}{68.7} & \multirow{2}{*}{41.2} & $284(1)$ & \multirow{2}{*}{5225} \\
\hline & & & $1752(2)$ & \\
\hline \multirow{2}{*}{3} & \multirow{2}{*}{68.7} & \multirow{2}{*}{41.2} & $139(1)$ & \multirow{2}{*}{2913} \\
\hline & & & $877(2)$ & \\
\hline \multirow{2}{*}{4} & \multirow{2}{*}{68.7} & \multirow{2}{*}{41.2} & $325(1)$ & \multirow{2}{*}{3872} \\
\hline & & & $1550(2)$ & \\
\hline
\end{tabular}

Obtained results enable evaluation of the fatigue limit by force $P_{a, N}$ (precise definition: proportion of samples broken by force $P_{a, N}$ during the number of basic cycles $N_{0}=10^{7}$, is equal to $1-\alpha=0.95$ ). Let $P_{j}, N_{j}$ be the load and number of cycles to fracture for the $j$-th sample. To reduce the load to a basic number of cycles, we will use the «upper» part of the fatigue curve with index $m_{1}, \overline{P_{j}}=P_{j}\left(N_{j} / N_{0}\right)^{1 / m_{1}}$. Based on [5, item 6.3.3.1] limit $P_{a, N}$ is equal to

$$
P_{a, N}=\mathrm{M}[P]+Z_{1-\alpha} \sigma[P],
$$

where $\mathrm{M}[P], \sigma[P]$ are the estimates of mathematical expectation and standard deviation; $Z_{1-\alpha}$ is the quantile of $1-\alpha$ level for the normal distribution with zero mathematical expectation and unit variance.
Table 2. Fatigue limit values of welded joints of a gondola car of 12-4106-01 model

\begin{tabular}{|c|c|c|}
\hline \multirow{2}{*}{ Points } & \multicolumn{2}{|c|}{ Fatigue strength $\sigma_{a, N}, \mathrm{MPa}$} \\
\cline { 2 - 3 } & Bolster assembly & Side wall rack sealing assembly \\
\hline 1 & 32.2 & 12.1 \\
\hline 2 & 33.6 & 19.0 \\
\hline
\end{tabular}

Fatigue limit (by stresses) $\sigma_{a, N}$ are the stresses due to the action of force $P_{a},{ }_{N}$. Finite element models of the studied assemblies have been developed for their determination. Distribution of stresses from applied working loads in the samples is given in Figures 7, 8. Performed calculation confirms that stresses are maximum in the points, where cracks initiate (Figure 6, blue marks).

Strain measurement of samples was conducted to check the validity of modeling results. Stresses were measured in 15 points on the bolster assembly and in 8 points on the side wall rack sealing assembly, respectively.

Table 2 gives the experimentally established values of fatigue limit $\sigma_{a, N}$ of the studied assemblies. Minimum fatigue limit values for them are equal to $12.1 \mathrm{MPa}$ (side wall rack sealing assembly), and 33.6 MPa (bolster assembly). Established values of fatigue limit, as shown by calculation of car body stressed state, guarantee operation up to initiation of a fatigue crack for 34.1 and 57.0 years for the boslter assembly and side wall rack sealing assembly, respectively.

\section{Conclusions}

1. Performed experimental-calculation studies of fatigue resistance of full-scale samples of the bolster assembly and side wall rack sealing assembly of a gondola car of 12-4106-01 model revealed that their 
operating life depends on fatigue resistance of welded joints of assembly structural elements. Fatigue limit for them is equal from $12.1 \mathrm{MPa}$ (side wall rack sealing assembly) up to 33.6 MPa (bolster assembly).

2. It is found that in the studied assemblies of gondola car of 12-4106-01 model the fatigue cracks initiate in two most stressed zones. The established values of fatigue limit, as shown by calculations of stressed state of the car body, guarantee operation up to initiation of the fatigue crack during 34.1 and 57.0 years for the bolster assembly and side wall rack sealing assembly, respectively.

1. Bityutsky, A.A. (2009) Analysis of development of methods for evaluation of fatigue strength of load-carrying structures of freight car bodies. In: Study of fatigue strength of assemblies and selection of parameters of new freight cars: Transact. Ed. by A.A. Bityutsky. St.-Petersburg, Inzhenerny Tsentr Vagonostroeniya, 7, 6-13 [in Russian].

2. Khilov, I.A., Afanasiev, A.E. (2009) Selection of parameters of side wall rack sealing assembly of a gondola car. Ibid., 7, 34-43 [in Russian].
3. Bityutsky, A.A., Afanasiev, A.E. (2009) Study of fatigue strength of side wall rack sealing assemblies of new design of a gondola car body. Ibid.,7, 54-61 [in Russian].

4. Plotkin, V.S., Druzhinin, S.S., Chentsov, E.I. (1978) Study of fatigue strength of wall sealing assemblies of 4-axle all-metal gondola cars. In: Transact. of VNIIV, 35, 21-26 [in Russian].

5. (2016) GOST 33211-2014: Freight cars. Requirements to strength and running characteristics. Moscow, Standartinform [in Russian].

6. (1983) Norms for calculation and design of new and modernized cars (non self-propelled) of $1520 \mathrm{~mm}$ track railways of the Ministry of Railroads. Moscow, GosNIIV-VNIIZhT [in Russian].

7. (1996) Norms for calculation and design of cars (non self-propelled) of $1520 \mathrm{~mm}$ track railways of Ministry of railroads. Moscow, GosNIIV-VNIIZhT [in Russian].

8. $R D$ 24.050.37-95: Freight and passenger cars. Methods of testing for strength and running characteristics [in Russian].

9. (2017) Gondola car of 12-4106-01 model. Program and procedure of testing of service life of the bolster assembly and side wall rack sealing assembly of a gondola car. PM 100-17/ Its [in Russian]. 


\title{
COMPLEX FOR INVESTIGATION OF ARC WELDING PROCESSES
}

\author{
Yu.N. SARAEV ${ }^{1}$, A.G. LUNEV ${ }^{1}$, A.S. KISELEV ${ }^{2}$, A.S. GORDYNETS ${ }^{2}$ and M.V. TRIGUB ${ }^{3}$ \\ ${ }^{1}$ Institute of Strength Physics and Materials Science-of SB RAS \\ 2/4 Akademicheskaya Ave., 634055, Tomsk, Russia. E-mail: litsin@ispms.tsc.ru \\ ${ }^{2}$ National Research Tomsk Polytechnic University \\ 30 Lenin Ave., 634004, Tomsk, Russia. E-mail: kas@tpu.ru \\ ${ }^{3}$ V.E. Zuev Institute of Atmospheric Optics of SB RAS \\ 1 Acad. Zuev Sq., 634055 Tomsk, Russia. Email: trigub@tpu.ru
}

\begin{abstract}
The work presents the results of development and manufacture of a unique research complex for investigation of fast processes of heat-mass transfer in consumable electrode arc welding. Advantages of the developed complex over the traditionally applied ones using film and video cameras with shadow principle of registration of heat-mass transfer characteristics are shown. Fast processes were studied with application of high-speed video recording with illumination of the arc gap by $\mathrm{Cu}-\mathrm{Br}$ laser beam, improving visualization of the studied object — the process of melting and transfer of each drop of electrode metal under the conditions of intensive light of the electric arc. The paper contains explanatory diagrams, control algorithms, video frames of a separate welding microcycle, examples of oscillogram-recording and graphical representations of changes in their quantitative values. 13 Ref., 1 Table, 14 Figures.
\end{abstract}

Keywords : welding, surfacing, video filming, melting, heat-mass transfer, laser, control, stability, electric arc, consumable electrode welding

Processes of heating and melting of welding electrode or wire, formation and transfer of electrode metal drops in welding largely determine the stability of strength properties of permanent joints. The nature of melting and transfer of electrode metal in fusion welding is determined by a large number of physical phenomena, namely heat-mass transfer, gas- and thermodynamics, electromagnetic processes, running in the arc, on the surface and in the volume of the electrode, molten drops of both the base and electrode metal [1-3].

Analysis of the work devoted to kinetics of electrode metal melting, shows that metal transfer from the electrode into the weld pool, proceeds in the form of drops of different diameter $[4,5]$. Transfer mechanism depends on many factors, namely, gravity force acting on the drop, force of surface tension of liquid metal, electromagnetic forces, pressure of evaporating metal vapours and other factors. Investigation of the kinetics of electrode metal melting and transfer into the weld pool is inextricably connected with recording the fast processes. The nature of melting and transfer can change, depending on the applied consumable electrode welding process. This is primarily related to the difference in the action on electrode metal drop located at electrode tip, of a complex of forces, determining not only the frequency of electrode metal transfer into the weld pool, but also the duration of molten metal staying under high-temperature impact of the electric arc. The latter fully determines the intensity of micrometallurgical reactions in the drop and the pool, which are responsible for the quality and strength properties of the formed permanent joint [6, 7].

For a long time high-speed filming has been one of the main methods for studying the fast processes of electrode metal melting and transfer. It is usually performed in synchronism with recording of the basic energy parameters of the technological process. For all the variety of the methods for visualization of the processes of electrode metal melting and transfer into the weld pool, fast processes running at the stage of molten metal melting and transition of each drop of electrode metal into the weld pool, are still insufficiently studied. This limits our understanding of the mechanism of heat-mass transfer, and requires development and realization of new experimental complexes. The noted circumstance is indicative of the urgency of the performed research, the results of which will provide a new highly efficient tool, when studying complex processes of heat-mass transfer, accompanying formation of permanent joints.

The objective of the work was studying the features of fast processes of heat-mass transfer at formation of permanent joints by the methods of consumable electrode arc welding with illumination of the 


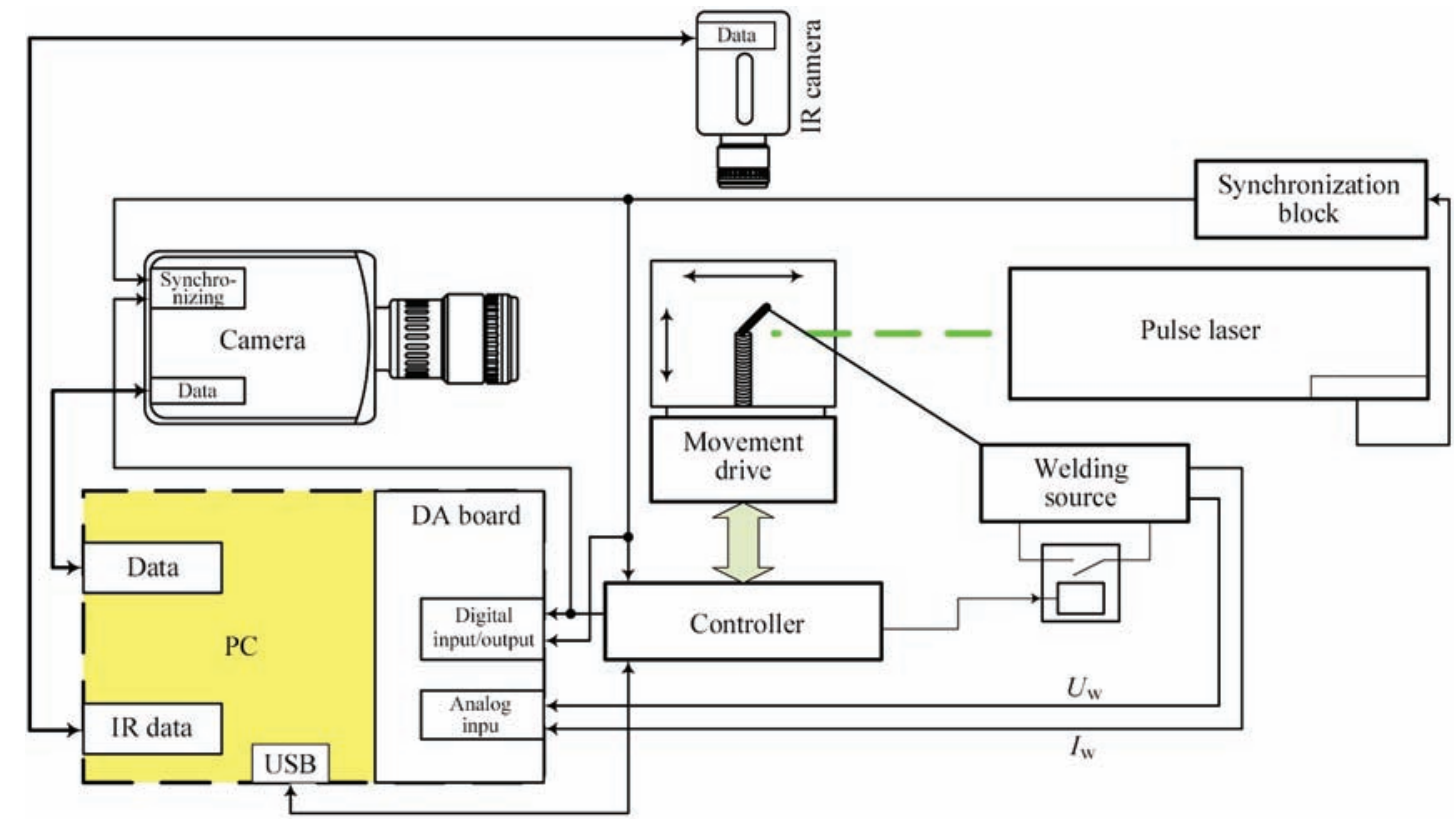

Figure 1. Complex for recording and investigation of fast processes of heat-mass transfer in consumable electrode arc welding

arc gap by a laser beam, in order to complement the modern concepts of the most effective methods of increasing the stability and effectiveness of the existing technologies.

Procedure and technique of experimental investigations. Research complex, presented in Figure 1, can be an example of realization of the research direction, which can allow achievement of the above-defined goal.

Recording of the technological process parameters is performed as follows. Special software (SW) is used to define the algorithm for performance of the welded joint (or surfacing), and the task is sent from personal computer (PC) to the controller. The controller controls movement of the table with the sample and starts the welding process. After 1-2 s delay since the moment of welding start, the controller sends a signal (Trigger) of the start of recording to a highspeed video camera and data acquisition board, which records the electric parameters (current, voltage). Each frame of high-speed videorecording is synchronized with illumination laser pulses through a synchronization unit [8-10]. Synchronization pulses also provide marking of current and voltage oscillograms for a more precise alignment of the oscillograms with videorecording frames [11]. Recording is stopped by a controller signal.

The complex envisages application of an infrared thermal imaging camera for recording the thermal fields during welding (surfacing). Thermogram interpretation provides information about the kinetics of heat propagation, rate of weld pool and HAZ cooling, dimensions of weld pool and HAZ, and change of their temperature in time $[12,13]$.
Robotized welding platform. Possibility of obtaining repeatable results, when studying gas-shielded arc welding is largely determined by the human factor. Therefore, stability and accuracy of maintaining the main parameters of the welding mode are directly related to welder's skills. Moreover, during performance of high-speed videofilming of the welding process, there is an additional problem of its synchronization with the moment of appearance of the studied object in the video camera focus.

Solution of the problem of repeatability of experimental results is complete automation of the welding process during investigations. At present the industry is widely applying various mechanisms for automation of arc welding processes, for instance, six-axis robotic manipulators. However, application of ready solutions is impossible, because of basic shortcomings, namely: welding torch is always moving that makes high-speed videofilming difficult. Moreover, such manipulators feature excess capabilities, making their maintenance more complicated.

An important link in the developed complex is the robotic welding platform, which during investigations ensures automatic movement of the sample being welded by one of the selected movement trajectories, in order to ensure the required weld geometry, in keeping with the requirements of GOST 6996-66 «Welded joints. Methods of mechanical properties determination». Realization of the method of movement of the sample using a robotic-type platform, is related to the need to obtain repeatable results during investigation performance, particularly in the field of gas-shielded mechanized arc welding. To eliminate the human factor and solve the problem of repeatabil- 
ity of experimental results, the presented complex ensures full automation of the welding process during investigation performance.

Taking into account the above-said, a working model of a robotic platform for performance of arc welding and surfacing of test samples during experimental studies, was developed and manufactured. The platform was designed proceeding from the considerations of correspondence of its technical characteristics to the parameters of typical test welded joints, namely, dimensions and weight of the real samples. As in most cases welding or surfacing are performed in the downhand position during experiments, and there is no need to change the length of the interelectrode gap, two axes are sufficient for sample movement. Accuracy of torch movement in gas-shielded semi-automatic welding is not more than $1 \mathrm{~mm}$, so that the discreteness and accuracy of sample positioning are sufficient. Overall dimensions of the platform are selected so as to provide the possibility of its mounting into a standard 19-inch stand $800 \mathrm{~mm}$ deep.

\section{Main technical parameters of the platform}

Number of motion axes, pcs . 2 Maximum size of samples being welded

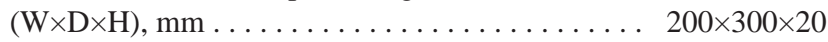

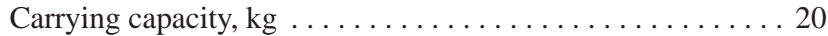

Discreteness of sample movement, $\mathrm{mm} \ldots \ldots \ldots \ldots \ldots . .1$

Accuracy of sample positioning, $\mathrm{mm} \ldots \ldots \ldots \ldots \ldots .1$

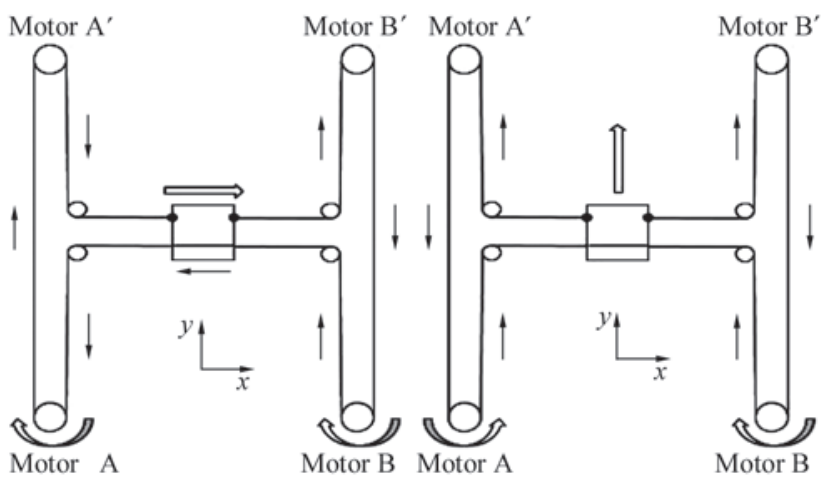

Figure 2. Kinematic diagram of robotic platform

Range of setting sample movement rate, $\mathrm{mm} / \mathrm{min} \ldots \ldots$ 0 -5000 Overall dimensions of the platform $(\mathrm{W} \times \mathrm{D} \times \mathrm{H}) \ldots 505 \times 740 \times 350$ Platform weight, $\mathrm{kg} \ldots \ldots \ldots \ldots \ldots \ldots \ldots \ldots$

H-BOT kinematic diagram of the platform was selected (Figure 2), as the most optimum and reliable for the specified technical characteristics. In order to increase the precision, rigidity and carrying capacity of the platform, the sample mounting stage moves on linear bearings along cylindrical guides of $20 \mathrm{~mm}$ diameter, using a reinforced toothed belt $25 \mathrm{~mm}$ wide. Applied as a drive are step electric motors of NEMA 34 type size, which operate in microstepping mode to increase the smoothness. Platform protection from moving beyond the limits of movement axes is realized by applying inductive limit switches, which are also used for moving it to «zero» initial position.

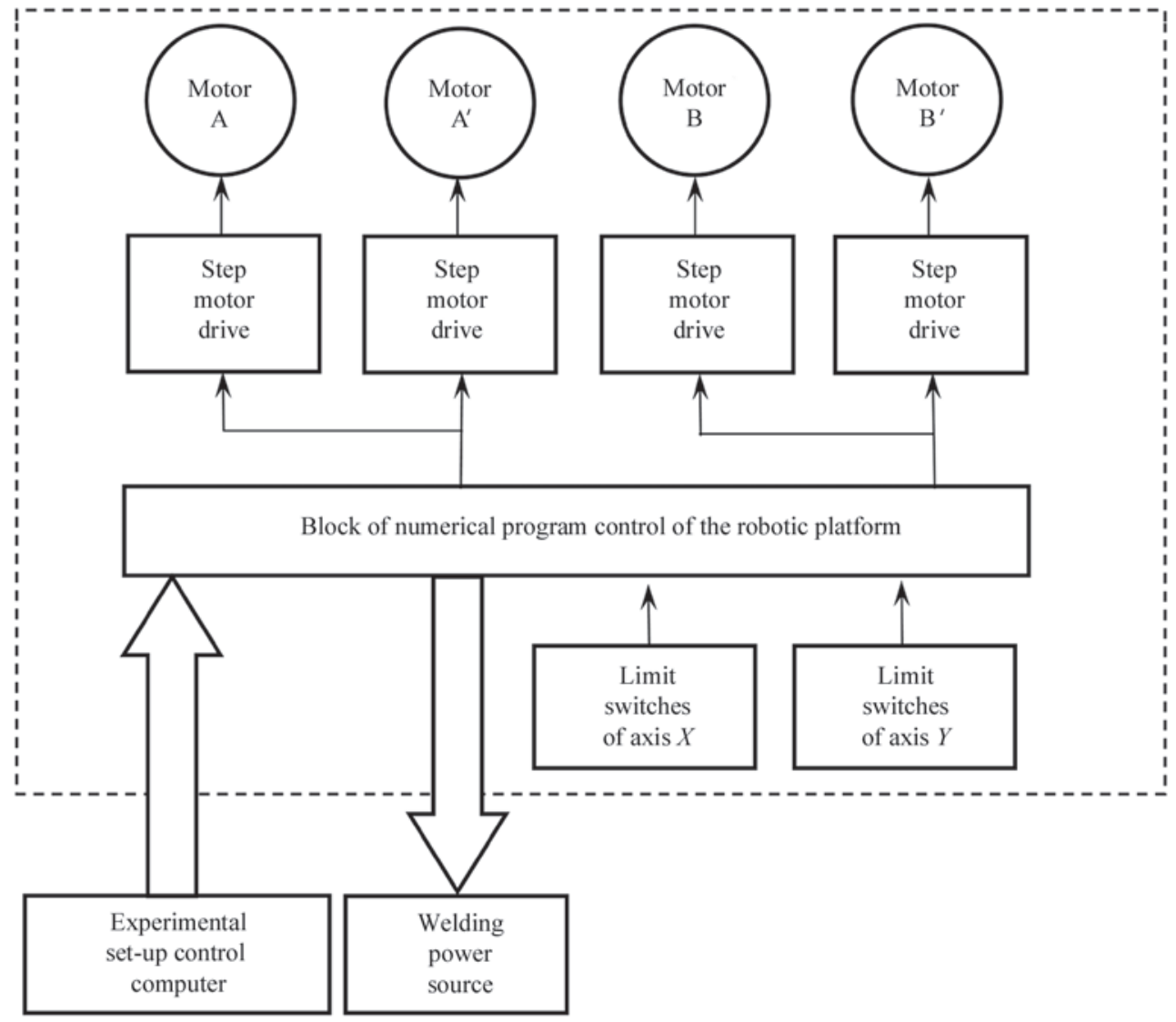

Figure 3. Functional schematic of the robotic platform 


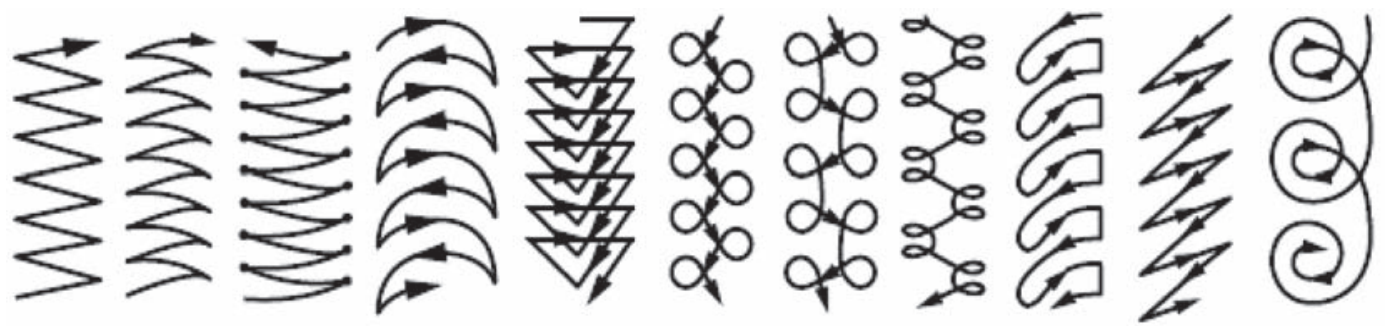

Figure 4. Variants of platform movement trajectories

Oscillograms of current in the welding circuit and voltage in interelectrode gap

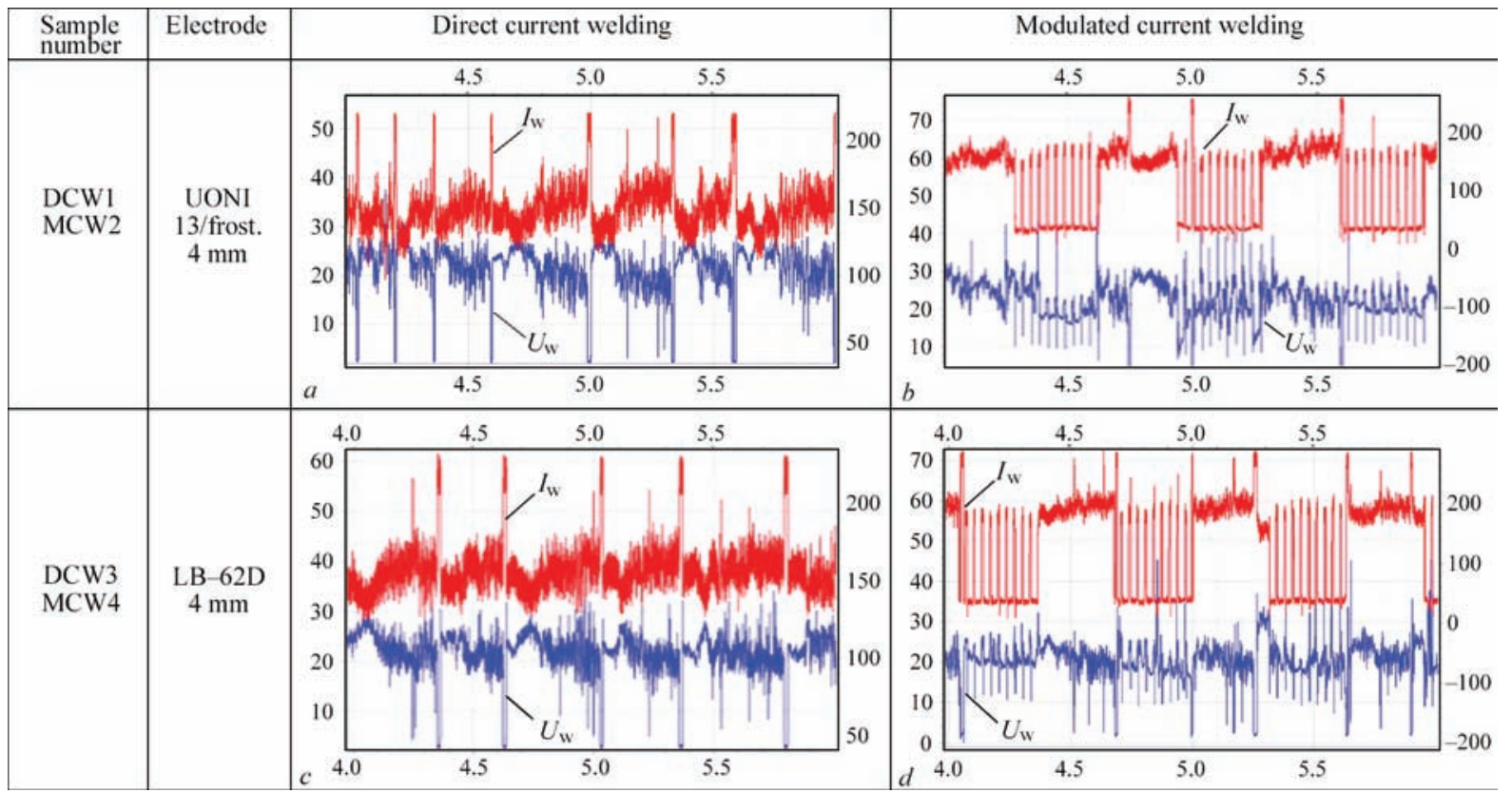

Figure 3 shows the functional schematic of the robotic platform. The purpose of most of the blocks is described above, except for numerical control block, which is designed for conversion of the commands of experimental set-up control computer into the respective signals for step motor control. Standard G-codes are used as the commands. They are described in detail in GOST 20999-83 «Numerical control units for

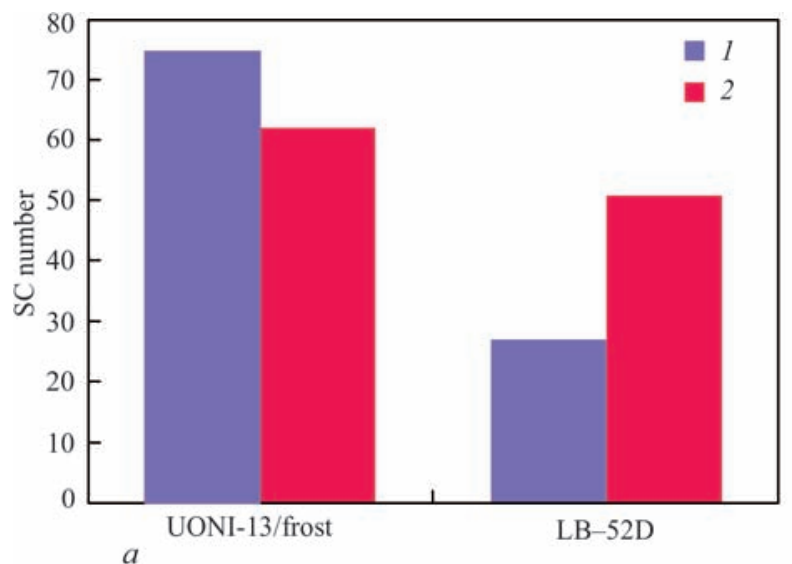

metal-working machines. Part program data coding», that greatly simplifies programming the path of platform movement (Figure 4). Welding power source switching-on and-off is performed using «dry» contact that allows connecting it to the experimental setup in most of the cases without any additional matching devices.

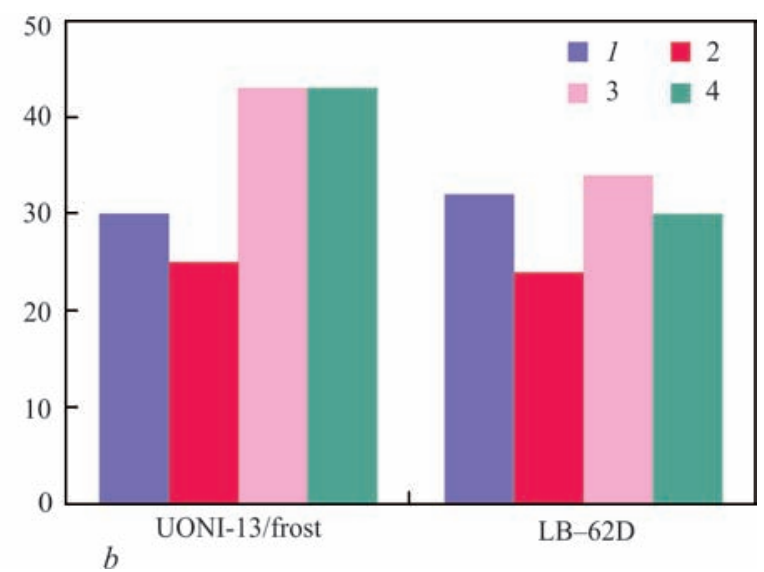

Figure 5. Number of short-circuits per $10 \mathrm{~s}$ : $a$ — welding the root weld (RW) with $3 \mathrm{~mm}$ electrodes $(1$ — root, direct current; 2 — root, modulated current); $b$ - making the filling weld (Fil.W) and facing weld (Fac.W) with $4 \mathrm{~mm}$ electrodes ( 1 - filling, direct current; 2 - filling, modulated current; 3 - facing, direct current; 4 - facing, modulated current) 

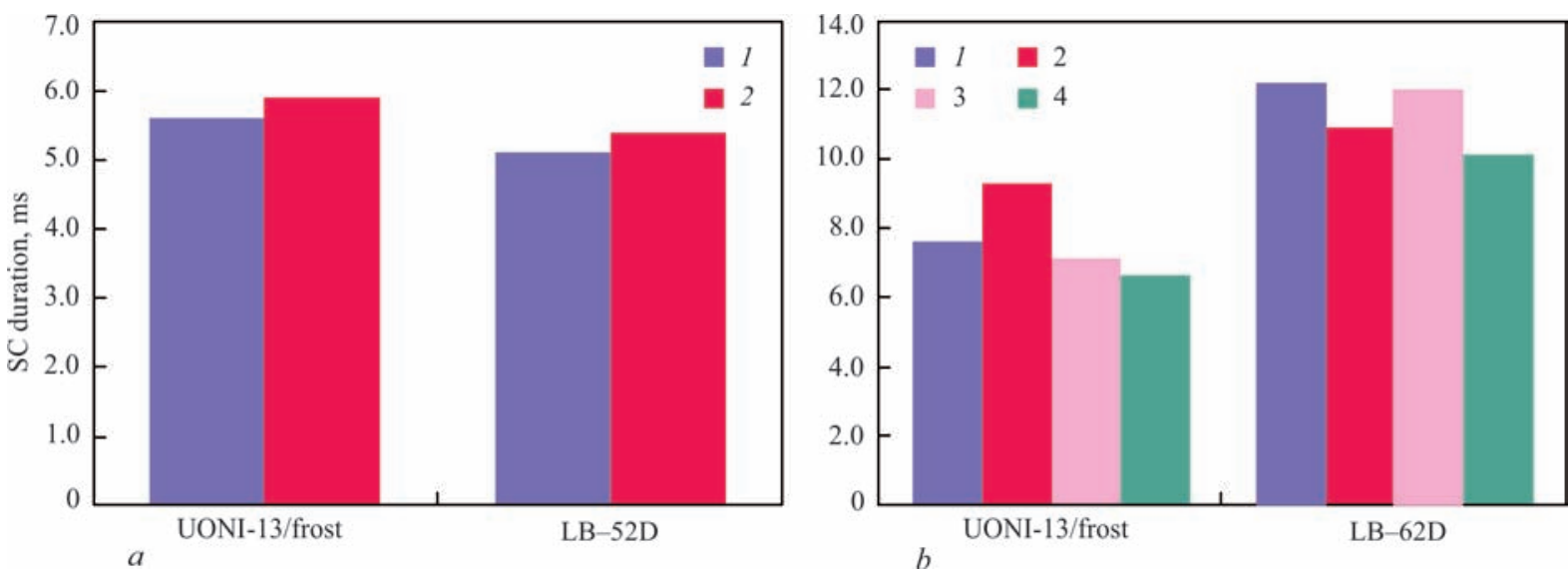

Figure 6. SC duration: $a$ - making RW with 3 mm electrodes; $b$ - making Fil.W and Fac.W with 4 mm diameter electrodes (same designations as in Figure 5)
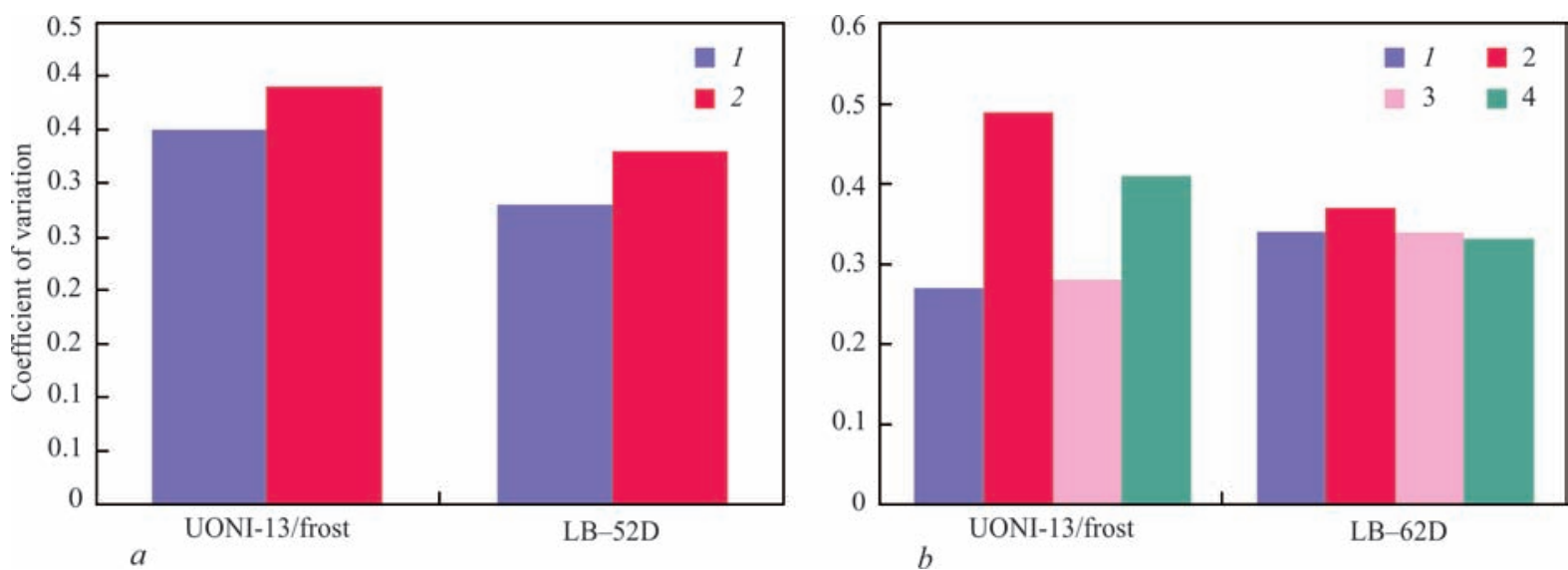

Figure 7. Coefficient of variation of SC duration: $a$ - making RW with 3 mm electrodes; $b$ - welding Fil.W and Fac.W with 4 mm electrodes (same designations as in Figure 5)

Processing investigation results. Processing procedure consists of three stages: determination of average values of current, voltage, power and heat input in the specified time range; statistical processing of the parameters of short-circuits (SC) during welding (surfacing), i.e. obtaining information about the number of SC per a unit of time, average SC duration, average value of $\mathrm{SC}$ current, coefficient of variation of SC duration; plotting comparative diagrams of obtained parameters from welding modes, electrode types, etc.

The Table gives the characteristic oscillograms of arc current and voltage, recorded during welding, where DCW is direct current welding, MCW is welding in the mode of low-frequency modulation of welding current, 1,3 is welding of root welds; 2, 4 is welding of filling layers.

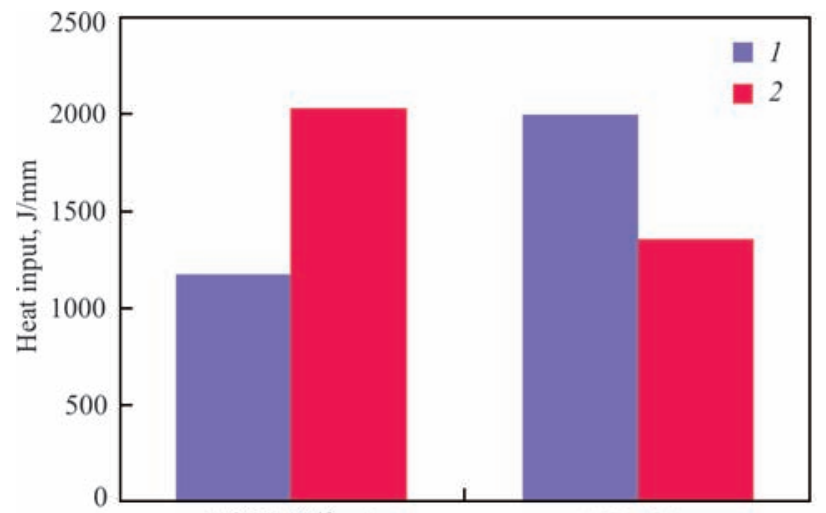

$a$

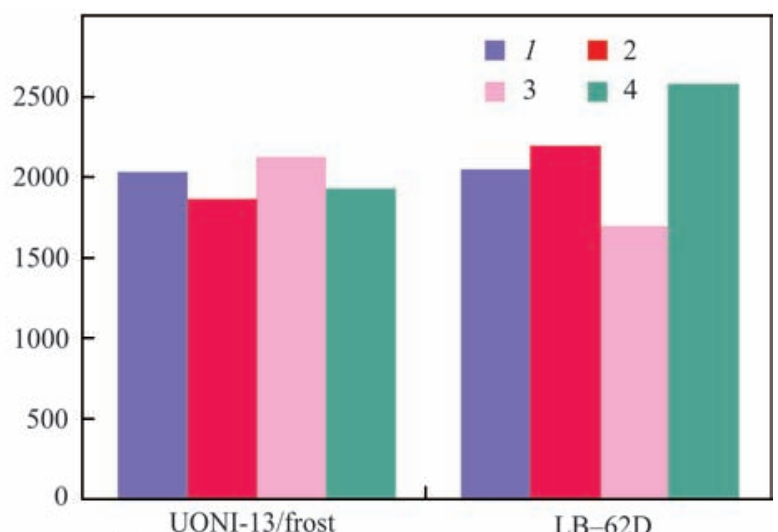

$b$

Figure 8. Heat input consumed in welding: $a$ - making RW with $3 \mathrm{~mm}$ electrodes; $b$ - making Fil.W and Fac.W with 4 mm electrodes (designations are the same as in Figure 5) 

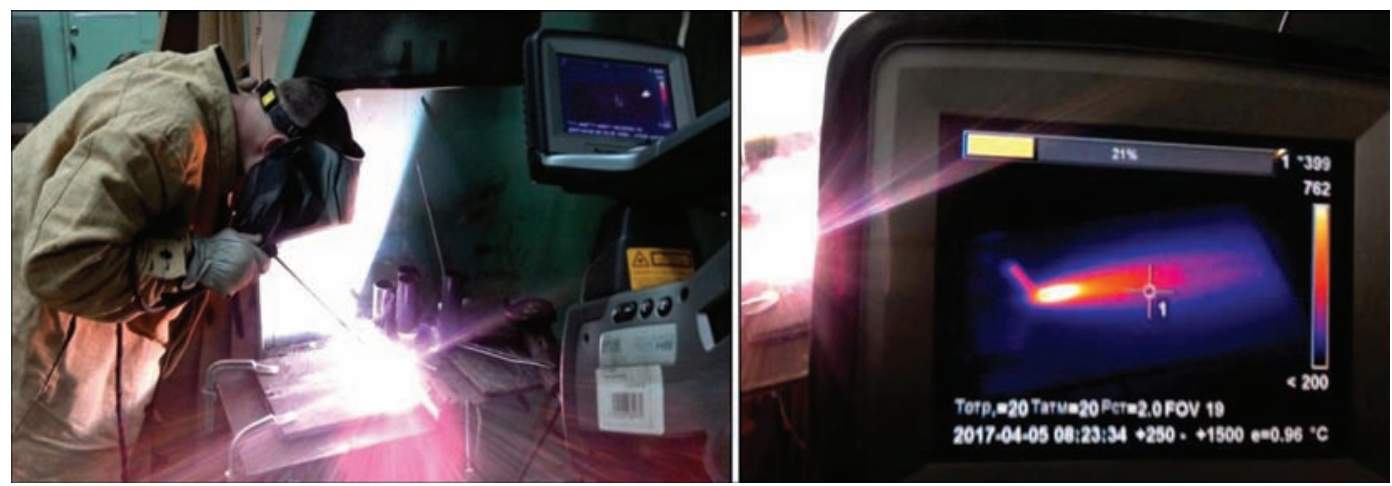

Figure 9. Thermal imaging of temperature fields on the plate surface in downhand welding

Figures 5-8 show bar charts, plotted as a result of processing experimentally obtained oscillograms of the main energy parameters of welding modes. Analysis of the given diagrams allows making a quantitative assessment of the characteristics of heat-mass transfer in coated electrode manual arc welding, which, together with analysis of experimentally obtained thermal imaging fields allow full assessment of heat-mass transfer characteristics.

Figure 9 shows the fragments of thermal image filming.

Results of thermal imaging obtained with application of a special processing program of the research complex, can be represented in the form of thermal imaging pictures, which are shown in Figure 10. Experimentally obtained thermal fields allow establishing the weld pool length, and, therefore, also solidification process rate in the formed welded joint.
In mechanized welding processes, the frequency of transition of molten electrode metal into the weld pool is equal to $25-300$ drops per second that makes it very difficult to study the fast processes, either at the melting stage or at the stage of their transition to the weld pool.

In order to process the results of experiments on studying the heat-mass transfer characteristics in mechanized welding processes, special software was applied as part of the complex. It allows presenting them, similar to manual arc welding, in the form of graphic images and numerical values of heat-mass transfer characteristics: heat input, frequency of electrode metal drop transfer, coefficients of variation of frequency, SC current duration and amplitude, thermal field isotherms and graphs of the change of thermal cycles of welding.

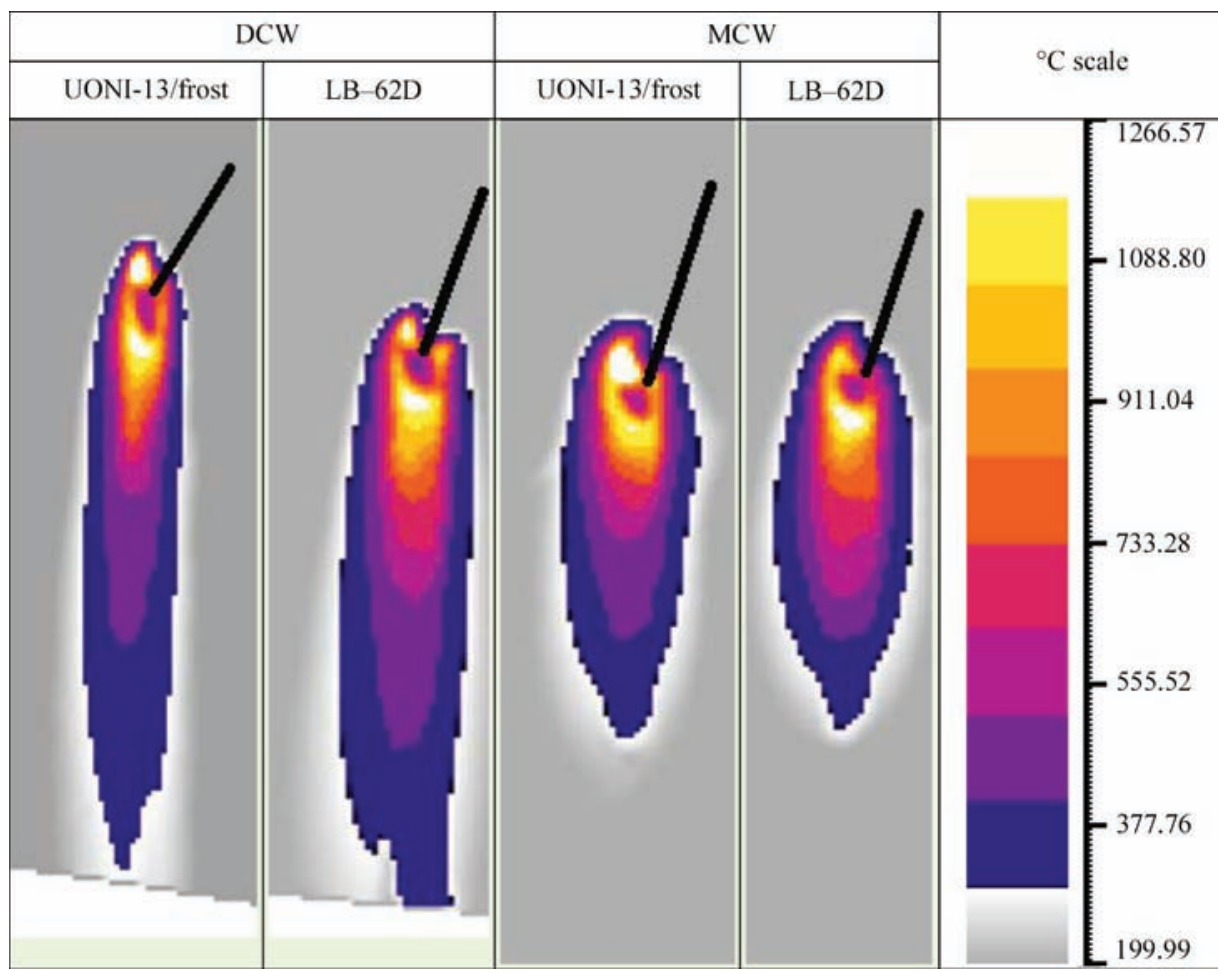

Figure 10. Distribution of temperature fields at DCW and MCW with $4 \mathrm{~mm}$ electrodes 

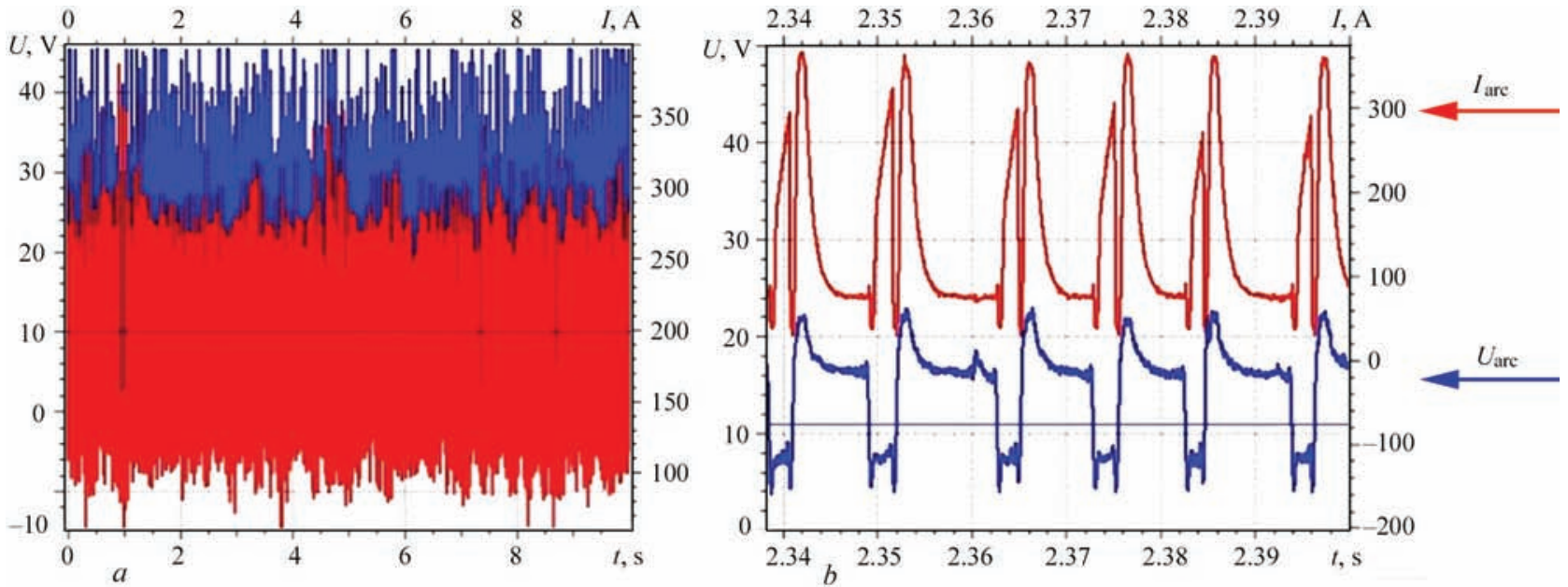

Figure 11. Example of processing the results of measurement of current and voltage of the arc during experimental studies: $a$ - without filtering background noise; $b$ - after filtering at result output for analysis

Visualization of measurement results and their processing depend entirely on methods of parameter recording, which determine the ability of measurement system to ensure suppression of high-frequency noise by removing from the spectra of voltage and current oscillograms the high-frequency components, having a high amplitude, determination of threshold value of voltage at SC (this task is the responsibility of the researcher and is performed by manual assign- ment of the threshold by a marker line on voltage oscillogram), Figure 11. This is followed by: automatic sampling of SC in the required time range, determination of current and duration of each SC, calculation of average value of SC current in the obtained sample, average duration of SC and coefficient of variation SC duration. Obtained data can be presented in the form of tables, as well as bar charts (Figure 12).

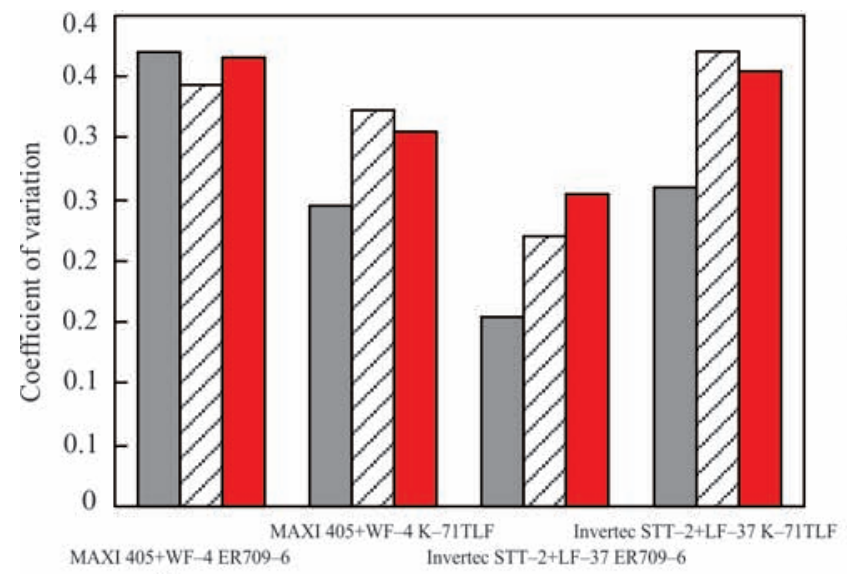

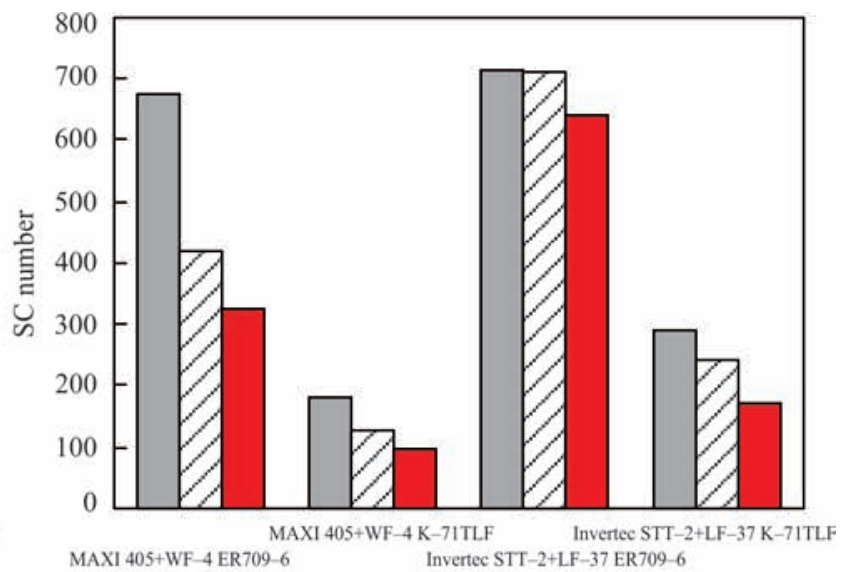

b

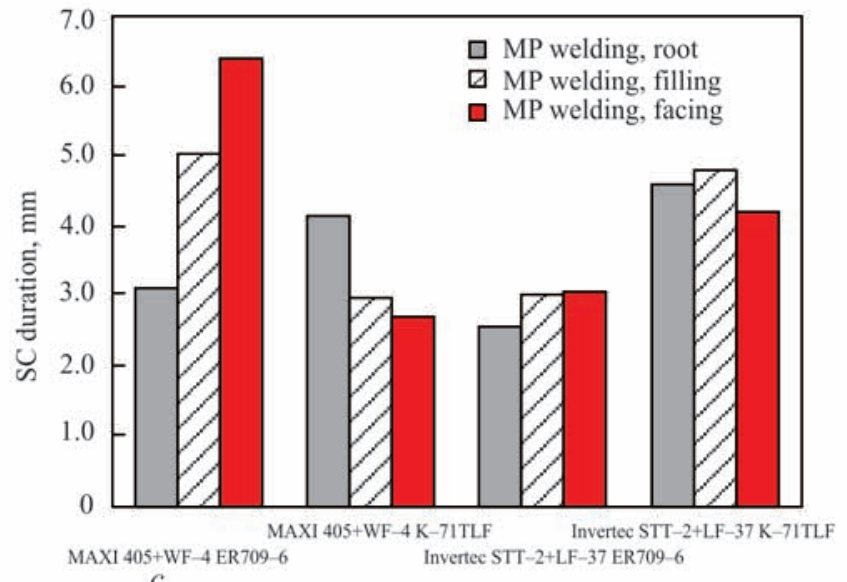

$c$

Figure 12. Examples of bar charts for mechanized welding in $\mathrm{CO}_{2}$ with short-circuiting of the arc gap: $a$ - coefficient of duration variation (MP welding); $b$ - SC number (MP welding); average SC duration (MP welding) 


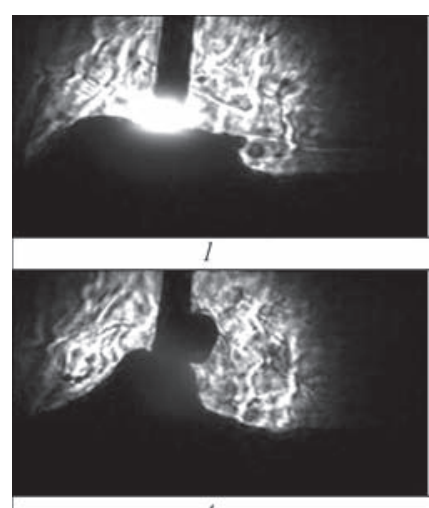

4
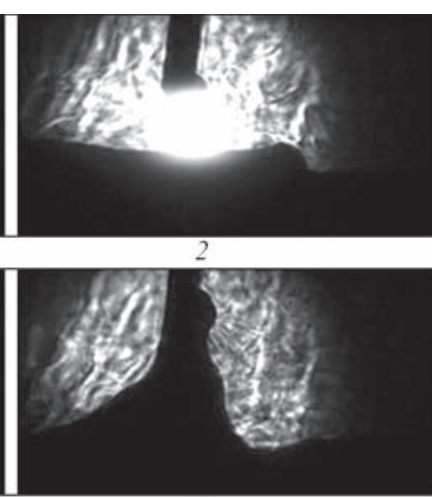

5

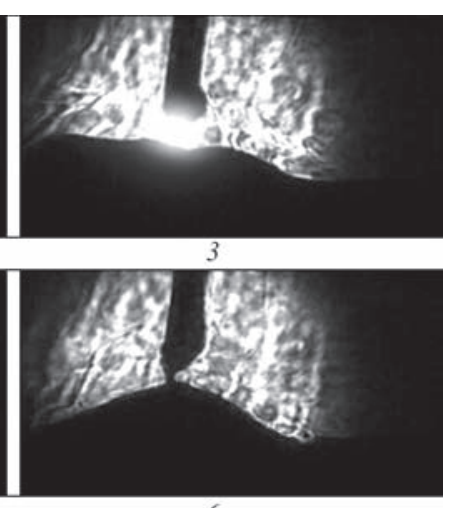

6

Figure 13. Videoframes of the process of electrode metal melting and transfer in mechanized $\mathrm{CO}_{2}$ welding with solid wire, videofilming frequency of 5000 frames per second (illumination of the arc gap by a spotlight with xenon lamp)

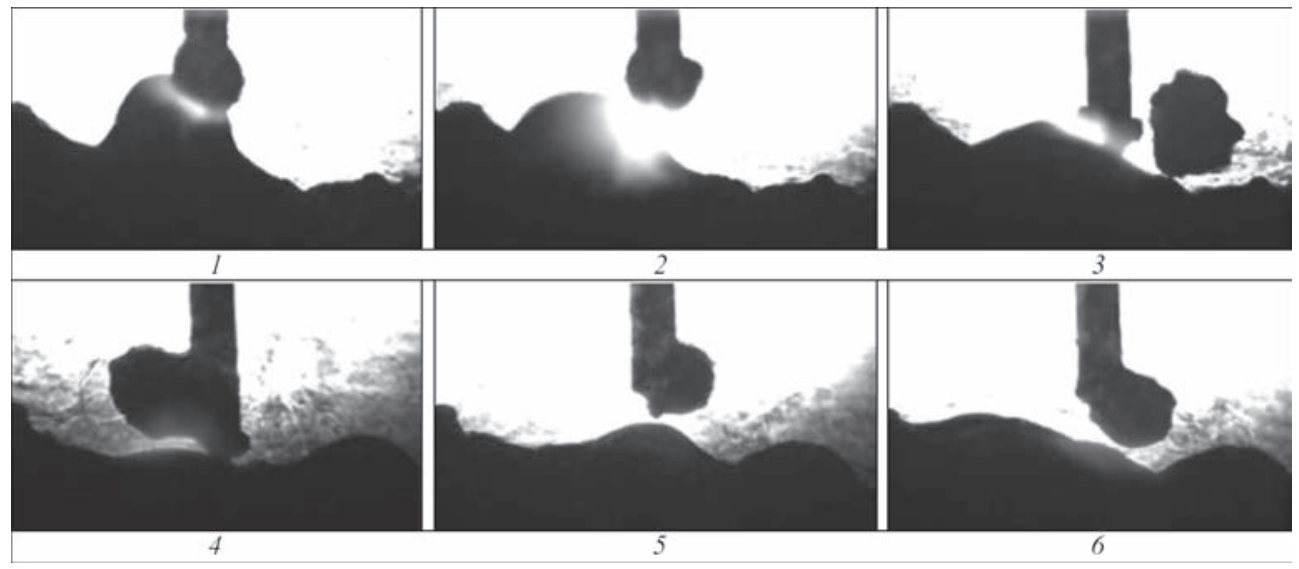

Figure 14. Videoframes of the process of electrode metal melting and transfer in mechanized welding in $\mathrm{CO}_{2}$ with solid wire, videofilming frequency is 5000 frames per second (illumination of the arc gap by $\mathrm{Cu}-\mathrm{Br}$ laser beam)

Average values are calculated by numerical integration of current, voltage and their product (power). Welding speed, which allows detemination of the heat input, is calculated as the ratio of the length of weld (deposited coating) to the time, consumed when making this weld (coating). In addition, the complex includes a module of high-speed videorecording of the process of electrode metal melting and transfer, as weld as module for oscillography of the main energy parameters of the welding process, which is performed in synchronism with recording of melting and transfer of each electrode metal drop. Pulsed laser illumination is used in order to improve the quality of videofilming of the process of electrode metal melting and transfer.

However, the processes of heat-mass transfer running in a complex electrodynamic system of power source-arc-weld pool-item at different welding processes, including those with pulsed variation of energy parameters of the mode, are still poorly understood. Studying these phenomena involves a number of difficulties, associated with the speed of running of heat-mass transfer processes at simultaneous action of powerful light of the welding arc (Figure 13).
Figures 13 and 14 show videoframes of welding microcycle (period of melting and transfer of one electrode metal drop). Comparison of videoframes confirms the earlier assumption that application of coherent laser radiation during filming should promote better visualization of the studied object of heat-mass transfer. Performed experiments fully confirmed the correctness of the selected direction of research complex development.

In conclusion it can be noted that the robotic type research complex, designed for studying the features of fast processes of heat-mass transfer, when making permanent joints by consumable electrode arc welding under the conditions of illumination of the arc gap by $\mathrm{Cu}-\mathrm{Br}$-laser beam, has the required technical characteristics and can be effectively applied for producing test samples during performance of experimental studies, related to finding the ways to improve the reliability of critical structures, operating under extreme conditions.

Conducted trials of the research complex fully confirmed its high effectiveness, when studying the fast processes of heat-mass transfer in consumable electrode electric arc welding, that certainly expands the modern understanding of the most efficient meth- 
ods to improve the stability and performance of the current technologies.

The work was performed using RSF funds under Project \#16-19-10010 in 2016-2018.

1. Karkhin, V.A. (2015) Thermal processes in welding. 2nd Ed. St.-Petersburg, Politekhn. Un-t [in Russian].

2. Paton, B.E., Maksimov, S.Yu., Sidoruk, V.S., Saraev, Yu.N. (2014) To problem of arc self-regulation in consumable electrode welding. Svarochn. Proizvodstvo, 12, 3-11 [in Russian].

3. Saraev, Y.N., Bezborodov, V.P., Gladkovsky, S.V., Golikov, N.I. (2016) The ways of reliability enhancement of welded metal structures for critical applications in the conditions of low climatic temperatures. AIP Conf. Proc., 1783, 020195.

4. Saraev, Y.N. (2011) Adaptive pulse technological processes of welding and pad weld is a new high-performance method of obtaining of permanent joints of high-strength steels. World $J$. Engineering, Special Issue, 8, 989.

5. Saraev, Yu.N. (2002) Adaptive pulsed-arc mechanized welding methods in construction of main pipelines. Svarochn. Proizvodstvo, Svarochn. Proizvodstvo, 1, 4-7 [in Russian].

6. Saraev, Yu.N. (2010) Substantiation of concept of safety improvement and survivability of technical systems operated in the regions of Siberia and Extreme North, based on application of pulsed welding technologies. Tyazholoe Mashinostroenie, 8, 14-19 [in Russian].
7. Saraev, Yu.N., Bezborodov, V.P., Gladkovsky, S.V., Golikov, N.A. (2016) Study of properties of manganese steel welded joints produced by low-frequency pulsed arc welding. Deformatsiya i Razrushenie, 1, 36-41 [in Russian].

8. Saraev, Yu.N. (1988) Control of electrode metal transfer in $\mathrm{CO}_{2}$-welding with short circuit of arc gap (Review). Avtomatich. Svarka, 12, 16-23 [in Russian].

9. Yermachenko, V.M., Kuznetsov, A.P., Petrovskiy, V.N. et al. (2011) Specific features of the welding of metals by radiation of high-power fiber laser. Laser Physics, 21(8), 1530-1537.

10. Dimaki, V.A., Sukhanov, V.B., Troitskiy, V.O., Filonov, A.G. (2012) Stabilized laser on copper bromide with automated operation modes having average generation power of $20 \mathrm{~W}$. Pribory i Tekhnika Eksperimenta, 6, 95-99 [in Russian].

11. Saraev, Yu.N. (2017) Exploratory research of reliability improvement of critical metal structures, operated under extreme load conditions and low climatic temperatures. In: High technologies in the projects of RSF. Siberia. Ed. by S.G. Psakhie et al. Tomsk, NTL, 134-202 [in Russian].

12. Saraev, Yu.N., Lunev, A.G., Kiselev, A.S. et al. (2018) Investigation of effect of energy parameters of coated electrode arc welding on stability of heat- and mass transfer. Svarochn. Proizvodstvo, 2, 3-13 [in Russian].

13. Dilthey, U., Stein, L., Woeste, K., Reich, F. (2003) Latest developments and trends in high-efficient welding technologies. The Paton Welding J., 10-11, 146-152. 


\title{
TECHNOLOGY FOR EBW OF AIRCRAFT STRUCTURES OF TITANIUM ALLOYS*
}

\author{
V.M. NESTERENKOV, Yu.V. ORSA, K.S. KHRIPKO and O.V. MAKHNENKO \\ E.O. Paton Electric Welding Institute of the NAS of Ukraine \\ 11 Kazimir Malevich Str., 03150, Kyiv, Ukraine. E-mail: office@paton.kiev.ua
}

\begin{abstract}
Presented are the results of development of efficient technological processes of electron beam welding of girder structures of titanium VT-6 alloy with high resistance of welded joints to the formation of fatigue cracks, the diffuser of gas turbine engine of OT-4 alloy using slot welds, the body of medium pressure chamber of gas-turbine engine of VT5L alloy, providing a high accuracy of geometric dimensions. 5 Ref., 16 Figures.
\end{abstract}

Key words: electron beam welding, aircraft structures, titanium alloys, variable cross-section parts, slot welds, residual stresses, fatigue resistance

EBW is a welding method which is optimally suitable for manufacture of many aircraft structures of titanium alloys. In the perfect vacuum protection, it provides a combination of a sufficiently high specific power of the heating source (excessive concentration in most cases is not needed, because of impossibility in producing «zero» gaps in the butt) with the $\mathrm{CNC}$ capabilities in accurate repeatability the trajectory of welding at a strict synchronization of movement with control of electron beam power parameters. The work presents three examples of technology of EBW of the above-mentioned products.

EBW of thin-walled corrugated load-carrying aircraft structures of VT-6 alloy. The girder structures of I-beam type with a thin-walled web of a wavy profile (corrugated), located between two flanges of much larger thickness, are of a great interest to the aircraft construction in view of reducing the total mass at a high load capacity. In this case, the use of titanium alloy, in addition to reducing the mass, provides also a high corrosion resistance.

Such methods of manufacturing similar structures, as casting, stamping, forging with subsequent machining are economically inefficient. Obvious is the economic advantage of using welding in manufacturing of girder structures from separate parts, which are technologically efficient from the point of view of their production. But in this case, the technical difficulties arise. Firstly, the process of manufacturing a welded I-beam corrugated structure envisages welding along a complicated curvilinear trajectory.
Secondly, this requires obtaining a complete fusion of web with flanges with the formation of a smooth transition of the weld between the web and flange. Thirdly, the geometric accuracy of the entire structure can be provided only if there is a significant reduction or compensation of residual welding deformations. Finally, in some cases, there is a need to join the flanges with a web at the thickness ratio of up to 12:1.

In our opinion, in this case the EBW method, already because of its main characteristic features, satisfies the most of the above-mentioned requirements, in particular from the point of view of the accuracy of power and welding movement control [1].

For the development of EBW technology, a prototype of the experimental structure of a corrugated I-beam was used, the sketch of which is shown in Figure 1. The prototype imitates a load-carrying structure of such a beam with thick enough flanges of $7.62 \mathrm{~mm}$ thickness and a thin-walled corrugated web of $0.64 \mathrm{~mm}$ thickness, which has a perpendicular intersection with a cylindrical tube of the same thickness in the center. As a structural material for the prototype, and then for the mock-ups of long-length load-carrying aircraft structures, the widely used VT-6 alloy (Ti-6Al-4V) $(\alpha+\beta)$ was applied, capable of providing the strength, equivalent to that of the base metal, at any conditions of postweld annealing at the temperatures of not higher than the temperature of a polymorphic transformation [2].

Surely, different schemes for welding of such a T-joint are possible: both the welding through the

\footnotetext{
${ }^{*}$ Based on the report presented at the International Conference «Titanium 2018. Production and Application in Ukraine», June 11-13, 2018, Kiev, E.O. Paton Electric Welding Institute of the NAS of Ukraine.
} 


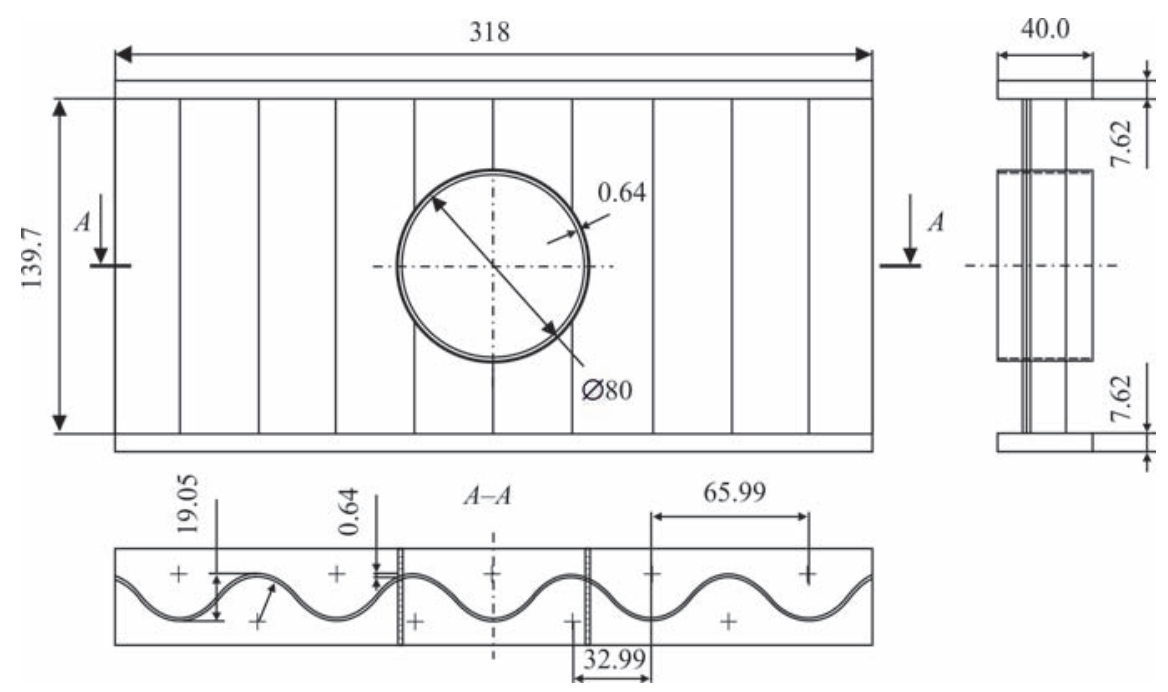

Figure 1. Design of the prototype of corrugated I-beam

flange, and one-sided welding by an electron beam directed to the edge of flange butt with the web at a small angle to this flange surface. These welding schemes were once tested and it was concluded that all of them do not meet the above-mentioned requirements to a sufficient extent.

As a result, we stopped on the scheme of welding with an inclined electron beam on both sides of the web in two passes, as shown in Figure 2. The welding is performed by an electron beam inclined by $30^{\circ}$ from the vertical, directed to the edge of the vertically arranged butt between the flange (or shell) and the wavy web. After making a partial penetration of this butt on one side, the entire assembly is turned over by $180^{\circ}$ to perform the final pass.

Here, it should be noted that the main difficulty in realizing this welding scheme is the fact, that due to the complicated accurate mechanical fitting of ends of the thin corrugated semi-product, the gaps are possible in the separate butt regions. The problem is also aggravated when the flange itself represents not a plane surface, as shown in the prototype scheme,

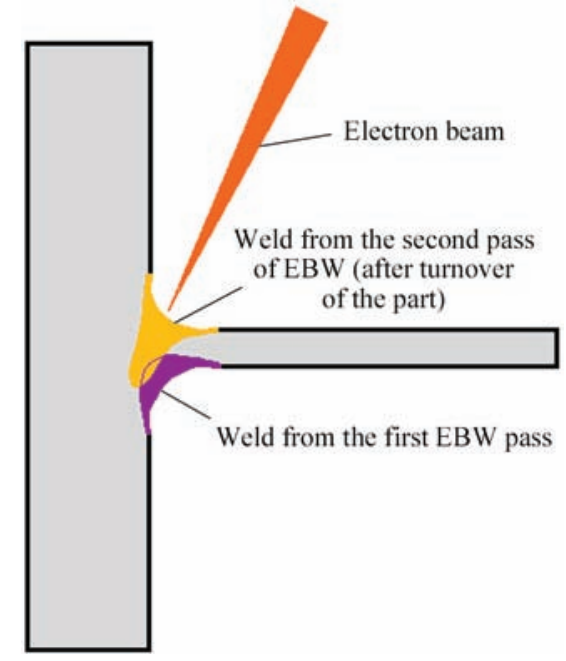

Figure 2. Scheme of double-sided EBW of T-joint in two passes but a curved one, i.e. when the height of the I-beam is smoothly changing along its length (we also practiced this variant). As a result, the exceeding of gap and its length value above a certain critical limit leads with a high probability to the formation of local burn-outs of the weld, an example of which is shown in Figure 3.

Thus, the main task of the first pass is the quality fusion of two mated surfaces even in the presence of small local gaps. That is namely the reason why the force tacks and the first pass were produced at «mild» conditions, i.e. by a nonconcentrated electron beam. Moreover, instead of the traditional continuous welding mode, we used a pulsed modulation of the electron beam current, which, in comparison with the continuous welding, allowed reducing the heat input into edges welded, thereby preventing their local overheating and enhancing the effect of the surface tension force in maintaining the weld pool molten metal. All this allowed providing the formation of a relatively shallow weld with a face surface in the form of a «fillet» between the mated surfaces (as conventionally shown in scheme of Figure 2). At the same time, the maximum admissible local gaps in the joint should not exceed: up to $0.1 \mathrm{~mm}$ in the T-joint of $7.60 \mathrm{~mm}$ of the flange and $0.64 \mathrm{~mm}$ of the web and up to $0.08 \mathrm{~mm}$ - at the same web and flange thicknesses (equal to $0.64 \mathrm{~mm}$ ).

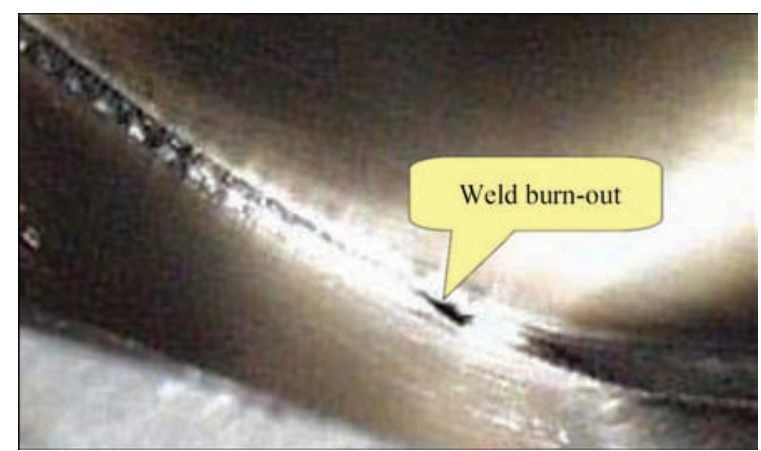

Figure 3. Local weld burn-out at the inadmissible gap in the joint 


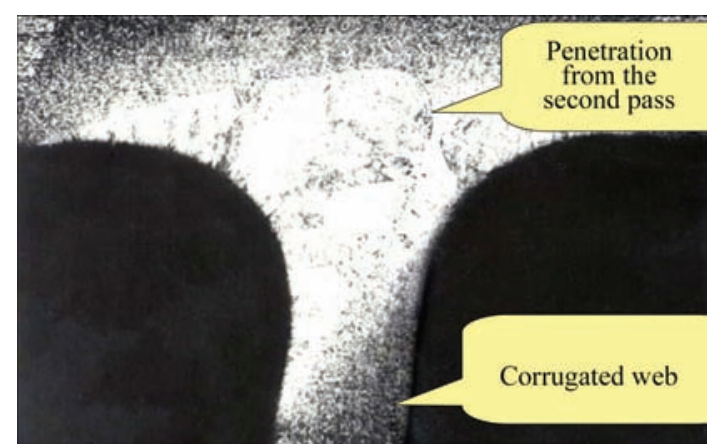

Figure 4. Macrosection $(\times 35)$ of T-joint of web and shell

After the product is turned over by $180^{\circ}$, the final pass is made. It should provide already a complete fusion at the contact point of wavy web with beam flange (or shell wall), guaranteeing overlapping the penetration zone of the first pass. As far as in the first pass a partial fusion of web edge with flange along the entire length has already been produced, the local gaps in the remaining part of the joint are already uncritical. It is even possible to perform welding with a maximum concentrated electron beam with the formation of a so-called vapor gas channel, however, it is not necessary to do that because of the formation of root defects. We selected a compromise welding mode with a moderate concentration of electron beam and with the use of pulsed modulation of its current, which provides minimum sufficient depth and width of the weld with a relatively wide root part (Figure 4) and a smooth face surface in the form of a «fillet» between the mated surfaces (Figures 4 and 5).

Using the practiced technology, both the prototypes, mentioned above, (the sketch of Figure 1), as well as the full-scale six-meter mock-up of the corrugated I-beam (Figure 6) were successfully welded.

Then, the calculation evaluations of residual stresses and fatigue resistance of such a six-meter corrugated beam of titanium VT-6 alloy were carried out.

It is known [3] that for the VT-6 alloy, the fatigue limit on the basis of $10^{5}$ cycles corresponds approximately to $588 \mathrm{MPa}$, i.e., if the residual nonrelaxed stresses and the concentration of stresses are not taken
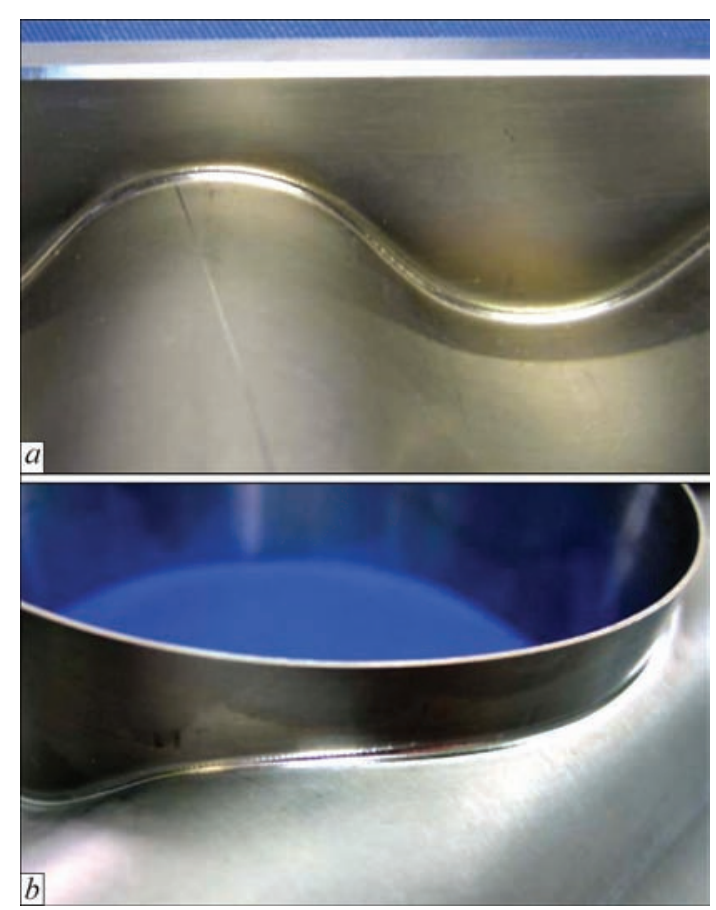

Figure 5. Face weld surface after pulsed EBW of joints of wavy web, respectively, with flange $(a)$ and shell $(b)$

into account, then, at a preset base of $8 \cdot 10^{4}$ cycles, there is a rather large margin of strength in terms of stresses.

The results of mathematical modeling of residual stresses show that after EBW the level of longitudinal residual stresses in the flange reaches $500 \mathrm{MPa}$ (Figure 7).

According to the technical specifications, after welding the beam is subjected to low-temperature tempering, which reduces residual stresses by approximately $40 \%$, i.e., the longitudinal stresses in the weld zone remain at the level of $300 \mathrm{MPa}$.

Taking into account the already available data [4], the carried out calculations of the fatigue resistance of a six-meter welded beam after a similar heat treatment showed that the zone of welded joints is characterized by a sufficiently high resistance to fatigue crack formation at a preset base of $8 \cdot 10^{4}$ cycles. Moreover, small local web thinning in the weld zone affects only
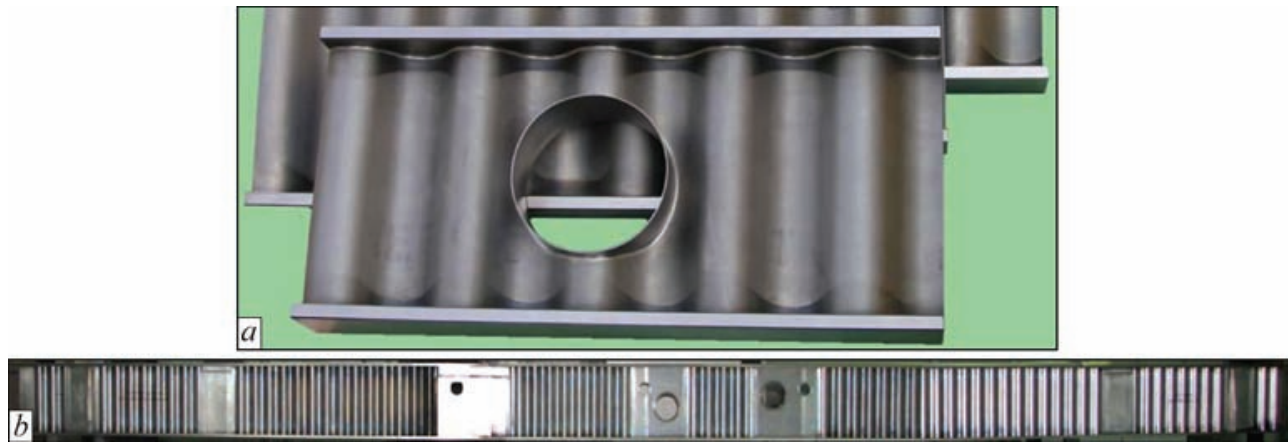

Figure 6. Welded assemblies: short prototype of the section of corrugated I-beam with transverse pipe (a) and full-scale six-meter mock-up (b) 

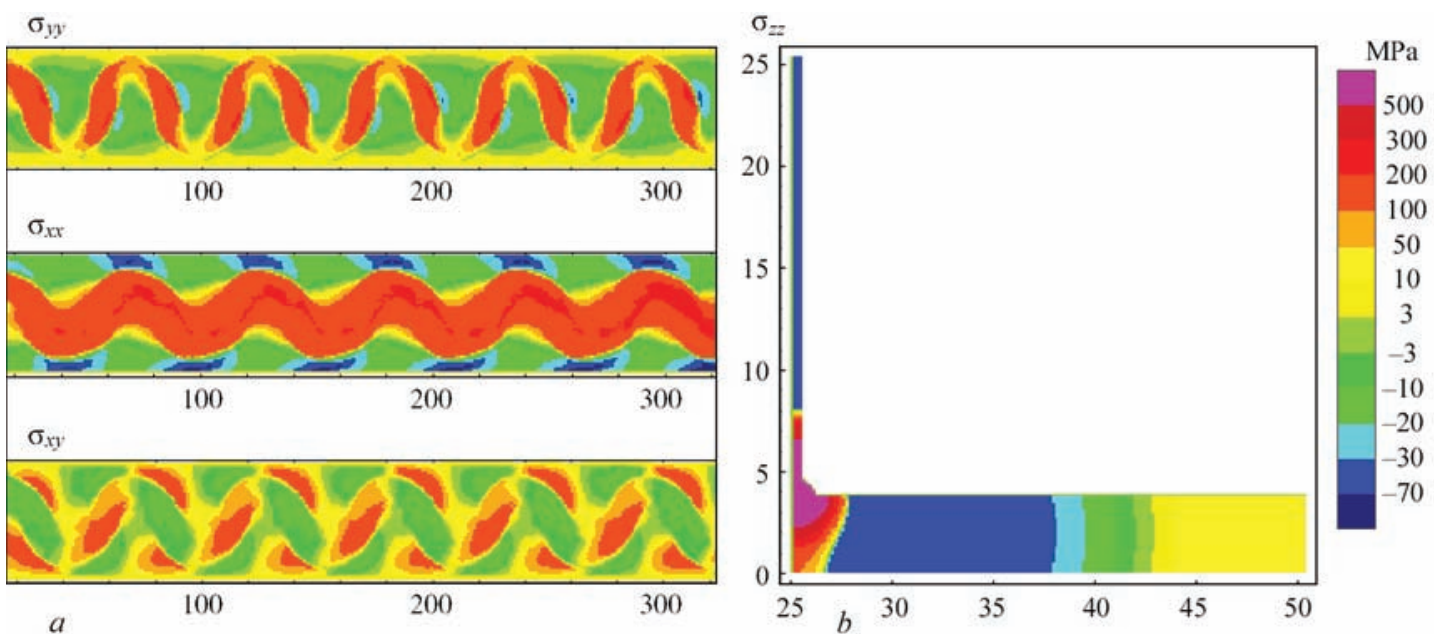

Figure 7. Distribution of residual stresses in the plane (a) and in the joint cross-section $(b)$

the tangential stresses at the edges of the beam, but it has only a very small effect on the initiation of fatigue cracks.

EBW of gas turbine engine diffuser of titanium OT-4 alloy. The existing until now technology of assembly of parts of gas turbine engine (GTE) diffuser of the titanium pseudo- $\alpha$-alloy OT- 4 provided producing of a joint with the help of tenons at the ends of blades, which are inserted into the slots of a covering disc and welded-in around the contour using the method of argon-arc welding (AAW). An obvious drawback of this technology is a significant distortion of the product shape, in particular, an unacceptable decrease in the value of a reference gap A (Figure 8). Even the use of subsequent thermal straightening of

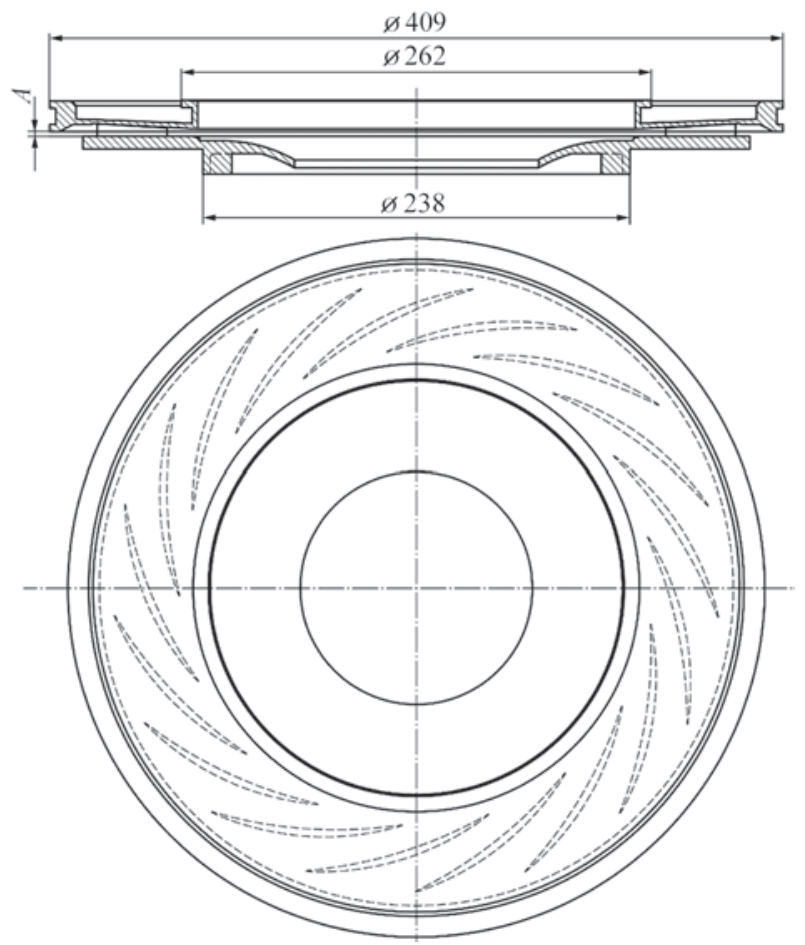

Figure 8. Sketch of GTE diffuser prototype the product in a rigid rigging does not always lead to a positive result.

It was decided to replace the welding method from AAW to EBW, and, accordingly, to modify the design of the diffuser elements joined for the most full applying of the EBW capabilities. It was decided to remove the mentioned «tenons» from the ends of all 17 blades of the lower disc and to join them with each other by slot welds (directly through $2.5 \mathrm{~mm}$ thickness of the covering disc), providing a tight contact of these ends with a solid lower surface of the covering disc. In this case, the above-mentioned slot welds should have a closed contour, geometrically similar to that of the blade section (Figure 9).

It was experimentally established that the value of the weld axis displacement from the edge of the blade end should be $1.0 \mathrm{~mm}$. The parameters of welding mode were selected based on the conditions for producing a narrow weld with a penetration depth of at least $6 \mathrm{~mm}$ without root defects.

In fact, the contour welded is formed by two successive slot welds. A slight increase in the penetration depth of the second slot weld (right in Figure 10) was finally compensated by a corresponding decrease in the electron beam current (by $2 \mathrm{~mA}$ ).

The EBW technology practiced on the prototype specimens was further applied in manufacture of a

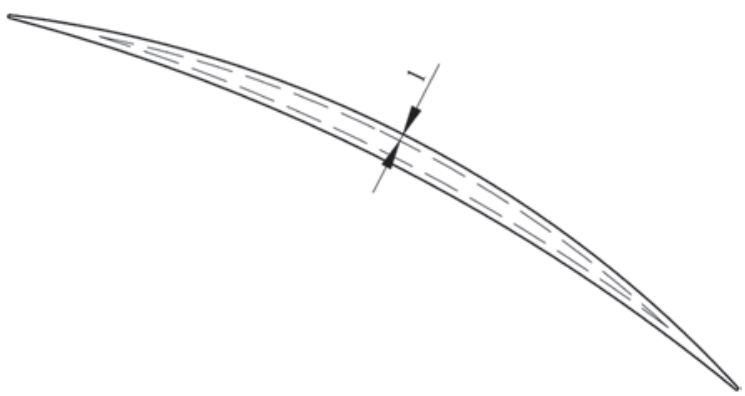

Figure 9. Contour of slot weld on the covering disc of diffuser relatively to the blade section 


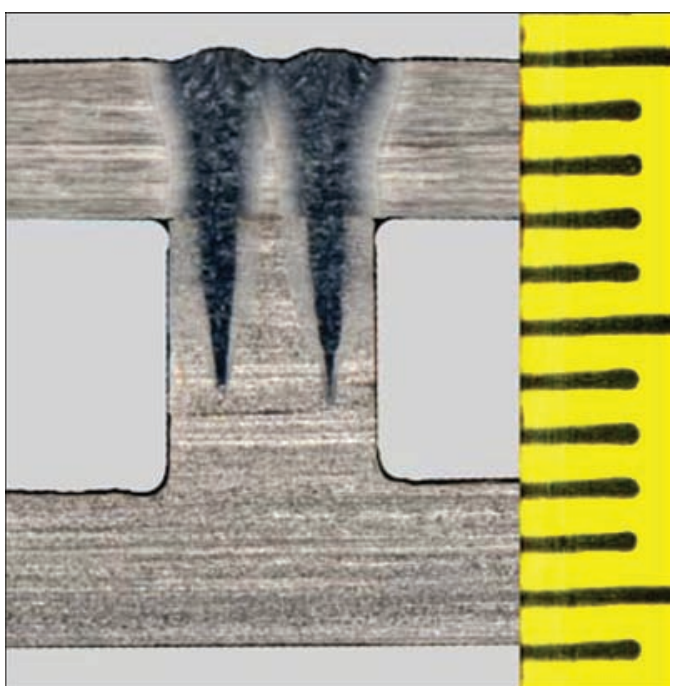

Figure 10. Macrosection of T-joint produced by two slot welds real GTE diffuser 0020102040-01SB (Figure 11) and transferred together with it to the Customer.

EBW of body of GTE medium-pressure chamber of titanium VT5L alloy. The body of a medium-pressure chamber (MPC) of the gas turbine engine is a complex structure consisting of supports and blades of the cast titanium $\alpha$-alloy VT5L. In accordance with the technical requirements, the MPC elements should be welded together on the inner and outer band flanges, providing the required mutual arrangement of the blades and supports relative to the engine axis [5]. The number of blades and supports is 34 , respectively, the total number of welds across the inner and outer diameter is 68 , the outer diameter of the MPC body in the assembly-welding device does not exceed the diameter of $1390 \mathrm{~mm}$. The EBW process should provide a full penetration of a part of a variable cross-section (see Figure 12) along the entire length of a butt with the formation of the face and reverse beads of the weld without undercuts

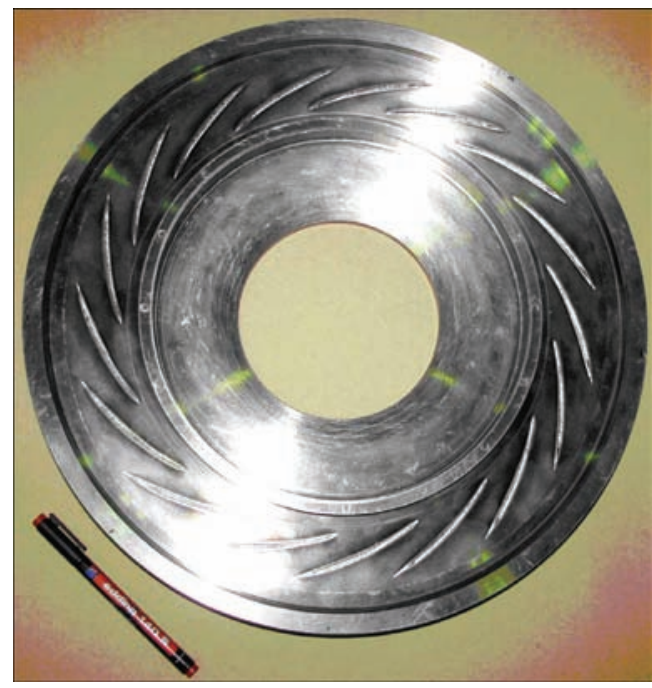

Figure 11. Outer surface of the diffuser covering disc after EBW of ends of 17 blades by slot welds

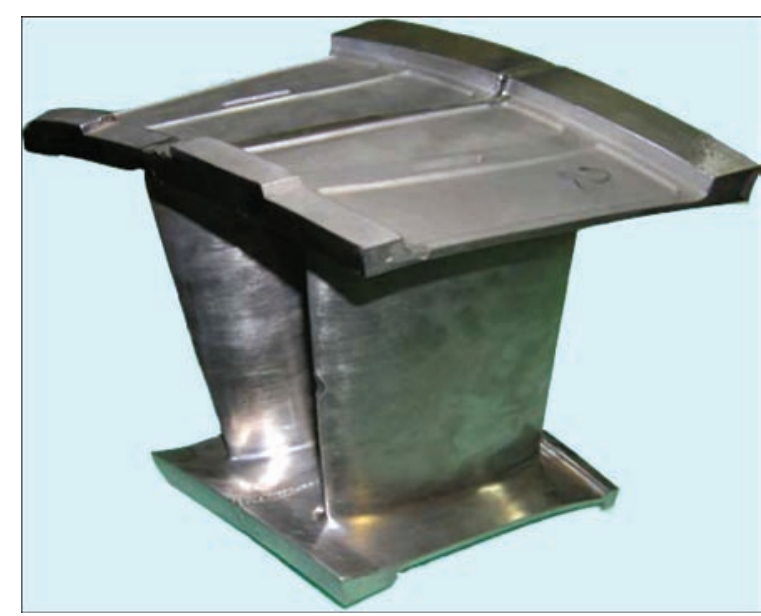

Figure 12. Pair of MPC supports, welded by outer and inner welds and dents, and also the protection of the blade airfoil and adjoining surfaces from damage by a penetrating electron beam.

For the outer joining, the scheme of EBW is used with the almost downward movement of the horizontal beam, and for the inner one - with longitudinal movement in the plane $Z-X$ inclined at $35^{\circ}$ from the beam vertical.

In the first case, the thickness welded varies from 5 to $17 \mathrm{~mm}$, while in the second case, due to the beam inclination, it varies from 5.5 to $24 \mathrm{~mm}$. Accordingly, the welding parameters should change synchronously with the change in the thickness welded (Figure 12).

For both spatial schemes of welding (i.e., outer and inner welds), a universal assembly-welding device (rigging) was designed and manufactured, which provides a fixation of all the body elements, free input and output of the electron beam to the technological tabs, made of the product material, as well as the copper protection of the product from the penetrating electron beam (Figures 14 and 15, respectively).

Starting from the thickness of the metal welded $\left(\delta_{w}\right)$ of $14 \mathrm{~mm}$, a weld with almost parallel walls of the cast zone is formed (Figure 16), while the width of the weld in the root part is in the range of $2.4-2.6 \mathrm{~mm}$.
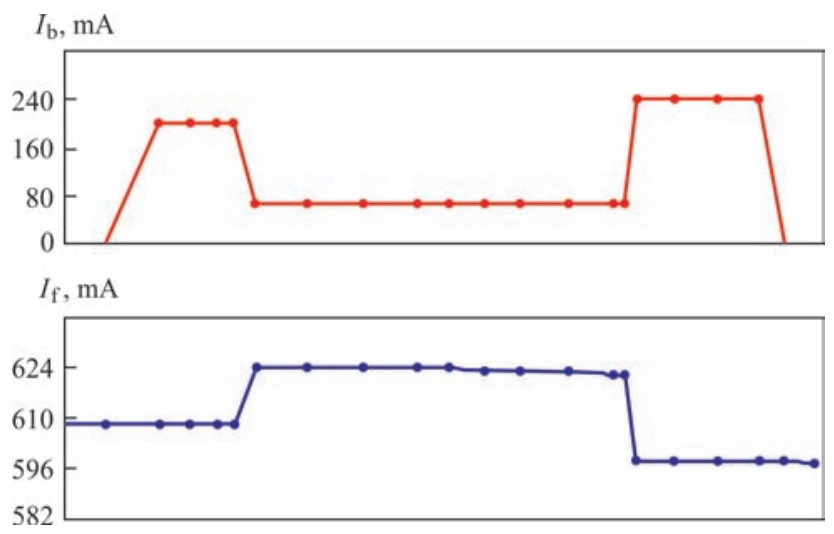

Figure 13. Diagrams of changing beam and focusing current during welding of a part with variable thickness 


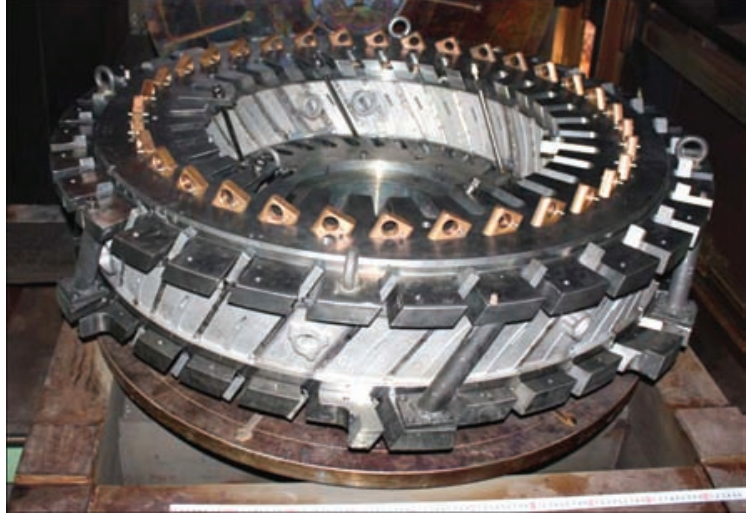

Figure 14. Body of MPC in the rigging for welding of outer joints by horizontal electron beam
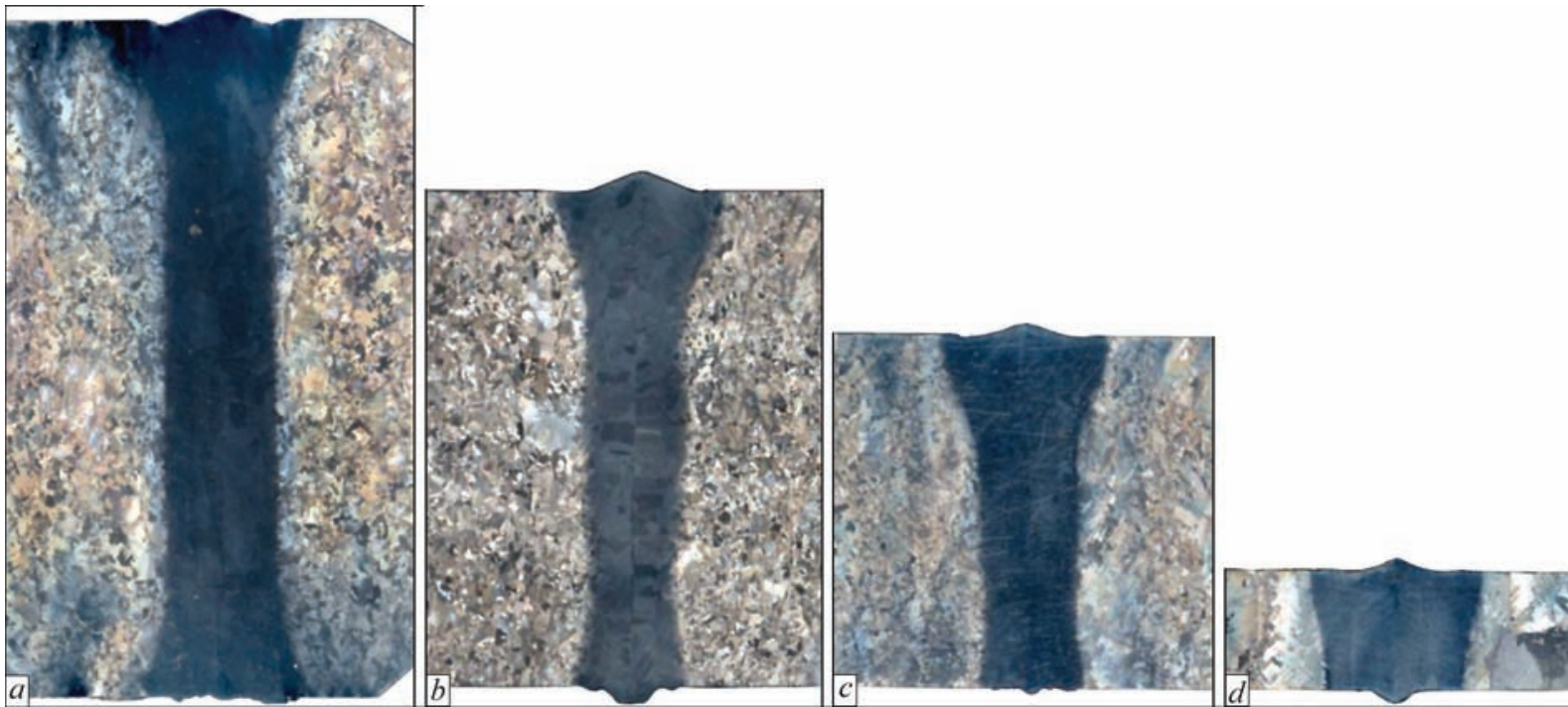

Figure 16. Macrostructure of welded joints of cast alloy VT5L of different thickness in EBW with a full penetration: $a-\delta_{\mathrm{w}}=26$; $b-17 ; c-14 ; d-5 \mathrm{~mm}$

The control of the medium-pressure chamber body geometry after EBW of all the joints showed the admissible deviations of real dimensions from those specified in the drawings, which confirms the advantage of using EBW in manufacturing of GTE parts.

1. Paton, B.E., Nazarenko, O.K., Nesterenkov, V.M. et al. (2004) Computer control of electron beam welding with multi-coordinate displacements of the gun and workpiece. The Paton Welding J., 5, 2-5.

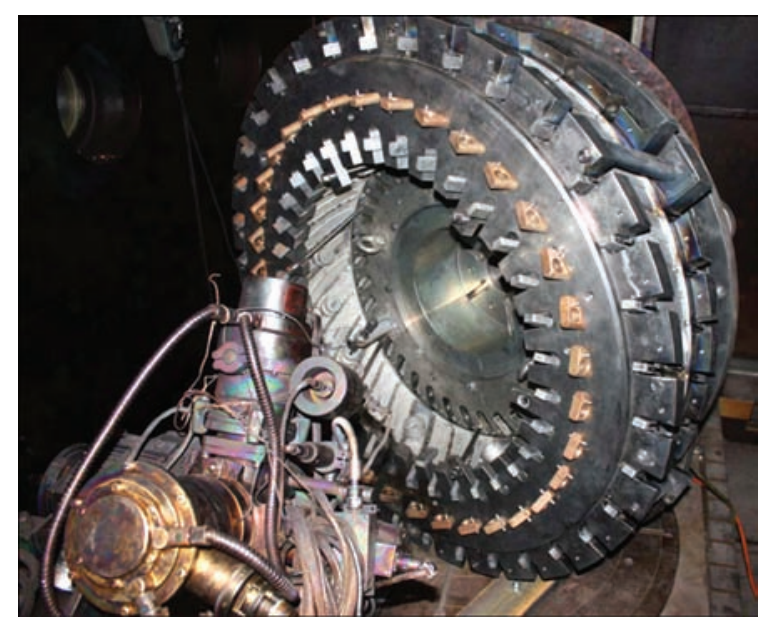

Figure 15. Body of MPC in the rigging for longitudinal welding (in the plane $Z-X$ ) of inner welds by inclined electron beam
2. Zamkov, V.N., Prilutsky, V.P., Petrichenko, I.K. et al. (2001) Effect of the method of fusion welding on properties of welded joints in alloy Ti-6Al-4V. Ibid., 4, 2-6.

3. (1977) Titanium alloys in machine building. Ed. by G.I. Kapyrin. Leningrad, Mashinostroenie [in Russian].

4. Makhnenko, V.I. (2006) Resource of safe service of welded joints and assemblies of modern structures. Kyiv, Naukova Dumka [in Russian].

5. Nesterenkov, V.M., Kravchuk, L.A., Arkhangelsky, Yu.A. et al. (2015) Electron beam welding of medium-pressure chamber of gas turbine engine. The Paton Welding J., 12, 29-33.

Received 25.06.2018 


\title{
EFFECT OF THERMAL CYCLE OF TIG WELDING ON STRUCTURE AND PROPERTIES OF PSEUDO- $\beta$-TITANIUM ALLOYS
}

\author{
S.V. AKHONIN, V.Yu. BELOUS and R.V. SELIN \\ E.O. Paton Electric Welding Institute of the NAS of Ukraine \\ 11 Kazimir Malevich Str., 03150, Kyiv, Ukraine. E-mail: office@paton.kiev.ua
}

\begin{abstract}
The structural pseudo- $\beta$-titanium alloys have found a wide application in aircraft and rocket construction. However, while producing welded joints of pseudo- $\beta$-alloys applying method of fusion welding, the difficulties arise connected with change in the structure and formation of metastable phases in welded joint. In this paper, using the developed mathematical model of TIG process, the influence of welding thermal cycle on the weld shape, cooling rate and structure of welded joint metal of the pseudo- $\beta$-titanium alloy VT19 was investigated. Amount of phases in the weld metal, heat-affected zone and base metal was determined, phase composition and its effect on the mechanical properties of welded joints were predicted. 8 Ref., 4 Tables, 11 Figures.
\end{abstract}

Keywords : TIG welding, high-strength titanium alloys, mathematical modeling

Structural pseudo- $\beta$-titanium alloys have found wide application in products of aircraft and rocket construction. The alloys of this class can be efficiently hardened by heat treatment, consisting of hardening and aging and having 10-20\% higher strength than $\alpha$-alloys. However, production of welded joints of pseudo- $\beta$-titanium alloys using fusion welding provokes difficulties caused by change of structure and formation of metastable phases in welded joint [1-3].

Selection of methods, modes and technology of fusion welding of titanium $\beta$-alloys depends on type of welded structure, its designation, operation conditions and nature of heat treatment before and after welding. The main criterion for selection of modes and technology of welding is the optimum interval of cooling rates in welding. It should be considered that quality of welded joints depends on structure and properties of a near-weld zone, which are determined by welding thermal cycle. Therefore, it is reasonable to compare various modes of TIG welding on their heat effect on the weld and near-weld zone [4, 5].

Aim of the present paper is an analytical investigation of thermal conditions in a welding zone using mathematical modeling method for TIG welding, determination of dependence of structure of welded joint areas and its mechanical properties on welding modes.

Work procedure. Investigation of effect of thermal cycle of TIG welding on structural transformations was carried out using the method of mathematical modeling of thermal processes in welding of pseudo- $\beta$-titanium alloy VT19. The base of the method is a heat-balance equation. A 3D mathematical model of thermal processes in titanium during welding with scanning heat source was built for calculation determination of effect of welding mode parameters on weld formation using the finite element method. It is based on differential equation of heat conductivity and states boundary conditions describing heat exchange of product with environment.

Received temperature field was used for determination of such thermal parameters as distribution of maximum temperatures and cooling rate in welded joint section.

Used finite element 3D model of welding thermal processes was proposed in work [6]. The calculation thermal fields in the deposited product were received taking into account given above initial and boundary conditions. Based on the calculation results the isothermal curves of maximum temperatures were plot-

Table 1. Welding modes, which were subjected to mathematical modeling

\begin{tabular}{|c|c|c|c|c|}
\hline Number of mode & Welding current, A & Arc voltage, $\mathrm{V}$ & Welding rate, $\mathrm{m} / \mathrm{h}$ & Penetration depth, mm \\
\hline 1 & 240 & 12 & 10 & 3.8 \\
\hline 2 & 310 & 12 & 10 & 6.0 \\
\hline 3 & 320 & 12 & 16 & 1.9 \\
\hline 4 & 620 & 12 & 16 & 6.0 \\
\hline
\end{tabular}


ted. They were used for determination of geometry and size of penetration zone, HAZ, zone of polymorphous transformation.

Effect of thermal cycle in TIG welding of VT19 alloy on cooling rates in welded joint. 4 modes of TIG welding with different rate and heat input were investigated (Table 1).

Figure 1 shows an example of calculation distribution of the maximum temperatures and microsection of received experimental welded joint, produced at mode No.2 (see Table 1). This joint was used for mathematical modeling of thermal processes of TIG welding of pseudo- $\beta$-titanium alloy VT19. The difference in width of deposited bead in calculation and experimental sample made $3.1 \%$, width of back bead $2.4 \%$. Such small values of error between calculation and experimental data prove the adequacy of the developed mathematical model.

Calculation results of mathematical modeling allowed determining the effect of heat input and welding rate on penetration depth, weld shape and distribution of the maximum temperatures in the welded joint section (Figure 2).

In order to determine the effect of thermal welding cycle on cooling rate and structure of welded joint metal the modes were selected, at which complete penetration of weld metal (No.2 and No.4) with lower and higher value of heat input are provided. For this modes the cooling rates in temperature range from 1600 to $100{ }^{\circ} \mathrm{C}$ were calculated. The analysis of received calculation data showed that in cooling from
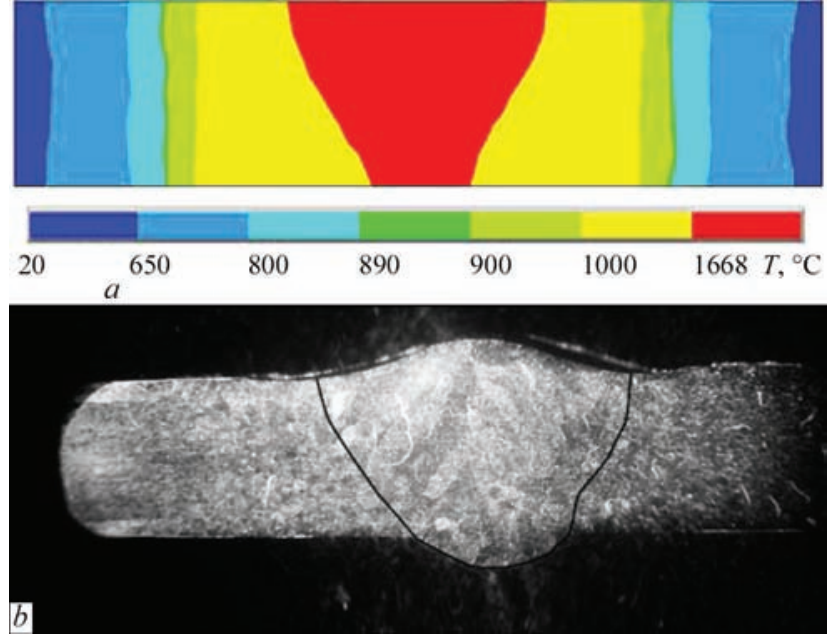

Figure 1. Result of calculation of penetration zone of base metal and HAZ shape, heat source: $I=310 \mathrm{~A}, U=11 \mathrm{~V}, \eta=0.43, v=$ $=10 \mathrm{~m} / \mathrm{h}(a)$; microsection of TIG joint $\left(I_{\mathrm{w}}=310 \mathrm{~A}, U_{\mathrm{a}}=11 \mathrm{~V}\right.$, $\left.v_{\mathrm{w}}=10 \mathrm{~m} / \mathrm{h}\right)(b)$

1667 to $890{ }^{\circ} \mathrm{C}$ the highest cooling rates are noted in the weld metal. In cooling from $1200{ }^{\circ} \mathrm{C}$ the cooling rate in the middle of weld at mode with lower welding rate reaches values of $228{ }^{\circ} \mathrm{C}$ (Figure 3,a) and the cooling rate in the fusion zone achieves $130{ }^{\circ} \mathrm{C} / \mathrm{s}$.

Increase of cooling rate and current does not result in noticeable changes in cooling rates in these ranges of temperatures and the maximum value of cooling rates is even somewhat lower, namely $217^{\circ} \mathrm{C} / \mathrm{s}$.

When reaching the temperature interval of 1000 $900{ }^{\circ} \mathrm{C}$ the maximum cooling rate in the weld center on the surface makes $177^{\circ} \mathrm{C} / \mathrm{s}$, weld metal cools with

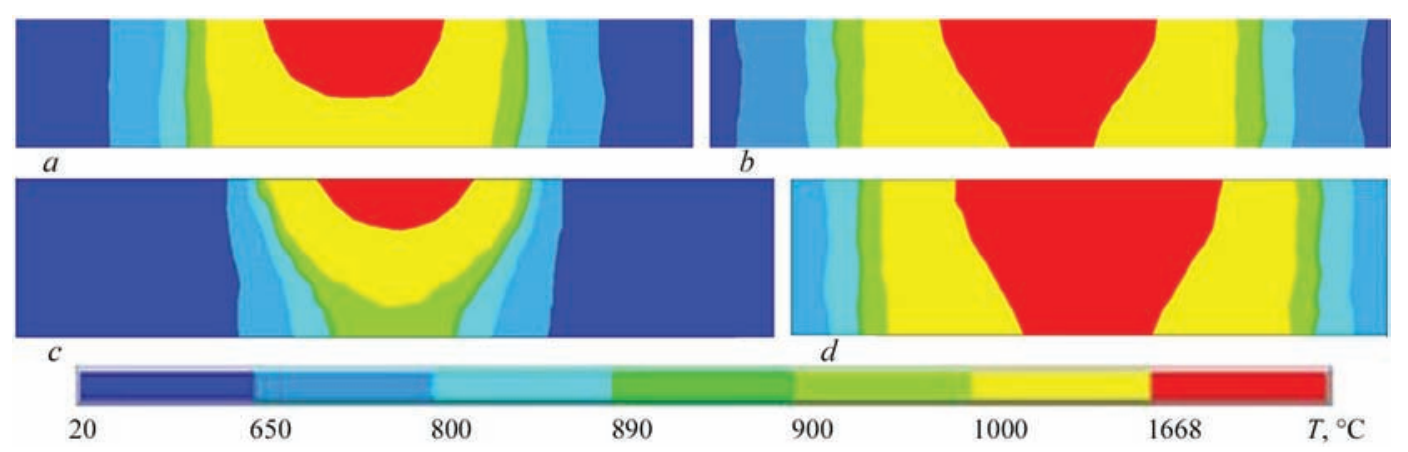

Figure 2. Effect of heat input and welding rate on penetration of titanium alloy VT19: $a-$ mode No.1; $b-2 ; c-3 ; d-4$

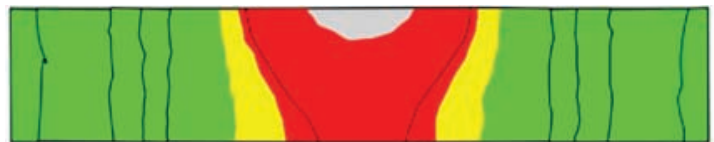

$a$

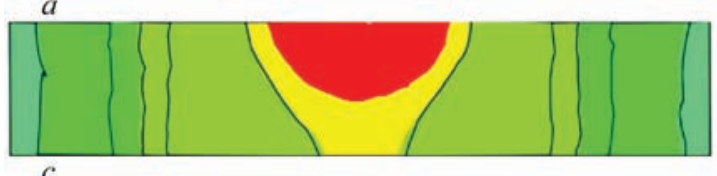

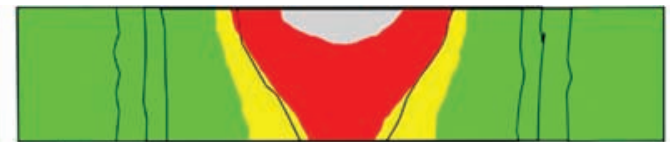

b

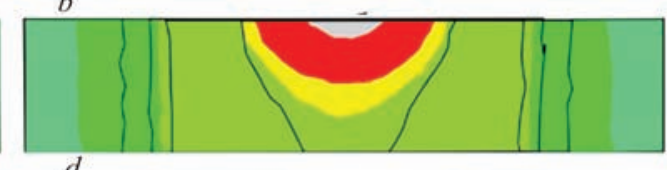

$d$

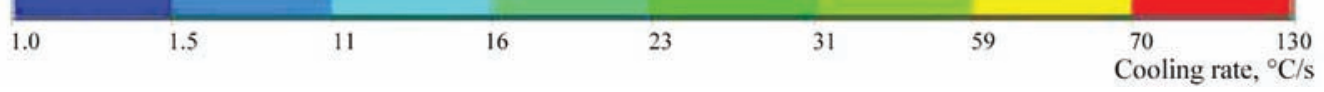

Figure 3. Distribution of cooling rates in temperature range: $a-1200-1100{ }^{\circ} \mathrm{C}$ (mode No.2); $b-1200-1100{ }^{\circ} \mathrm{C}(\mathrm{No} .4)$; $c-1000-$ $900^{\circ} \mathrm{C}(\mathrm{No} .2) ; d-1000-900^{\circ} \mathrm{C}(\mathrm{No} .4)$ 


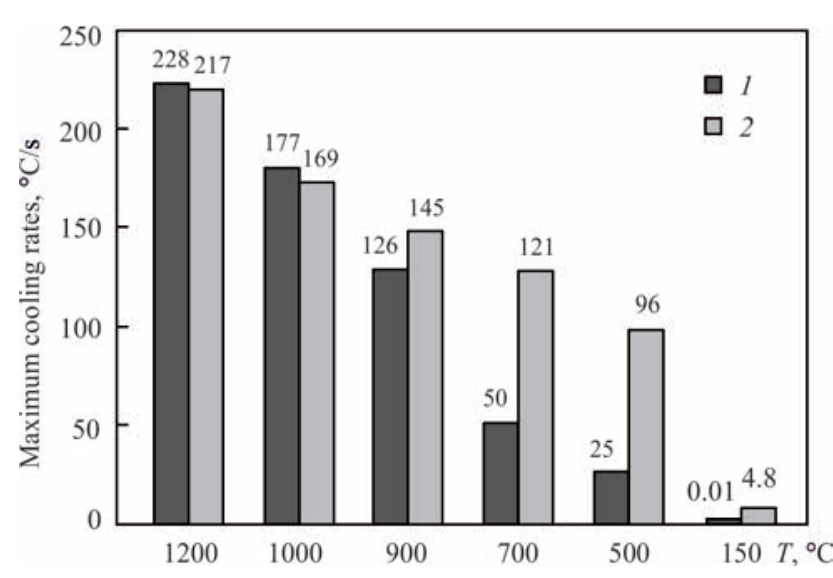

Figure 4. Values of maximum cooling rates at different temperatures: $1-310 \mathrm{~A}, 10 \mathrm{~m} / \mathrm{h} ; 2-620 \mathrm{~A}, 16 \mathrm{~m} / \mathrm{h}$

$130-70{ }^{\circ} \mathrm{C} / \mathrm{s}$ rate, and in HAZ the cooling rates lie in the limits from 59 to $23{ }^{\circ} \mathrm{C} / \mathrm{s}$ (Figure 3,c). The cooling rates at mode with higher heat input has similar values, i.e. the maximum rate makes $169{ }^{\circ} \mathrm{C} / \mathrm{s}$, but area of the sample, in which such values are registered, is significantly larger (Figure 3,d). At that the cooling rate from the back side of the weld is smaller than in the sample at mode with lower welding rate.

In the temperature interval $900-800{ }^{\circ} \mathrm{C}$ the cooling rate of weld metal in the center on the area of $6.5 \mathrm{~mm}$ width and at $2.5 \mathrm{~mm}$ depth is still makes $130-70^{\circ} \mathrm{C} / \mathrm{s}$. In the rest part of weld metal and HAZ the cooling rates becomes even and make $31-23{ }^{\circ} \mathrm{C} / \mathrm{s}$. In the sample welded with higher welding rate, the maximum cooling rates drop to $145^{\circ} \mathrm{C} / \mathrm{s}$ and area, at which cooling rates of $130-70{ }^{\circ} \mathrm{C} / \mathrm{s}$ are registered, is more than in the sample with lower cooling rate. When reaching the temperature range corresponding to temperature of polymorphous transformation of alloy VT19, 800-700 ${ }^{\circ} \mathrm{C}\left(T_{\mathrm{m}}=780{ }^{\circ} \mathrm{C}\right)$ [7], the cooling rates reduce and in the fusion zone they are in the limits from $59-23{ }^{\circ} \mathrm{C} / \mathrm{s}$, and the maximum cooling rate $11^{\circ} \mathrm{C} / \mathrm{s}$ is registered in HAZ. At that, following the diagram, $\beta \rightarrow \alpha$ transformations are started to be registered in the HAZ areas distant from the weld center. In the sample with higher heat input the cooling rates high for such a temperature range are still observed, namely in the weld center they make $70-120^{\circ} \mathrm{C} / \mathrm{s}$, in HAZ reach $59{ }^{\circ} \mathrm{C} / \mathrm{s}$. The cooling rate in the weld center of sample produced at mode with $10 \mathrm{~m} / \mathrm{h}$ welding rate reach $16^{\circ} \mathrm{C} / \mathrm{s}$ and that for $\mathrm{HAZ}$ is $11^{\circ} \mathrm{C} / \mathrm{s}$ in a temperature range $600-500^{\circ} \mathrm{C} / \mathrm{s}$. The cooling rate values make less than $0.01{ }^{\circ} \mathrm{C} / \mathrm{s}$ in the weld and HAZ of the sample produced at mode No.2 in temperature range

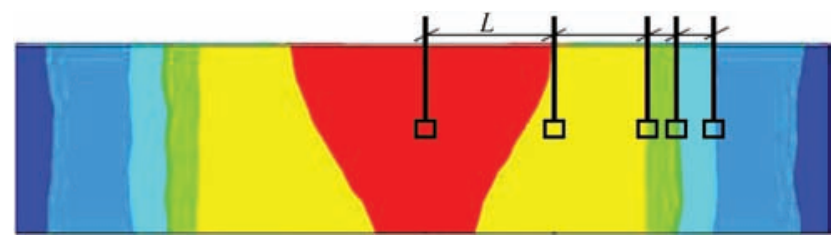

Figure 5. Scheme of determination of size of areas with maximum temperatures in welded joint $(L-$ length of area)
$200-100{ }^{\circ} \mathrm{C} / \mathrm{s}$. The cooling rates of $4.8^{\circ} \mathrm{C} / \mathrm{s}$ are registered in the weld of sample produced at mode with higher heat input in temperature range $50-150^{\circ} \mathrm{C}$.

Received results of the cooling rates allow concluding that the highest cooling rates at high temperatures $\left(1000{ }^{\circ} \mathrm{C}\right.$ and more) are registered at mode with low heat input. At temperature decrease (less than $1000{ }^{\circ} \mathrm{C}$ ) the maximum rates of cooling are registered in the welded joint produced with higher heat input. At that a pace of change of cooling rates at this mode is also bigger (Figure 4).

Effect of TIG welding thermal cycle on amount of $\beta$-phase in the joints of pseudo- $\beta$-titanium alloys. Amount of forming $\beta$-phase in the weld and HAZ was determined for prediction of phase composition. For this modes Nos 2 and 4 were used in welding of experimental sample of pseudo- $\beta$-titanium alloy VT19 [8]. Cross-microsections of produced welded joint were used for determination of structure and amount of $\beta$-phase in different areas, for which the cooling rates in different temperature ranges (Figure 5) were received using the mathematical modeling.

Amount of $\beta$-phase was determined by computer processing of received microsections of the welded joint. Determination of microstructure is based on the fact that various phases has distinct etching and colouring. Thus, $\beta$-phase has light colour and $\alpha, \alpha^{\prime}$, $\alpha^{\prime \prime}$ are dark. As a result shape and size of separate grains can be determined and amount, shape and direction of grains, separate phases and structural constituents, change of internal structure of metals and alloys depending on conditions of their manufacture and treatment are stated.

The structure was examined in the middle of sample of $6 \mathrm{~mm}$ thickness. Distance $L$ (see Figure 5) is the distance from the middle of weld to examined point on cross-microsection of welded joint.

The base metal of VT19 alloy of $6 \mathrm{~mm}$ thickness, at which TIG welding was carried out, has a grain diameter of $0.05-0.50 \mathrm{~mm}$ (Figure 6, $a$ ). In some grains of subsurface zone of BM there is nonuniform distribution of $\alpha$-phase particles in grain (Figure 6,b). Disperse $\alpha$-phase, size of $\alpha$-phase particles makes $1-2 \mu \mathrm{m}$ and less, is present in the base metal in large amount. Amount of $\beta$-phase in the base metal makes $31 \%$.

Weld metal of joint, produced by TIG welding at mode No.2 (see Table 1), consists of equiaxial and elongated in a direction of heat removal $\beta$-phase grains, hairlike boundaries of which appear at the background of dendrite structure (Figure 7,a). Amount of $\beta$-phase in this area makes $74 \%$.

Weld metal and HAZ of the joint, produced by TIG welding at mode No.4 (see Table 1) differing by parameters and configuration of zones, direction of crystallites growth, have microstructure, consisting of $\beta$-phase grains, identical to the joint performed by TIG welding at mode No.2 (Figure $7, b$ ). 


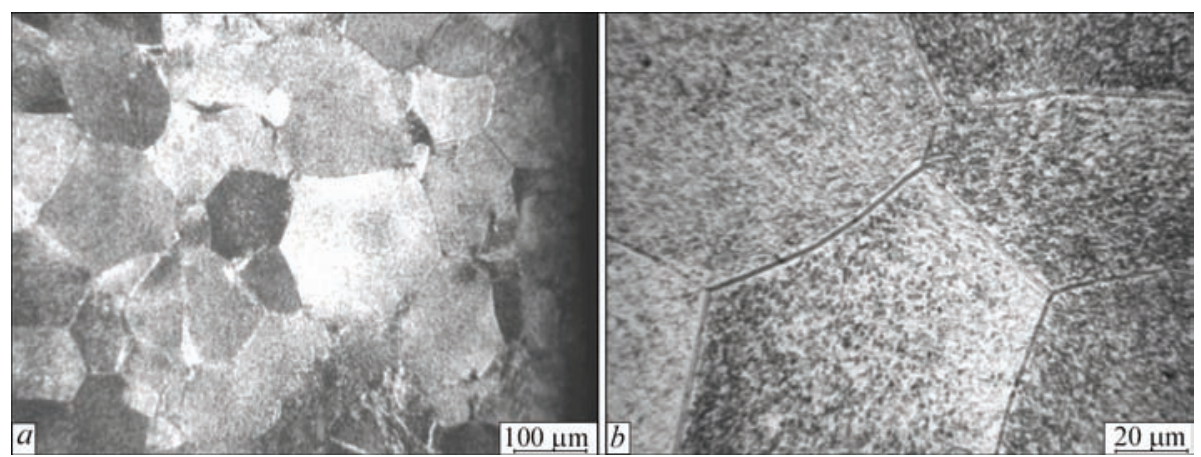

Figure 6. Microstructure of subsurface layer of base metal VT19

A fusion zone (Figure 8,a) is located at $5.4 \mathrm{~mm}$ distance from a weld axis. Weld grains at the background of dendrite structure are to the right on the photo and equiaxial $\beta$-grains of HAZ area close to the fusion zone are on the left. Amount of $\beta$-phase in this area makes $81 \%$. Partially fused grains belonging si- multaneously to HAZ metal as well as base metal can be seen directly in the fusion zone.

HAZ area, where complete polymorphous transformation took place during welding, consists of equiaxial $\beta$-grains (Figure $8, b$ ), has $4.75 \mathrm{~mm}$ width. Here amount of $\beta$-phase is on the level of $80 \%$.

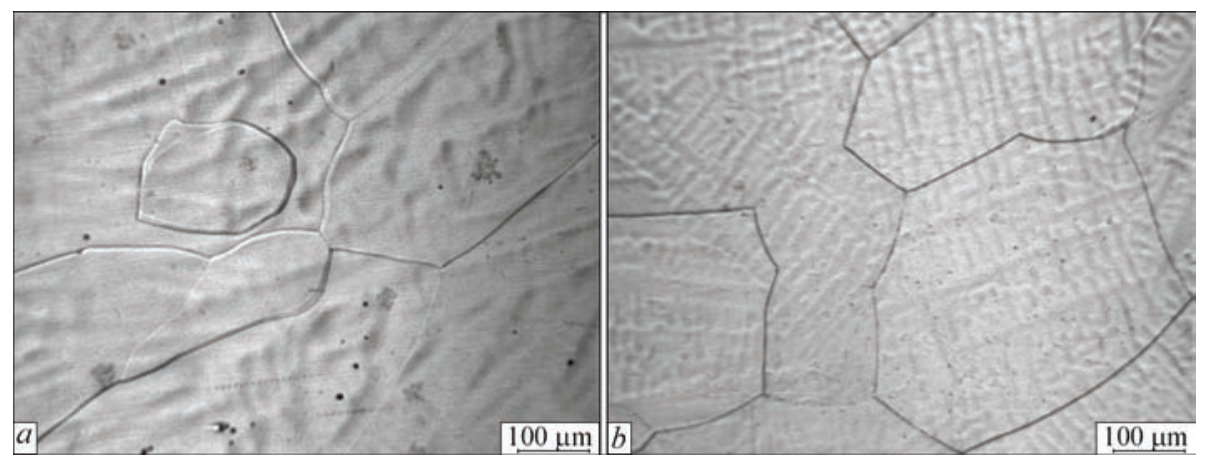

Figure 7. Microstructure of welded joint metal from pseudo- $\beta$-titanium alloy VT19, produced by TIG welding: $a-$ mode No.2; $b-$ No.4
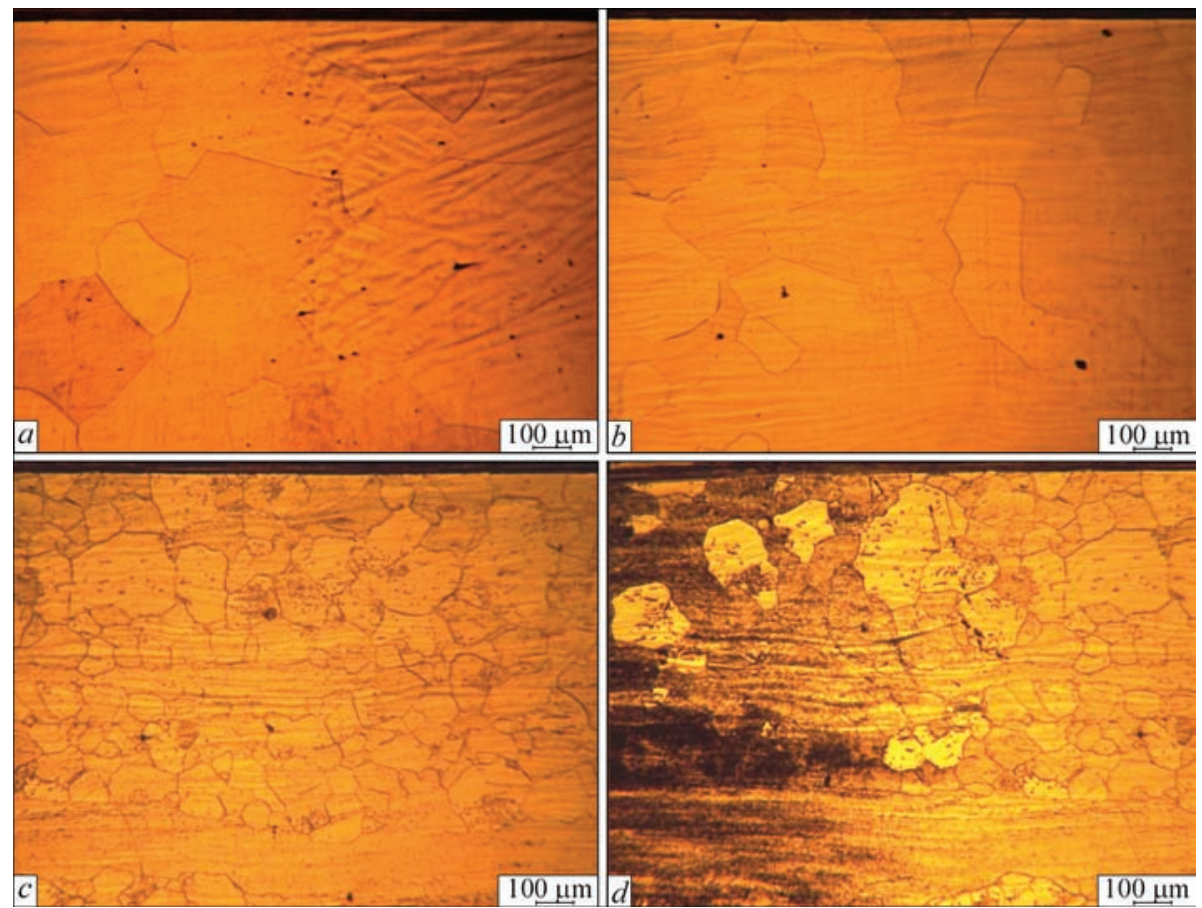

Figure 8. Microstructure of HAZ metal of welded joint from pseudo- $\beta$-titanium alloy VT19 produced by TIG welding without filler wire, mode No.1: $a$ - fusion zone; $b$ - area of complete polymorphous transformation; $c$ - zone of incomplete polymorphous transformation; $d$ - boundary between the zone of incomplete polymorphous transformation and base metal 


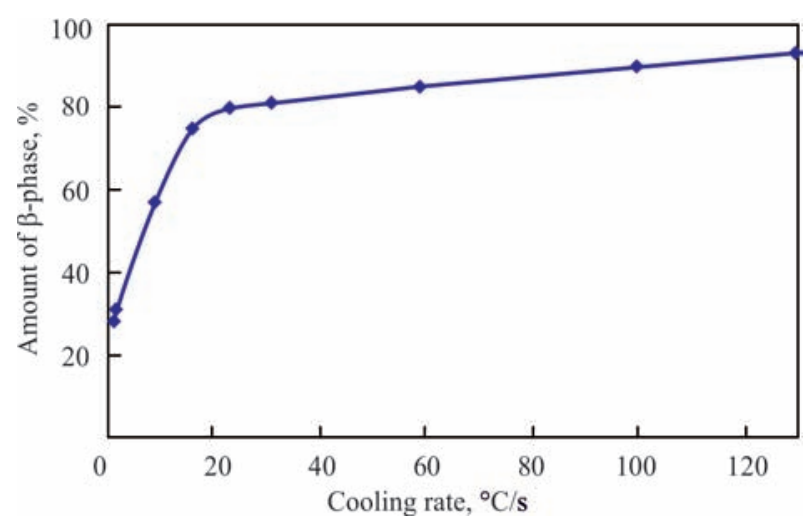

Figure 9. Dependence of amount of $\beta$-phase in metal of welded joint from pseudo- $\beta$-titanium alloy VT19 on maximum cooling rates at temperature of end of polymorphous transformation $\left(800{ }^{\circ} \mathrm{C}\right)$

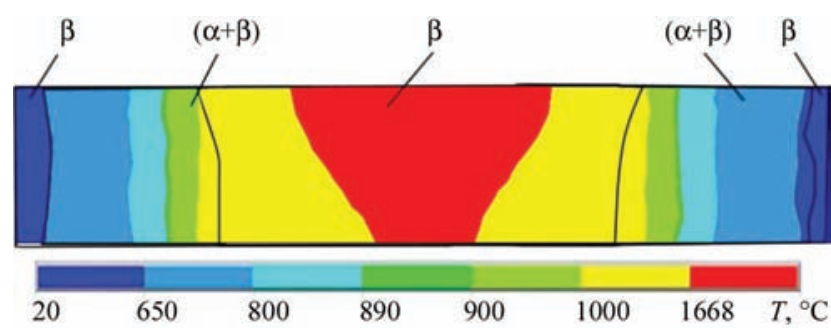

Figure 10. Distribution of phases in section of welded joint produced at the following mode: $I=310 \mathrm{~A}, v_{\mathrm{w}}=10 \mathrm{~m} / \mathrm{h}$

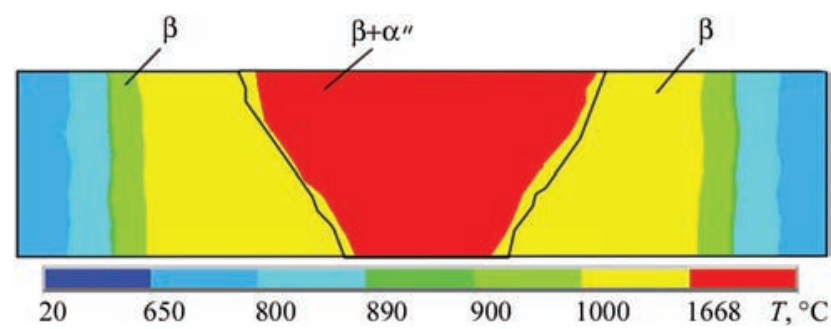

Figure 11. Result of calculation of penetration zone in welding $\left(I=620 \mathrm{~A}, v_{\mathrm{w}}=16 \mathrm{~m} / \mathrm{h}\right)$

HAZ area, where incomplete polymorphous transformation is observed, has $2.5 \mathrm{~mm}$ width (Figure 8, c). Here in $\beta$-grains there are the particles of other phases, which can be found in the base metal, in particular, $\alpha$-phase. Amount of $\beta$-phase is $75 \%$.

Figure $8, d$ shows transfer from the area of incomplete polymorphous HAZ transformation to the base metal. Amount of $\beta$-phase makes $57 \%$ at the bound- ary of transfer from the area of incomplete polymorphous transformation to the base metal. In the base metal amount of $\beta$-phase makes $31 \%$.

Obtained using mathematical modeling the calculation maximum cooling rates at temperatures of start of $\beta \rightarrow \alpha$ polymorphous transformation $\left(810^{\circ} \mathrm{C}\right)$ were compared with the experimentally received data on content of $\beta$-phase in the considered areas of welded joint, made at mode No.1 $\left(I_{\mathrm{w}}=310 \mathrm{~A}, v_{\mathrm{w}}=10 \mathrm{~m} / \mathrm{h}\right)$ for the points at distance $\mathrm{L}$ from the weld center (Table 2).

Based on compared data a dependence of amount of $\beta$-phase on maximum cooling rate at temperature of start $\beta \rightarrow \alpha$ polymorphous transformation $\left(810^{\circ} \mathrm{C}\right)$ in alloy VT19 was obtained (Figure 9).

Also, a distribution of phases in the cross-section of welded joint produced at mode No.2 (Figure 10) and No.4 (Figure 11) (see Table 1) was obtained comparing the received calculation data of shape of weld metal, HAZ and base metal, cooling rates, and experimental data of amount of $\beta$-phase in different areas of the welded joint.

As can be seen from obtained results, $\beta$-phase is mainly formed after welding at mode No. 2 in the middle of weld. Metastable $\alpha^{\prime}$ and $\alpha^{\prime \prime}$-phases are absent in the welded joint. According to quantitative calculation of phase distribution in the welded joint section, an area of $\beta$-phase makes $78 \mathrm{~mm}^{2}$, and $\alpha$-phase is $58 \mathrm{~mm}^{2}$ (Table 3 ).

In welding at mode No.4 $\beta$ - and metastable $\alpha^{\prime \prime}$ phase (Figure 11) are observed in the weld center. $\beta$-phase prevails in HAZ and base metal. It is provoked by high gradient of cooling rates in different temperature ranges. Area of $\beta$-phase in welded joint section makes $113 \mathrm{~mm}^{2}$. Area of metastable $\alpha^{\prime \prime}$-phase is $23 \mathrm{~mm}^{2}$ (Table 3 ).

Effect of TIG welding thermal cycle on mechanical properties of welded joints from pseudo- $\beta$-titanium alloy VT19. Mechanical tests of base metal and welded joints from pseudo- $\beta$-titanium alloy VT19, produced at modes Nos 2 and 4, were carried out. Analysis of mechanical properties shows reduction of strength indices and impact toughness in the welded joint in comparison with the base metal (Table 4). It is explained

Table 2. Amount of $\beta$-phase and maximum values of cooling rates in different areas of welded joint

\begin{tabular}{|c|c|c|c|c|c|c|}
\hline Parameter & Weld center & Fusion zone & $\begin{array}{c}\text { Area of complete } \\
\text { polymorphous } \\
\text { transformation }\end{array}$ & $\begin{array}{l}\text { Area of incom- } \\
\text { plete polymor- } \\
\text { phous transfor- } \\
\text { mation }\end{array}$ & $\begin{array}{l}\text { Boundary } \\
\text { between zone } \\
\text { of incomplete } \\
\text { polymorphous } \\
\text { transformation } \\
\text { and base metal }\end{array}$ & Base metal \\
\hline Distance from weld middle $L, \mathrm{~mm}$ & 0 & 5.43 & 7.8 & 14.5 & 15.8 & 17 \\
\hline Amount of $\beta$-phase, $\%$ & 74 & 81 & 80 & 75 & 57 & 31 \\
\hline Maximum cooling rates at $T=800^{\circ} \mathrm{C} / \mathrm{s}$ & 59 & 31 & 23 & 16 & 9 & 1.5 \\
\hline Maximum cooling rates at $T=500^{\circ} \mathrm{C} / \mathrm{s}$ & 16 & 11 & 11 & 1.5 & 1.5 & 1.5 \\
\hline
\end{tabular}


Table 3. Area of precipitation of metastable phases in TIG welding of pseudo- $\beta$-titanium alloy VT19

\begin{tabular}{|c|c|c|c|c|c|c|}
\hline \multirow{2}{*}{$\begin{array}{c}\text { Mode } \\
\text { number }\end{array}$} & \multicolumn{3}{|c|}{ Mode parameters } & \multicolumn{3}{c|}{ Area of phase precipitation, $\mathrm{mm}^{2}$} \\
\cline { 2 - 7 } & Welding current, A & Welding rate, $\mathrm{m} / \mathrm{h}$ & Heat input, $\mathrm{kJ} / \mathrm{cm}$ & $\beta$ & $\alpha$ & $\alpha^{\prime \prime}$ \\
\hline 2 & 310 & 10 & 803 & 78 & 58 & - \\
\hline 4 & 620 & 16 & 1004 & 113 & - & 23 \\
\hline
\end{tabular}

Table 4. Amount of $\beta$-phase and mechanical properties of base metal and welded joint of pseudo- $\beta$-titanium alloy VT19

\begin{tabular}{|c|c|c|c|c|c|c|}
\hline $\begin{array}{c}\text { Area of examination, } \\
\text { mode number }\end{array}$ & $\begin{array}{c}\text { Amount of } \beta \text {-phase, } \\
\%\end{array}$ & $\begin{array}{c}\text { Tensile strength } \sigma_{\mathrm{r}^{\prime}} \\
\mathrm{MPa}\end{array}$ & Yield limit $\sigma_{\mathrm{y}}, \mathrm{MPa}$ & $\begin{array}{c}\text { Relative elongation, } \\
\delta_{\mathrm{s}}, \mathrm{MPa}\end{array}$ & $\begin{array}{c}\text { Reduction of area } \\
\psi, \%\end{array}$ & $\begin{array}{c}\text { Impact toughness } \\
\mathrm{KVC}, \mathrm{J} / \mathrm{cm}^{2}\end{array}$ \\
\hline BM & 56 & 887 & 958 & 12 & 42 & 22 \\
\hline Weld, mode No.2 & 74 & 860 & 839 & 13,3 & 60 & 19 \\
\hline Weld, mode No.4 & 98 & 836 & 801 & 12 & 50 & 15 \\
\hline
\end{tabular}

by high content of $\beta$-phase in the weld metal of welded joint. Metastable $\beta$-phase has low strength and high ductility, therefore, welded joints have low strength indices. Strength and impact toughness of the welded joint produced at mode No.4 have lower indices in comparison with the welded joint of mode No.2. It allows making a conclusion that increase of heat input and welding rate (Table 3) has negative effect on strength and impact toughness of the welded joints from pseudo- $\beta$-titanium alloy VT19, and only promotes increase of content of $\beta$-phase in the weld metal due to increase of weld metal cooling rates with sample cooling.

Thus, TIG-welded joints of titanium alloy VT19 are reasonable to be produced at modes with lower heat input and welding rate.

\section{Conclusions}

1. A 3D mathematical model was built for investigation of thermal processes of TIG welding of pseudo- $\beta$-titanium alloys using finite element method. It allowed getting thermal fields in the deposited product, determining distribution of the maximum temperatures and cooling rates in section of welded joints at different heat input.

2. It is determined that the highest cooling rates at high temperatures $\left(1000{ }^{\circ} \mathrm{C}\right.$ and more) were registered at mode with low heat input. At temperature decrease (less than $1000{ }^{\circ} \mathrm{C}$ ) the maximum cooling rates are registered in the welded joint produced with higher heat input. At that, pace of variation of cooling rates at this mode is also large.

3. High cooling rates in a temperature range of start and end of polymorphous transformation determine content of $\beta$-phase in the weld metal of welded joint produced at mode No.2 at $90 \%$ level. Reduction of cooling rates results in decrease of amount of $\beta$-phase in the weld metal and heat-affected zone.

4. Received dependence of amount of $\beta$-phase on cooling rates allows making a conclusion that the most intensive decay of $\beta$-phase takes place at the boundary of heat-affected zone and base metal that can lead to formation of metastable phases in this zone of the welded joint and deterioration of joint mechanical properties.

5. Mechanical properties of the welded joint produced at mode No.2 are lower than the similar indices for the base metal. It is explained by high content of $\beta$-phase in weld metal of the welded joint. Metastable $\beta$-phase has low strength, therefore, welded joints have low strength indices. The welded joint made on mode No.4 has lower mechanical properties in comparison with the base metal and joint of mode No.2 that is explained by increase of content of $\beta$-phase in the weld metal due to rise of metal cooling rates with sample cooling down.

1. Antashev, V.G., Nochovnaya, N.A., Shiryaev, A.A. Izotova, A.Yu. (2011) Perspectives of development of new titanium alloys. Vestnik MGTU im. N.E. Baumana. Seriya Mashinostroenie, SP2, 60-67 [in Russian].

2. Moiseev, V.N. (1998) $\beta$-titanium alloys and perspectives of their development. MiTOM, 12, 11-14 [in Russian].

3. Khorev, A.I. (2009) Development of structural titanium alloys for manufacture of components of aerospace engineering. Svarochn. Proizvodstvo, 3, 13-23 [in Russian].

4. Gurevich, S.M., Kulikov, F.R., Zamkov, V.N. et al. (1975) Welding of high-strength titanium alloys. Moscow, Mashinostroenie [in Russian].

5. Khorev, A.I. (2007) Theoretical and practical fundamentals for improvement of structural strength of modern titanium alloys. Tekhnologiya Lyogkikh Splavov, 2, 144-153 [in Russian].

6. Akhonin, S.V., Belous, V.Yu., Muzhichenko, A.F. et al. (2013) Mathematical modeling of structural transformations in HAZ of titanium alloy VT23 during TIG welding. The Paton Welding J., 3, 24-27.

7. Khorev, A.I. (2012) Titanium superalloy VT19. Tekhnologiya Mashinostr., 6, 5-8 [in Russian].

8. Akhonin, S.V., Belous, V.Y., Berezos, V,A. Selin, R.V. (2018) Effect of TIG-welding on the structure and mechanical properties of the pseudo- $\beta$ titanium alloy VT19 welded joints. Mat. Sci. Forum, Vol. 927, 112-118. 


\title{
REPAIR OF LARGE-SIZED BLADES OF THE FAN OF GAS-TURBINE ENGINE*
}

\author{
I.B. MARKOV, I.A. PETRIK, A.G. SELIVERSTOV and Yu.A. MARCHENKO \\ JSC «Motor Sich» \\ 15 Motorostroiteley Ave., 69098, Zaporozhye, Ukraine. E-mail: motor@motorsich.com
}

\begin{abstract}
The paper presents the results of work on restoration of damaged area of gas-turbine engine fan by welding of a fragment by electron beam process. Fatigue limit $\sigma_{-1}$ was determined for fan blades for D-36 engine with $16-65 \cdot 10^{3} \mathrm{~N}$ thrust repaired by his technology. Metallographic examination of the blades with fragment welding was carried out after fatigue tests. Perspective directions for increase of fatigue limit of repaired fan blades were proposed. 8 Ref., 2 Tables, 9 Figures.
\end{abstract}

Ke y word s : electron beam welding, titanium alloy, fan blades, fragment welding, heat treatment, structure, fatigue limit

Fan blades are one of the most critical and loaded parts of an aircraft engine. Fan blades are expensive, because of application of individual billets and long cycle of mechanical and heat treatment, polishing and finishing of blades. Therefore, widening the range of blade repair techniques is urgent and economically feasible. The largest number of operational damage of blades is associated exactly with ingress of foreign objects into the engine. It should be noted that most of all blade damage is located in the above-flange part on the leading edge. Fan blade damage lowers engine characteristics, and considerable damage resulting from ingress (for instance, birds), affects flight safety.

Repair documentation in place at JSC «Motor Sich» enterprise envisages certain norms for damage extent, acceptable without correction, as well as repair of damage by such methods as straightening of the leading edge, cleaning and polishing of nicks, cutting damaged sections of the leading edge of not more than $700 \mathrm{~mm}^{2}$ total area. It should be taken into account that cutting the edges lowers the engine thrust. In the cases, when damage exceeds those allowed by repair documentation, the parts are rejected.

JSC «Motor Sich» tried out the technology of repair of D-36 engine fan blades from two-phase titanium alloy VT3-1 by electron beam welding (EBW) of a fragment instead of the damaged section with subsequent determination of the fatigue limit $\sigma_{-1}$. The technology is based on our enterprise experience [1], as well as allowing for the experience of other enterprises on reconditioning repair of elements and assemblies of gas-turbine engines [2].

Welding technology was first tested on flat samples. Sample welding was performed from two sides in electron beam unit ELU-20, which is fitted with program control of mode parameters, program displacement of electron beam gun and part by assigned coordinates. Welding was followed by two-step heat treatment (HT) of the samples, first step of annealing by the electron beam (EBA), second step in the furnace. Mechanical properties were determined on welded and solid samples, type XIII, to GOST 699666. SC «Ivchenko-Progress» performed strength calculations and determined the highest acting stresses in the anticipated areas of weld location. Regions with maximum stresses include the transition from airfoil to antivibration flange and area of the joint of the airfoil with blade root attachment. Calculation results allowed defining the repair zone, weld location (Figure 1) and parameters for further performance of fatigue testing of D-36 fan blades [3]. Bending vibrations in the fourth form were specified for determination of $\sigma_{-1}$ in the repair zone for fatigue testing.

Optimum configuration of the fragment was developed (Figure 2) and dimensions of run-off tabs (Figure $1, b$ ) were determined, taking into account the fact that undercuts can form at EBW on the edges of a blade, which has final dimensions. Fragment material corresponds to the part base material.

Further work was performed on full-scale samples of the blades. Damaged blade areas were cut accord-

\footnotetext{
${ }^{*}$ Based on the report presented at the International Conference «Titanium 2018. Production and Application in Ukraine», June 11-13, 2018, Kiev, E.O. Paton Electric Welding Institute of the NAS of Ukraine.
} 


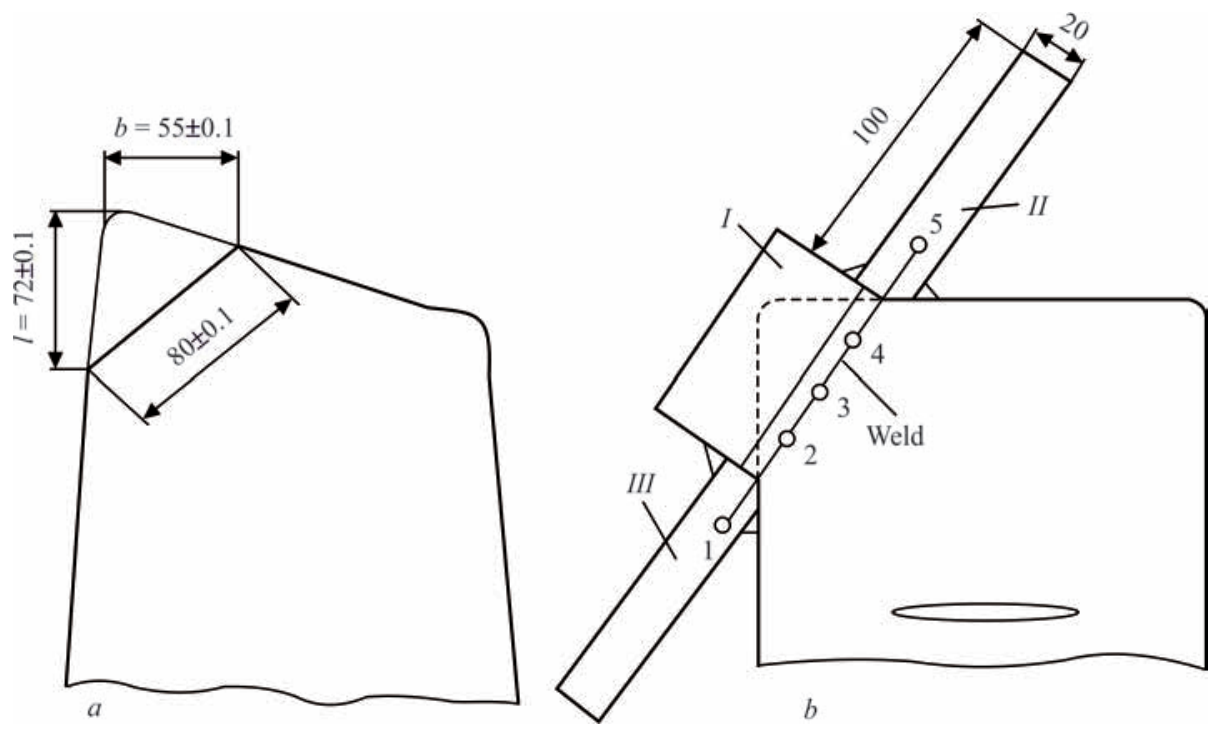

Figure 1. Schematic of calculated zones of repair (a) and location of the weld (b): I — welded fragment; $I I, I I I-$ run-off tabs; $1-5$ — base points of weld division into sections

ing to earlier determined calculated repair zones (Figure 1, a; Figure 3, a).

In the welding zone the fragment was machined to suit the blade airfoil profile and fitted to ensure repetition of profile configuration, providing a smooth transition and $0.3 \mathrm{~mm}$ allowance around the contour from both sides.

Welding of the blade with tack-welded fragment (Figure $3, b$ ) was performed by EBW from two sides. The weld was divided into sections by five base points (Figure 1,b), with correction of welding modes, depending on the change of the thickness of blade airfoil profile section from 1.2 up to $2.4 \mathrm{~mm}$. Programming of welding mode parameters allowed ensuring sound formation of the weld, and avoiding appearance of defects in the form of burns-through (Table 1).

After blade welding, two-step HT (Figure 3,c) was conducted by the following mode: HT first step was performed by EBA in specialized unit Lara-52 at $T=910{ }^{\circ} \mathrm{C}$ with 10 min soaking. EBA modes were selected by analogy with other GTE parts from twophase titanium alloys, and considerably reduced distortion [4]. Second step - furnace annealing - was performed in a shielding atmosphere at $T=650{ }^{\circ} \mathrm{C}$ for $3.0-3.5 \mathrm{~h}$.

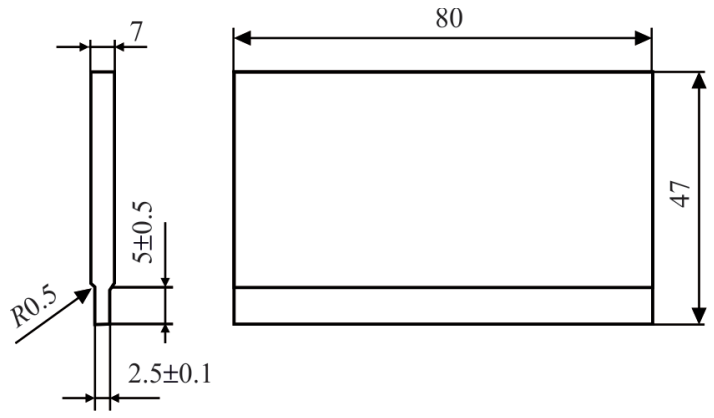

Figure 2. Configuration of the fragment in the welding area
Furtheron, machining of welded fragment was performed up to achieving the required profile configuration with preservation of initial dimensions (Figure 3, d). Finished blades were subjected to control of the repaired locations by LYuM1-OV method and to X-ray testing. No defects were found by control results.

Fatigue testing was conducted with determination of $\sigma_{-1}$ of three batches of full-scale blade samples (Figure 4):

- first batch in the quantity of 8 pcs taken from different engines, having different operating time
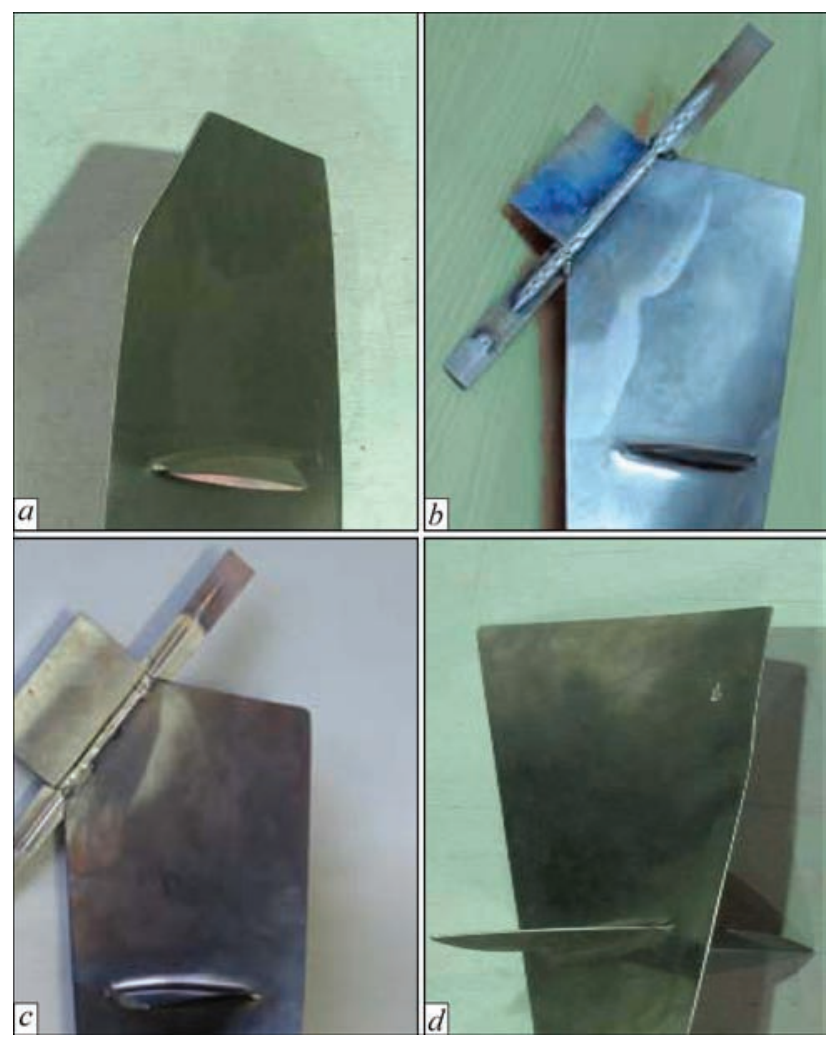

Figure 3. Steps of blade repair performance: $a$ - cutting; $b-$ EBW; $c$ - HT; $d-$ machining 


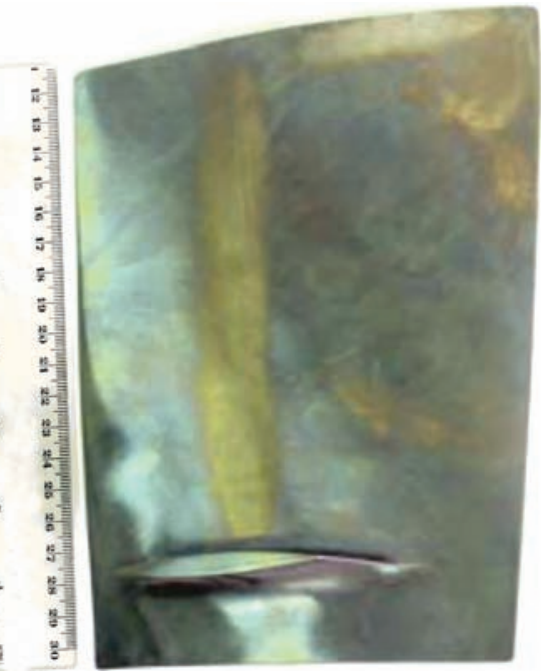

Figure 4. Sample for fatigue testing

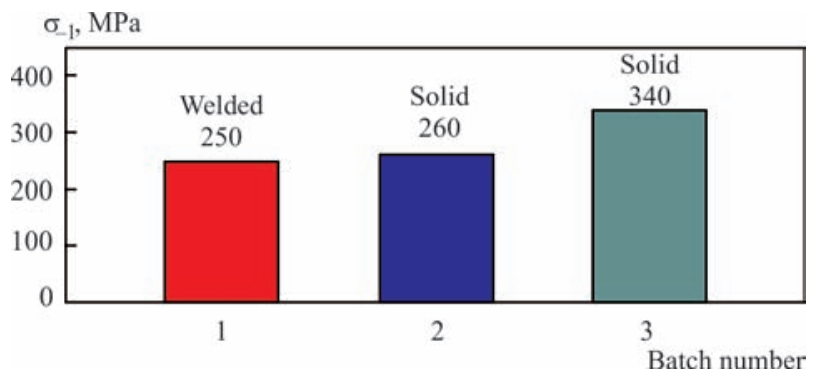

Figure 5. Fatigue limit for three batches of blades

and repaired by welding a fragment (welded) (Table 2). Sample fracture occurred at the stress of 280 $340 \mathrm{MPa}$, after $N=7.4 \cdot 10^{6}$ cycles;

- second batch in the quantity of 4 pcs, taken from one engine, with operating period of $3599 \mathrm{~h}$ (solid). Sample fracture occurred at the stress of 280 $340 \mathrm{MPa}$, after $N=7.4 \cdot 10^{6}$ cycles;

- third batch in the quantity of 6 pcs, taken from one engine, with operating time of $5597 \mathrm{~h}$ (solid). Sample fracture occurred at the stress of $370 \mathrm{MPa}$, after $N=7.4 \cdot 10^{6}$ cycles.

Testing was conducted at room temperature and vibrations by the fourth bending form (at the frequency of the order of $1074 \mathrm{~Hz}$ ), determined by SC
Table 1. EBW modes

\begin{tabular}{|c|c|c|c|c|c|}
\hline $\begin{array}{c}\text { Pass } \\
\text { number }\end{array}$ & $v_{\mathrm{w}}, \mathrm{m} / \mathrm{h}$ & $I_{\mathrm{w}}, \mathrm{mA}$ & $I_{\mathrm{f}}, \mathrm{mA}$ & $U, \mathrm{kV}$ & $H, \mathrm{~mm}$ \\
\hline \multicolumn{6}{|c|}{ Face side (trough); direction by points 1-2-3-4-5 } \\
\hline 1 & 60 & $14-18-22-22$ & 630 & 60 & 220 \\
\hline \multicolumn{7}{|c|}{ Reverse side (back): direction by points: 5-4-3-2-1 } \\
\hline 2 & 60 & $20-18-13-13$ & 630 & 60 & 220 \\
\hline
\end{tabular}

«Ivchenko-Progress» for distribution of the most intensive stresses in the repair zone.

It should be noted that three samples from the batch of blades (welded) failed, two of which with individual (ind.) No.1502F and $1439 \mathrm{~F}$ had the same operating time and were taken from one engine, despite the fact that their fracture occurred at different testing stress (Table 2). Coarse-grained structure and defects revealed in the weld at metallographic examination, probably, had a negative effect on premature fracture of samples at testing. Lowering of $\sigma_{-1}$ for the first batch of welded blades is in place relative to the second batch of solid blades, which is within the limit of the error and is equal to $10 \mathrm{MPa}$. Difference in $\sigma_{-1}$ between the second and third batches of blades (solid) is equal to $80 \mathrm{MPa}$ (Figure 5), that is, probably, due to unfavorable influence of service factors. Fracture of both the welded and sold blades proceeded in the same manner, in the upper part of blade airfoil edge.

Results of testing solid samples of blades lead to the conclusion that the number of operating hours and the service conditions have a negative effect on $\sigma_{-1}$. This intermediate stage was conducted with the understanding that the data on $\sigma_{-1}$ of blades after operation, could be obtained exclusively by experiment. Unambiguous comparison of $\sigma_{-1}$ requires testing blades, repaired by welding a fragment, and solid blades by the serial technology with the same operating time (from the same engine).

In order to improve the service properties of parts, repaired by welding, a new idea was proposed of increasing $\sigma_{-1}$ by application of hardening techniques surface plastic deformation (SPD) [5]. In view of the complex geometry and high requirements to surface

Table 2. Results of fatigue testing of the first batch of blades (welded) with different operating time

\begin{tabular}{|c|c|c|c|c|c|}
\hline $\begin{array}{l}\text { Sample } \\
\text { number }\end{array}$ & Individual part number (ind.) & Operating time SSO/ALR*, h & Testing stress, $\mathrm{MPa}$ & Cycle number, $\cdot 10^{6}$ & Note \\
\hline 1 & $815 \mathrm{Ya}$ & 8996/4192 & 340 & 0.22 & Failed \\
\hline 2 & $355 \mathrm{~A}$ & $3302 / 13181$ & 310 & 20 & Did not fail \\
\hline 3 & $1502 \mathrm{~F}$ & $3491 / 17767$ & 310 & 0.57 & Failed \\
\hline 4 & $297 G$ & $8996 / 4192$ & 280 & 20 & Did not fail \\
\hline 5 & $1439 \mathrm{~F}$ & $3491 / 17767$ & 280 & 0.44 & Failed \\
\hline 6 & $431 \mathrm{~A}$ & $5684 / 17337$ & 250 & 20 & Did not fail \\
\hline 7 & 404Zh & 2439 & 250 & 20 & Same \\
\hline 8 & $915 \mathrm{~A}$ & $5684 / 17337$ & 250 & 20 & $\gg$ \\
\hline
\end{tabular}


quality, the technologist has at his disposal a very limited range of SPD techniques [6]. To have the ability to solve this problem, one of the most suitable is the «soft» method of blade hardening with steel spheres in the magnetic field, allowing increase of welded blade $\sigma_{-1}$ to the level of solid blades. The proposed method of blade hardening allows performance of differentiated (selective) processing, also with different intensity, of individual sections of blade airfoil [7].

Metallographic examination of the sites of blade fracture after testing was performed. Fracture is of fatigue nature with sites located on the leading edge in the area of the welded joint. Cracks propagated through the weld with transition into the blade base material. Welding defects of the type of inner cavities and micropores were revealed in blade fracture on the face of the leading edge, the size of which does not exceed the admissible requirements for standard welded joints.

Results of metallographic examination of blades with welded fragment revealed that impact of the thermal cycle of welding and heat treatment lead to grain coarsening (Figure 6).

Fracture sites are located on blades at average distance of 4-5 $\mathrm{mm}$ from weld axis that coincides with the data obtained in the work on determination of welded sample fracture sites [8].

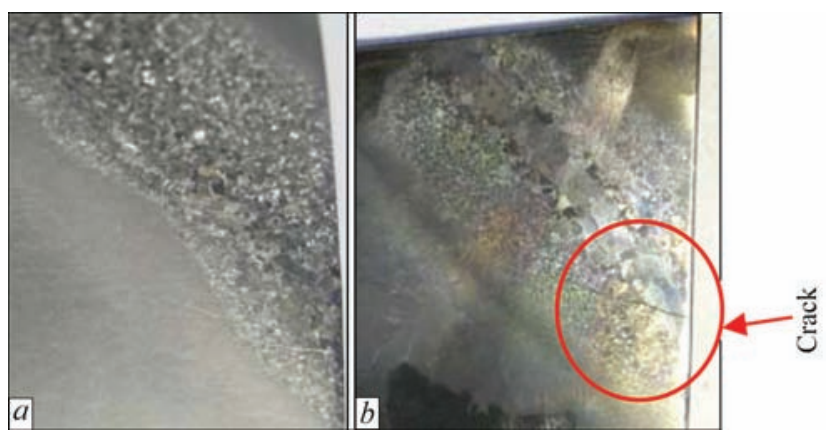

Figure 6. Structural changes after welding: $a$ - coarse-grain section; $b$ - welded joint fracture

Investigation of the microstructure was performed in Zeiss Axio Observer microscope with 50-500 magnification. View of macro- and microstructure of the weld zone is shown in Figures 7, 8.

Weld material has an acicular structure with coarse grains of primary $\beta$-phase (Figures 7, $a$; 8, a). In HAZ metal the microstructure is also represented by coarse grains of $\beta$-phase, with intragranular lamellar structure with their transition to globular-lamellar form $(\alpha+\beta)$ phase of base material (Figures $7, b-d ; 8, b-d$ ). Base metal microstructure corresponds to the second type of microstructure scale No.1 OST 1 90002-86.

Fractures along the opened blade cracks are of a gray hue and partially damaged. Judging by the preserved sections and by macroindications they are of fatigue nature, with sites located at the leading edge at

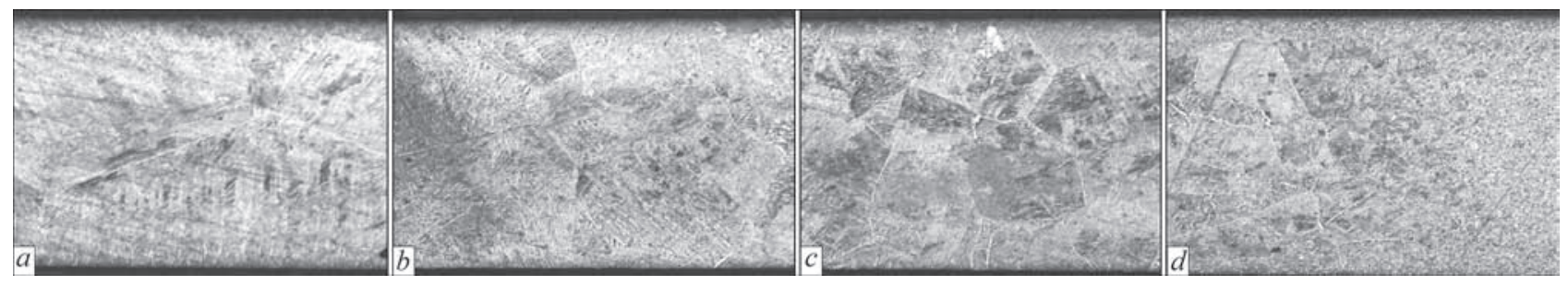

Figure 7. Macrostructure (×50) of blade weld zone: $a$ - weld; $b$ - weld + HAZ; $c-$ HAZ; $d-$ HAZ + base metal

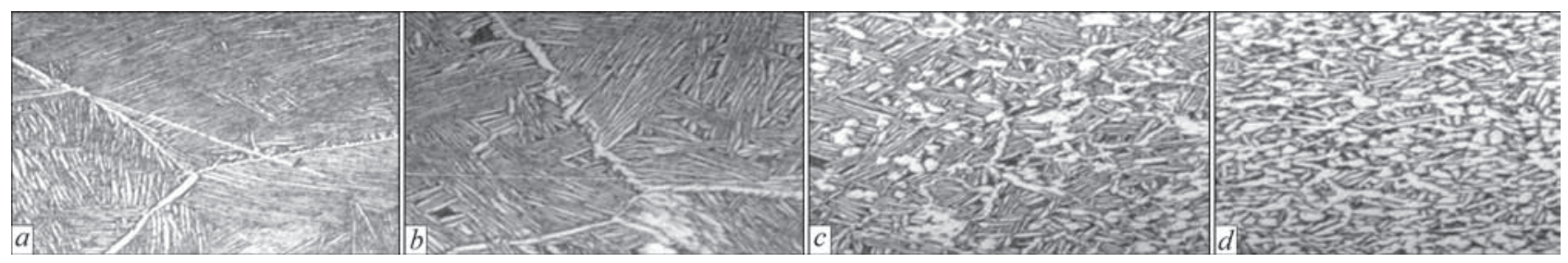

Figure 8. Microstructure $(\times 500)$ of blade weld zone: $a$ — weld; $b$ - weld + HAZ; $c$ - HAZ; $d$ - base metal
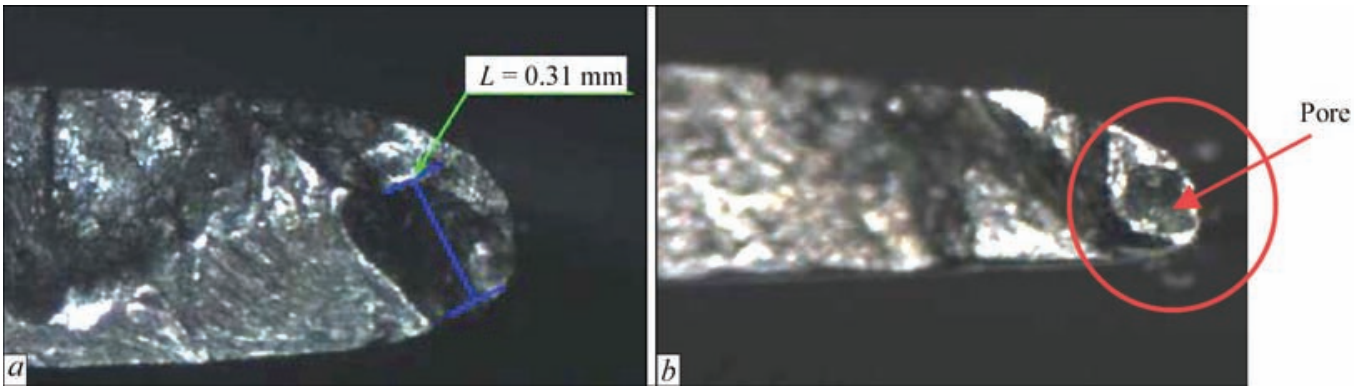

Figure 9. Welding defects of the type of inner cavities and micropores: $a-$ ind. No.815Ya $(\times 50)$; $b-$ ind. No.1502F $(\times 32)$ 
the distance of about 70-72 $\mathrm{mm}$ from the blade upper end face in the zone of EBW weld with subsequent frontal development from the back to the trough of the blade (Figure 7). Having analyzed the fracture structure, we can see that crack propagation in blades with ind. Nos $1502 \mathrm{~F}$ and $1439 \mathrm{~F}$ ran through the weld to the length of 7 and $9 \mathrm{~mm}$, respectively. It is indicated by coarse-grained structure, with subsequent propagation through the base metal with fine-grained structure. In blade No.815Ya crack propagation occurred on the length of $20 \mathrm{~mm}$ through the welding zone without reaching the base material, which is indicated by coarse-grained structure of the fracture. It should be added that presence of welding defects of the type of inner cavities and micropores was revealed in the fracture of blades (ind. No.815Ya, ind. No.1502F) on leading edge face, the size of which is admissible for standard welded joints (Figure 9).

\section{Conclusions}

1. Results of fatigue tests revealed lowering of $\sigma_{-1}$ of solid blades, after certain operation time that corresponds to the level of $\sigma_{-1}$ of welded blades.

2. Blades testing with vibrations by the fourth bending form showed that fracture of both the welded and solid blades occurred in the same manner in the site of the highest stresses, concentrated in the upper part of the airfoil leading edge, and it coincided with part of the trajectory of the fragment weld.

3. Weld trajectory should be located beyond the zone of action of maximum stresses. Here both the fourth and the first bending forms should be taken in to account.
4. Main directions of increasing $\sigma_{-1}$ of welded blades can be as follows:

- elimination of weld microdefects, revealed at metallographic examination;

- testing a selective method of hardening with metallic spheres in a magnetic field.

4. Considering different operating time and insufficient quantity of data, it is rational to continue performance of work on repair of fan blades with subsequent determination of $\sigma_{-1}$ of blades, having the same operating time and taken from one D-36 engine.

1. Petrik, I.A. (2007) Processes of restoration repair by welding and brazing of gas turbine engine blades of difficulty weldable alloys based on nickel and titanium. of Thesis for Cand. of Techn. Sci. Degree. Kiev, PWI [in Russian].

2. Nesterenkov, V.M., Orsa, Yu.V., Khripko, K.S. et al. (2017) Restoration repair of elements and units of gas turbine engines. The Paton Welding J., 11, 13-17.

3. Petrik, I.A., Ovchinnikov, A.V., Basov, Yu.F. et al. (2006) Improvement of performance of titanium alloy blades of aircraft engine fan. Vestnik Dvigatelestroeniya, 4, 104-107 [in Russian].

4. Marchenko, Yu.A., Petrik, I.A., Zhemanyuk, P.D. (2013) Optimizing the technology of electron beam annealing of compressor drums from VT8 titanium alloy. Promyshlennost $v$ Fokuse, 4, 42 [in Russian].

5. Sajdakhmetov, R.Kh. (2005) Advanced technologies for manufacture of flying vehicle structures from titanium alloys. Tashkent, TGAI [in Russian].

6. Krotinov, N.B. (2014) Surface plastic strain hardening of gas turbine engine blades. Vestnik SGTU, 3, 68-71 [in Russian].

7. Pukhalskaya, G.V., Koval, A.D., Loskutov, S.V. et al. (2009) Effect of treatment of compressor blades by spheres in magnetic field on formation of surface layer parameters and strength characteristics. Vestnik Dvigatelestroeniya, 2, 92101 [in Russian].

8. Pukhalskaya, G.V., Markov, I.B. (2016) Determination of mechanical properties in different zones of welded joints from VT3 titanium alloy. Ibid., 1, 89-91 [in Russian].

Received 22.06.2018 


\title{
MATERIALS FOR INDIVIDUAL ARMOUR PROTECTION (Review)
}

\author{
A.A. BABINETS ${ }^{1}$, I.A. RYABTSEV ${ }^{1}$ and A.I. PANFILOV ${ }^{2}$ \\ ${ }^{1}$ E.O. Paton Electric Welding Institute of the NAS of Ukraine \\ 11 Kazimir Malevich Str., 03150, Kyiv, Ukraine. E-mail: office@paton.kiev.ua \\ ${ }^{2}$ LLC «Steel Wrok», Kryvyi Rih, Ukraine. E-mail: a.panfilov@steel-work.net
}

\begin{abstract}
In the paper the available literature data on the properties of different materials, currently used in the means of individual armour protection, were analyzed and the methods for improving their bulletproof and other operational properties were evaluated. It is shown that at the present time to create the means of individual armour protection, a variety of materials are used: fabric aramid or polyethylene fibers, metal plates based on steels, titanium, aluminum and their alloys, as well as ceramics based on boron and silicon carbides, etc. The main advantages and disadvantages of these armoured materials are shown. On the basis of literary data, it was established that for the $3^{\text {rd }}-5^{\text {th }}$ class of protection, the armoured plates of structural alloyed steels were widely used. To minimize the disadvantages inherent in steel armoured plates, it is necessary to apply bimetallic compositions with alternating hard and soft layers, produced, among others, by welding or surfacing methods. 20 Ref., 4 Tables, 3 Figures.
\end{abstract}

Ke y wor $\boldsymbol{d}$ s: individual armour protection, classes of protection, armoured plates, properties of armoured materials, bulletproof, armour steels, composites, multilayer materials

At present, for manufacturing of means of individual armour protection a wide range of materials is used, ranging from light armour based on aramid or polyethylene fibers to hard «shells» of different steels, alloys and ceramics intended for protection of a person from the most dangerous threats during the combat actions [1-6]. Each of these materials has its advantages and disadvantages, depending on which it can be applied in different circumstances. Thus, due to its high degree of protection, relative ease of manufacturing and low cost, the armoured plates of different steels became widespread $[7,8]$. At the same time, a large majority of such armoured plates, which is the result of increasing their thickness, negatively affects the manoeuvrability of a person, the ability to perform certain tasks, and, thus, exposes him to the greater danger [9].

The aim of the work was to analyze the properties of different armoured materials currently used in the

Table 1. Characteristics of classes of protective structures [10] individual means of armour protection and to evaluate the methods of improving their bulletproof and other operational properties.

The use of armoured materials is regulated by the requirements of special standards, in particular, in Ukraine this is DSTU 4103-2002 «Means of individual protection, armour vests. General technical specifications» [10] (Table 1). According to these requirements, the means of individual armour protection are divided into three main classes: soft one with a protective structure based on special fabrics; semi-hard one with a basic fabric structure and additional hard protective elements and hard one on the basis of hard protective and shock proof elements.

The textile armoured materials and armoured panels of polyethylene fibers are used in soft means of individual protection of the $1^{\text {st }}, 2^{\text {nd }}$ classes and can withstand low-energy weapons such as revolvers and pistol bullets. To protect against high-energy weapons

\begin{tabular}{|c|c|c|c|c|}
\hline $\begin{array}{c}\text { Protection } \\
\text { class }\end{array}$ & Destruction weapon & Bullet type & Weight, g & Speed, m/s \\
\hline 1 & Pistol PM, 9 mm, bullet of type 57-N-181s & Steel jacket with steel core & 5.9 & $315 \pm 10$ \\
\hline 2 & Pistol TT, $7.62 \mathrm{~mm}$ bullet of type $57-\mathrm{N}-134 \mathrm{~s}$ & Same & 5.5 & $430 \pm 15$ \\
\hline \multirow{2}{*}{3} & Gun AK-74, $5.45 \mathrm{~mm}$ bullet of type 7N6 & $\gg$ & 3.4 & $910 \pm 15$ \\
\hline & Gun AKM, 7.62 mm bullet of type 57-N-231 & $\gg$ & 7.9 & $730 \pm 15$ \\
\hline \multirow{2}{*}{4} & Gun AK-74, $5.45 \mathrm{~mm}$ bullet of type 7N10 & Steel jacket with steel heat-hardened core & 3.6 & $910 \pm 15$ \\
\hline & Riffle SVD, $7.62 \mathrm{~mm}$ bullet of type $57-\mathrm{N}-323 \mathrm{~s}$ & Steel jacket with steel core & 9.6 & $850 \pm 15$ \\
\hline 5 & Gun AKM, 7.62 mm bullet BZ of type 57-N-231 & Steel jacket with steel heat-hardened core & 7.4 & $745 \pm 15$ \\
\hline 6 & Riffle SVD, $7.62 \mathrm{~mm}$ bullet B-32 of type $57-\mathrm{N}-323 \mathrm{~s}$ & Same & 10.4 & $830 \pm 15$ \\
\hline
\end{tabular}


Table 2. Comparative characteristics of protection, made from different armoured materials [13]

\begin{tabular}{|c|c|c|c|c|c|}
\hline \multirow{2}{*}{ Type of armoured material } & \multicolumn{5}{|c|}{ Class of protection according to DSTU 4103-2002 } \\
\hline & 1 & 2 & 3 & 5 & 6 \\
\hline Steel and its alloys & $135 / 1.7$ & $187 / 2.4$ & $343 / 4.4$ & $500 / 6.4$ & $860 / 11.0$ \\
\hline Titanium alloys & $135 / 3.0$ & $155 / 3.5$ & $310 / 7.0$ & $445 / 10.0$ & - \\
\hline Aluminum alloys & $135 / 5.0$ & $190 / 7.0$ & $590 / 22.0$ & $860 / 32.0$ & $1160 / 43.0$ \\
\hline Ceramics based on corundum & - & - & - & $380 / 19.5$ & $440 / 35.6$ \\
\hline
\end{tabular}

with a high penetrability ( $3^{\text {rd }}$ class and higher), for example, armour-piercing riffle bullets with heat-hardened cores, it is necessary to use semi-hard and hard means of protection with armour elements made of metals, alloys or ceramics $[1-6,11]$. In this case, the weight of the bulletproof vest of the $3^{\text {rd }}$ class is $6-9 \mathrm{~kg}$, that of the $4^{\text {th }}$ class is $10-12 \mathrm{~kg}$ and those of the $5^{\text {th }}-6^{\text {th }}$ classes are in the range from 11 up to $20 \mathrm{~kg}[7,9]$.

A large mass, as was indicated above, is one of the main drawbacks of steel armour plates. Therefore, in the armour vests of the $5^{\text {th }}$ and $6^{\text {th }}$ classes, ceramic materials based on boron and silicon carbides began to be used $[8,12-14]$. The main advantage of this type of materials is that they effectively resist bullets of armour-piercing and high-speed type, because the rate of cracks formation in ceramics is lower as compared to the rate of bullet penetration. This means that a high-speed bullet spends a lot of energy on fragmentation of material. In the process of ceramics fragmentation, a bullet starts decomposing into small elements, which are then easily retained by the aramid fibers [2]

However, if low-speed or pointed bullets hit the armour of ceramics, they behave in different way: separating pieces of ceramics, which subjected to cracking, such a bullet does not lose energy and accordingly, it is not destroyed and does not break up into several fragments. This can lead to an after-barrier impact of the bullet, i.e. to preserving of its properties after overcoming the armour protection. Hitting the same area with several bullets can be fatal [2,12]. In other words, the «survivability» of the ceramic armour, i.e., its ability to withstand several shots, is noticeably worse than that of the metal analogs, especially during hitting the butt between separate ceramic inserts, and a considerable thickness of protective structure creates great problems to designers of armour vests and limitations in service for users [13, 14].

The comparative characteristics on a bulletproof resistance of ceramics and traditional metal armour are presented in Table 2 [13]. From Table 2 it follows that for the protection of 5 and 6 classes, the thickness of the steel sheet of $6.5-11.0 \mathrm{~mm}$ and that of ceramic panel of several times higher is required.
One of the methods to provide simultaneously a sufficient class of protection and reduce the weight of armoured plates by $15-30 \%$ is the use of light alloys based on aluminum and titanium [7, 8, 14]. One of their advantages is also the absence of fragments during hitting of a bullet and a low degree of after-barrier injuries. Nevertheless, these alloys are expensive, difficult in processing, and exclude the creation of armour vests of the highest classes [8]. Thus, for the $3^{\text {rd }}$ class of protection and higher at the present time, the armoured plates of structural steels with the necessary mechanical properties became the most widely applied, the main of which are hardness, strength, elongation and toughness $[1-3,13]$. The main difficulty in creating bulletproof steel is determined by the need in combining high values of hardness and strength, which provide a resistance to penetration of bullet into the metal and a sufficient class of ductility and toughness to prevent its brittle fracture [1-3]. Thus, brittle steels of high hardness, as well as tough ductile steels of low hardness, are characterized by a low bullet resistance. The main alloying elements in armour steels are carbon, chromium, nickel, molybdenum, silicon [1-3]:

- carbon, first of all, provides an increase in the steel strength. At the same time, carbon significantly reduces the resistance of steel against the formation of solidification cracks. At a carbon content being lower than $0.44 \%$ in combination with other alloying elements and their respective mutual influence, it is not possible to obtain a hardness of steel higher than $H R C 50$, however, a carbon content of more than $0.48 \%$ is not advisable;

- chromium mainly increases the strength and hardenability of steel, and also contributes to some increase in its toughness due to the austenite grain refining. The chromium steels are sensitive to temper brittleness, the appearance of which can be avoided by their additional alloying with molybdenum;

- nickel increases the steel resistance to brittle fracture, ductility and toughness of steel, reduces sensitivity to stress concentrators and provides a high resistance to brittle fracture, but the disadvantage of these steels is a greater sensitivity to temper brittleness. As in the 
case of alloying with chromium, this can be avoided by additional alloying by molybdenum;

- molybdenum inhibits the growth of austenite grain. It is introduced to prevent temper brittleness. At the same time, the molybdenum by some increasing the hardness of ferrite, reduces its impact toughness;

- silicon like carbon hardens steel and increases the steel strength and reduces its toughness more than other alloying elements. In steel, there should be a sufficient amount of silicon, but not reducing the resistance against cracks formation.

Thus, most often the armoured steel represents a medium-carbon, medium-alloyed steel of the martensitic class $\left(\sigma_{t}\right.$ is at least $1500 \mathrm{MPa}$, hardness is HV 360-600). The high strength characteristics of armoured steels are achieved as a result of heat treatment, including hardening for martensite and low tempering [1-5]. Moreover, as to its structure, such armour can be homogeneous, i.e., uniform in hardness and toughness across the section, and heterogeneous: having an outer layer of higher strength and a rear tough, ductile layer which does not produce fragments [11]. The hardness of the outer layer of such materials is enhanced by surface hardening [1-3]. The typical representatives of armoured steels corresponding to the specified requirements are: MARS 240-300 (France); ARMOX 400-600 (Sweden); 4340 TOD (USA); 44S, 56 (Russia); RAMOR 550 (Finland), etc. $[4,6]$. The chemical composition, as well as mechanical properties of some of these steels, are given in Table 3. For example, a sheet of steel $44 \mathrm{~S}$ with a thickness of $5.5 \mathrm{~mm}$, having a hardness at the level of $H R C$ 55-57, provides protection against simple bullets of AKM, AK74 and SVD ( $3^{\text {rd }}$ class) and with an increase in sheet thickness to $6.5 \mathrm{~mm}$ the protection against bullets with a steel hardened core of $5.45 \mathrm{~mm}$ caliber is provided, which corresponds to the $4^{\text {th }}$ class of protection [1-4]. To provide a higher class of protection by the $5^{\text {th }}$ and $6^{\text {th }}$ classes, the thickness of sheets of $44 \mathrm{~S}$ steel type should be at least 7 and $15 \mathrm{~mm}$, respectively. At the same time, the bulletproof steel of grade 56

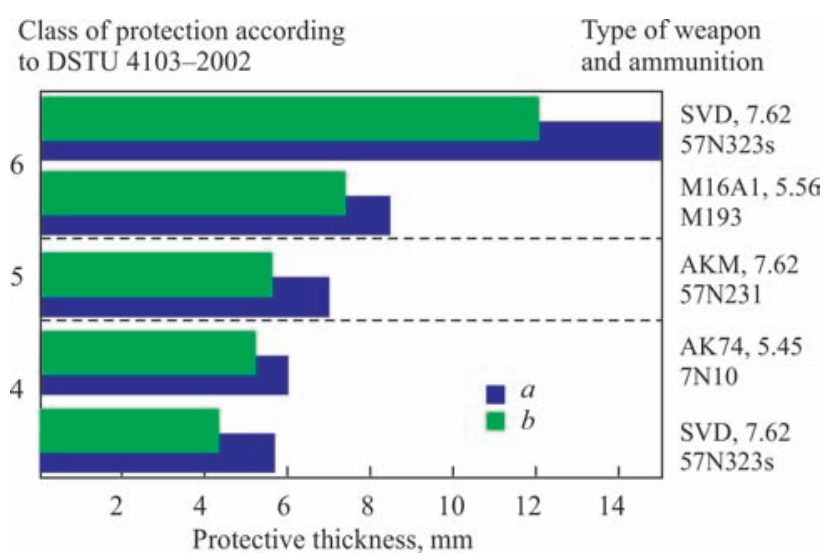

Figure 1. Comparison of protective characteristics of steels of grades 44S (a) and $56(b)[2,3]$

provides a protection according to the $6^{\text {th }}$ class even at the sheet thickness of $12 \mathrm{~mm}$ (see Figure 1).

However, with increase in thickness of the steel armoured sheet, the problem of its mass appears again. In addition, such armoured plates are not capable to save a person from the after-barrier impact of bullet. Even in case of impenetration of armoured vest, a bullet with a superpower after-barrier effect strikes the user's body [12, 15]. In addition, the armoured plates should provide a protection not only from the hitting of bullets, but also from the fragments, caused by a close burst of grenades or shells, and destruction of natural and artificial objects, as well as from the impact of air wave as a result of increasing (or decreasing) pressure in the places of explosions [16]. One more dangerous phenomenon to which steel armoured plates are exposed is a ricochet. When the bullet interacts with the protective plate at large angles from the normal, a bullet can ricochet and defeat the unprotected parts of the body, as well as the people around [1-3].

These drawbacks can be eliminated by optimizing the properties of the armour material [11] and the application of bimetallic composite armour panels [6, 17]. The basic principle of operation of such a two-layer armoured plate is the following $[5,14]$. The face layer should destroy or at least delay the jacket of the bullet, partially absorb its energy, flatten or break the core and

Table 3. Chemical composition and mechanical properties of bulletproof steels [4]

\begin{tabular}{|l|l|c|c|c|}
\hline \multicolumn{1}{|c|}{ Steel grade } & \multicolumn{1}{|c|}{ Rated chemical composition } & Sheet thickness, $\mathrm{mm}$ & $\sigma_{\mathrm{t}}$ MPa & Hardness $H V$ \\
\hline MARS 270 & $0.35 \mathrm{C}-0.75 \mathrm{Cr}-3.10 \mathrm{Ni}-0.40 \mathrm{Mo}$ & $<25$ & 2000 & $534-601$ \\
\hline MARS 300 & $0.50 \mathrm{C}-0.80 \mathrm{Si}-4.0 \mathrm{Ni}-0.40 \mathrm{Mo}$ & $\leq 8$ & 2180 & $578-655$ \\
\hline ARMOX 560 & $0.35 \mathrm{C}-1.0 \mathrm{Mn}-1.2 \mathrm{Cr}-3.0 \mathrm{Ni}-0.65 \mathrm{Mo}-0.002 \mathrm{~B}$ & $8-20$ & 1850 & $534-601$ \\
\hline ARMOX 600 & $0.43 \mathrm{C}-0.3 \mathrm{Mn}-0.25 \mathrm{Si}-0.5 \mathrm{Cr}-2.0 \mathrm{Ni}-0.35 \mathrm{Mo}-0.002 \mathrm{~B}$ & $4-10$ & 2150 & $570-640$ \\
\hline 4340 TOD & $0.4 \mathrm{C}-0.3 \mathrm{Si}-0.6 \mathrm{Mn}-0.8 \mathrm{Cr}-1.5 \mathrm{Ni}-0.2 \mathrm{Mo}$ & - & 1900 & $477-514$ \\
\hline RAMOR 550 & $0.36 \mathrm{C}-0.7 \mathrm{Si}-1.5 \mathrm{Mn}-1.5 \mathrm{Cr}-2.5 \mathrm{Ni}$ & $3-15$ & 2100 & $540-600$ \\
\hline 77Sh & $0.35 \mathrm{C}-1.4 \mathrm{Si}-1.1 \mathrm{Cr}-2.4 \mathrm{Ni}-0.3 \mathrm{Mo}$ & - & 1900 & $477-522$ \\
\hline Ts85 & $0.42 \mathrm{C}-1.5 \mathrm{Si}-1.1 \mathrm{Cr}-1.2 \mathrm{Ni}-0.45 \mathrm{Mo}$ & - & 2050 & $485-522$ \\
\hline SPS43 & $0.43 \mathrm{C}-1.65 \mathrm{Si}-1.2 \mathrm{Cr}-1.3 \mathrm{Ni}-0.45 \mathrm{Mo}$ & - & 2050 & $444-552$ \\
\hline 44S & $0.44 \mathrm{C}-1.1 \mathrm{Cr}-0.9 \mathrm{Ni}-0.8 \mathrm{Mo}$ & - & 2100 & $560-610$ \\
\hline 56 & $0.50 \mathrm{C}-3.0 \mathrm{Cr}-1.7 \mathrm{Ni}-1.95 \mathrm{Mo}-0.3 \mathrm{~V}$ & - & 2300 & $570-600$ \\
\hline
\end{tabular}




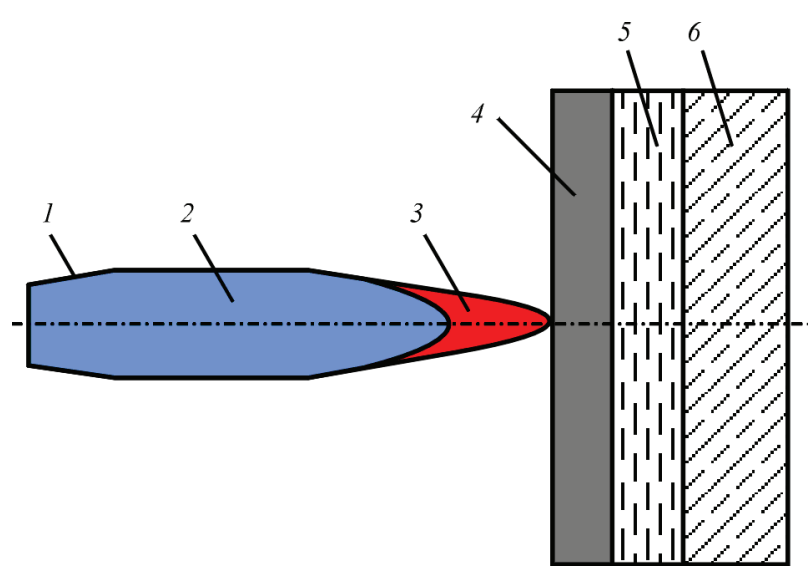

Figure 2. Scheme of shock interaction of a bullet with a bulletproof protection: 1 - jacket of a bullet; 2 - core with a jacket; 3 - incendiary composition; 4 - hard layer of armoured plate; 5 - tough layer of armoured plate; 6 - shockproof layer

distribute its action to a possibly larger area. To do this, it should be as solid and strong as possible, and not allow breaking with the entire bullet. The inner layer should absorb the energy of the remaining part of the bullet as much as possible, delay the secondary fragments and possible breaks of the first layer and not produce the secondary fragments by itself.

The shock of a bullet with a steel core against steel can be considered as a collision of bodies of two identical materials (Figure 2). There are data [15] on the increased ability of certain classes of materials and alloys to dissipate the energy of dynamic effects for a period of time which is commensurable with the time of interaction of a bullet with a barrier (see Table 4).

As is seen from the data in Table 4, the low-carbon steel St3 reduces the effect of after-barrier action to a lesser extent. The higher shockproof values are observed in complexly-alloyed steels, some titanium and nickel alloys and in the case of using bimetal Steel $25+$ Kh6VF [15]. The similar results were obtained in [6], according to which the multilayer armour made of a combination of steels St3 and U12A, showed a bullet proof at the level of special armour steel of type RAMOR 550, and at the same time allowed reducing the mass of armoured plates by $20 \%$.

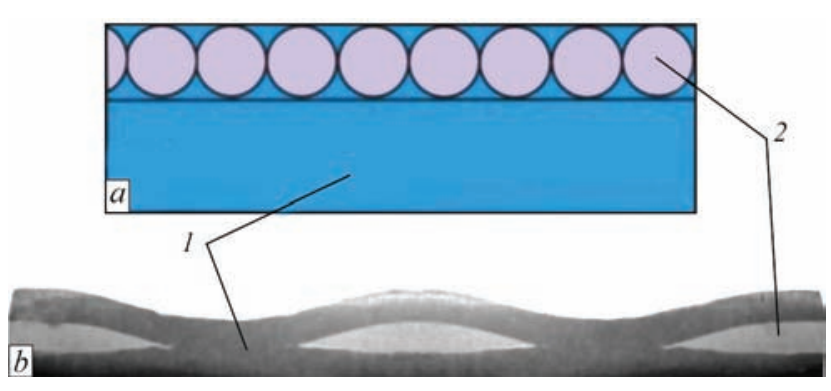

Figure 3. Variant of layers arrangement in the composite armoured plates $(a)$ and macrostructure of joint $(b)$ produced by explosion welding $[7,17]$ : 1 - Ti layer; 2 - intermetallic $\mathrm{TiAl}_{3}$ inclusions

At the same time, the serial production of bimetal armour at the territory of CIS was not mastered [13], although in the EU countries such armour is used rather extensively [11]. There are data $[11,17,18]$ on single attempts to create bimetallic armour by different welding methods. Thus, in the works $[11,18]$ with the help of explosion welding a composite of spring steel $65 \mathrm{G}$ and aluminum AD0 was produced. The tests of the produced materials showed that they can serve as effective plates for armour vests according to the $5^{\text {th }}$ class of resistance.

In the works $[7,17]$ it is proposed to improve the ballistic characteristics of titanium armoured plates by creating high-strength intermetallic compounds of titanium aluminides. The realization of this idea, which consists in alternating the layers of high-strength intermetallic with soft aluminum layers, is achieved by diffusion welding (Figure 3). In the authors' opinion, such an approach allows excluding brittle fracture of titanium armoured plate, as well as increasing the area, to which a pulse during hitting a bullet is transmitted, thus reducing the after-barrier effect.

From the scientific and practical point of view, the investigations on application of coatings of carbon nanotubes, characterized by a high elastic modulus of about $1.0 \mathrm{TPa}(0.21 \mathrm{TPa}$ for steel) and by an ultimate strength, as an outer layer of bimetallic armour plates - up to $45 \mathrm{GPa}[1,19,20]$ are of interest. However, for today nanomaterials are still very expensive,

Table 4. Results of firing the armoured packages of different materials by bullets PST from PM [15]

\begin{tabular}{|c|c|c|c|}
\hline Material grade & Sheet thickness, mm & Nature of defeat & After-barrier effect, \% \\
\hline St3 & 2.4 & Through penetration & $6-9$ \\
\hline 17Kh18N9 & 2.5 & $60 \%$ impenetration & 0 \\
\hline Steel 25 + Kh6VF & $2.0+0.5$ & Destruction/impenetration & 0 \\
\hline AD31 & 4.0 & Through penetration & 5 \\
\hline V95 & 4.5 & $80 \%$ impenetration & $5-6$ \\
\hline AD31+V95 & $2.0+2.0$ & Through penetration & 0 \\
\hline VT9 & 2.0 & Through penetration & 0 \\
\hline VT9 & 3.0 & Impenetration & $3-5$ \\
\hline VT20 & 2.0 & Through penetration & 0 \\
\hline KhN77YuR & 2.0 & Impenetration & \\
\hline
\end{tabular}


which makes it difficult to conduct investigations in this direction.

\section{Conclusions}

1. To create means of individual armour protection, a wide range of different materials was developed: fabric aramid or polyethylene fibers; metal plates of steels as well as titanium, aluminum and their alloys; ceramics based on boron and silicon carbides, etc. Each of these materials has its own advantages and disadvantages, depending on which it can provide protection by the $1^{\text {st }}-6^{\text {th }}$ class.

2. Due to sufficient reliability, low cost and versatility, for protection by the $3^{\text {rd }}-5^{\text {th }}$ classes the armoured plates of low-alloyed structural steels with high hardness, ductility and toughness found a wide application.

3. To reduce the weight of steel armoured plates, as well as to reduce the probability of obtaining after-barrier injuries and ricochet, it is proposed to use bimetallic plates with alternating hard and soft layers produced by different methods of welding and surfacing.

1. Kobylkin, I.F., Selivanov, I.F. (2014) Materials and structure of light armour protection. Moscow, N.E. Bauman NSTU [in Russian].

2. Gladyshev, S.A., Grigoryan, V.A. (2010) Armoured steels. Moscow, Interment Engineering [in Russian].

3. Grigoryan, V.A., Kobylkin, I.F., Marinin, V.M., Chistyakov, E.N. (2008) Materials and protective structures for local and individual armouring. Moscow, RadioSoft [in Russian].

4. Anastasiadi, G.P., Silnikov, M.V. (2004) Operating capability of armour materials. St.-Petersburg, Asterion [in Russian].

5. Bajdak, V.I., Blinov, O.F., Znakhurko, V.A. et al. (2003) Concept basics for development of means of individual armour protection. Moscow, Armouring. Politics. Conversion [in Russian].

6. Manzhura, S.A. (2017) Selection of armoured plate materials for individual means of armour protection of law enforcement forces. Systemy Ozbroennya i Vijskova Tekhnika, 2, 89-93 [in Ukrainian].

7. Bolotov, M.G., Ganeev, T.R., Novomlynets, O.O., Prybytko, I.O. (2015) New trends of application of titanium aluminides. Tekhnichni Nauky ta Tekhnologii, 2, 51-55 [in Ukrainian].

8. Novikov, V.A. (2015) Flak jacket: Modern materials and their properties. In: Proc. of Int. Sci.-Techn. Conf. of Young Sci- entists of V.G. Shukhov BSTU (1-30 May, Belgorod), 14431446.

9. Gorbunov, I.M., Kharchenko, E.F., Aniskovich, V.A. (2006) Analysis on scientific and technical level of development of modern armour protection means in Russia and abroad. Oboronny Compleks - Nauchno-Tekhnicheskomu Progressu Rossii, 4, 32-35 [in Russian].

10. (2002) DSTU 4103-2002: Means of individual protection, bulletproof vests. General specifications [in Ukrainian].

11. Zagoryansky, V.G. (2015) Substantiation for application of steel-aluminium bimetal on calculation criteria of bulletproof armour. Visnyk NTUU KPI. Seriya: Mashynobuduvannya, 3, 37-41 [in Ukrainian].

12. Guskov, A.V., Milevsky, K.A., Pavlova, O.V. (2014) Bulletproof vests with ceramic armour elements of honeycomb structure. Evrazijsky Soyuz Uchyonykh, 8-8, 45-46 [in Russian].

13. Mylnikov, V.V., Abrosimov, A.A., Romanov, I.D., Romanov, A.D. (2014) Analysis of materials and their properties, applied for means of individual armour protection. Uspekhy Sovremennogo Estestvoznaniya, 9-2, 143-147 [in Russian].

14. Chernyshov, E.A., Mylnikov, V.V., Mylnikova, M.V., Romanov, A.D. et al. (2014) Development of metal-ceramic elements of ballistic protection using aluminium-based ceramics. Sovremennye Naukoyomkie Tekhnologii, 4, 97-100 [in Russian].

15. Aleksentseva, S.E., Zakharov, I.V. (2011) Effect of shockproof properties of alloys on bulletproofness. Vestnik Samar. STU. Seriya: Tekhnicheskie Nauki, 4, 88-95 [in Russian].

16. Radonjic, V.M., Jovanovic, D.M., Zivanovic, G.Z., Resimic, B.V. (2014) Ballistic characteristics improving and maintenance of protective ballistic vests. Vojnotehnicki glasnik, 62 (Is. 4), 89-103. DOI: 10.5937/vojtehg62-4992.

17. Kryukov, D.B., Kozlov, D.B. (2016) Perspectives of application of metal composite materials for development of armouring of new generation. Vestnik Penzenskogo Gos. Unta, 2, 103-108 [in Russian].

18. Dragobetsky, V.V., Shapoval, A.A., Zagoryansky, V.G. (2015) Development of elements of individual protection means of new generation based on laminated metallic compositions. Izv. Vuzov, Chyorn. Metallurgiya, 58, 1, 44-48 [in Russian].

19. Morka, A., Jackowska, B. (2010) Ballistic resistance of the carbon nanotube fibres reinforced composites - numerical study. Comput. Mater. Sci., 50(4), 1244-1249. DOI:10.1016/j. commatsci.2010.03.046

20. Kurkov, S.N., Kukanov, S.A., Zajtsev, Yu.M. (2016) Application of nanostructured materials in protective compositions of individual armour means. Izv. Tulskogo Gos. Un-ta. Tekhnicheskie Nauki, 3, 53-59 [in Russian]. 


\title{
PROCEDURE FOR DETERMINATION OF INDUCTION OF CONTROLLING MAGNETIC FIELD IN POOL ZONE DURING ARC WELDING
}

\author{
A.D. RAZMYSHLYAEV ${ }^{1}$, P.A. VYDMYSH ${ }^{2}$ and M.V. AGEEVA ${ }^{3}$ \\ ${ }^{1}$ State Higher Educational Institution «Pryazovskyi State Technical University» \\ 7 Universitetskaya Str., 87500, Mariupol, Ukraine. E-mail: razmyshljaey@gmail.com \\ ${ }^{2}$ OJSC «Metinvest-Promservis» \\ 113-a, Nikopol Ave., 87500, Mariupol, Ukraine. E-mail: pstukmu@gmail.com \\ ${ }^{3}$ Donbass State Machine Building Academy \\ 72 Akademicheskaya Str., 84313, Kramatorsk, Ukraine. E-mail: maryna_ah@ukr.net
}

\begin{abstract}
It is shown that there are calculation procedures at the present time, which allow determining induction in the weld pool zone, which is generated by two-rod devices for input of the transverse magnetic field during arc welding. However, these methods are quite complicated in applying. In this paper, the calculation procedure for determining the numerical values of the induction components of a transverse magnetic field in the weld pool zone were proposed. The procedure is based on the use of experimental data on the value of induction, generated by the transverse magnetic field input device in the weld pool zone at different value of rod cross-sections of theses input devices. The calculation expressions and an algorithm for their use are proposed to determine the magnetic field induction components in the indicated zone. A good correlation of the calculated data with experimental ones is shown. The procedure is recommended for applying in arc surfacing and welding of products, made of materials, which are not ferromagnetics. 8 Ref., 6 Figures.
\end{abstract}

Keywords : transverse magnetic field, induction, ferromagnetic, weld pool

The effect of transverse magnetic field (TMF) in automatic submerged-arc welding and surfacing allows controlling the hydrodynamics of molten metal in pool, geometry of weld (bead), increasing the coefficient of electrode melting and refining the weld metal structure [1-4].

At the present time there are no simple methods for calculation of induction components in the weld pool zone, which are generated by input devices (ID) of TMF. The known calculation methods, suitable for these purposes, [5-7], are quite complicated. In work [8] the calculation method is also suggested for similar purposes. However, it should be noted that these methods do not allow obtaining the numerical values of induction under the rods for different design parameters of ID of TMF. It is necessary to develop such calculation method for determination of induction components, generated by ID of TMF, which will allow accounting for change of such parameters as the distance between the edges of rods and windings, sizes of rod sections and number of ampere turns (IW) and will be not characterized by excessive complexity. The development of such calculation method will simplify greatly the problem of optimizing the ID of TMF, being designed.

The aim of the present work is the development of an evaluation procedure for calculation of numerical values of induction components, generated by ID of TMF, in the pool zone as-applied to the arc welding and surfacing, allowing to determine the values of the given parameters quickly and at a sufficient accuracy for practice.

(C) A.D. RAZMYSHLYAEV, P.A. VYDMYSH and M.V. AGEEVA, 2018
To realize this aim, the following investigations were carried out. The simplest one is the design of ID of TMF in the form of two rods of a ferromagnetic steel, having windings on each rod. Figure 1 presents a scheme of ID of TMF and design of one of rods of this device. The main parameters and sizes of ID of TMF in Figure 1, $a$ : $a$ - distance between rods $A$ and $B$ at their lower edges; $h$-distance from edges to workpiece; $H$ - distance from coil to rod lower edge. Electrode wire axis coincides with $\mathrm{O}_{1} \mathrm{Z}_{1}$ axis. Figure $1, b$ gives the sizes: $b$ - rod width; $c$ - rod thickness; $L_{\mathrm{r}}$ - rod length: $L$ - winding height; $H$ - distance from rod edge to winding. Windings on rods $A$ and $B$ were connected in series so, that the lower edges of rods $A$ and $B$ had different poles: $N$ and $S$ (Figure 1, $a$ ).

To optimize ID of TMF, it is necessary to set such its parameters (from Figure 1, a), which could provide the maximum level of induction component $B_{x}$ between rods $A$ and $B$ along the axis $O X$ at the minimum level of a longitudinal component of induction $B_{z}$.

The rods were manufactured in the form of a pack of plates of electric steel 1512 (E42) of $0.5 \mathrm{~mm}$ thickness and $F_{r}=26 \times 16 \mathrm{~mm}$ section, on which the four-layer windings of copper wire of $1.0 \mathrm{~mm}$ diameter and $L=30 \mathrm{~mm}$ height with number of turns $W=100$, were arranged. The rods of $26 \times 8 \mathrm{~mm}$, $26 \times 32 \mathrm{~mm}, 32 \times 52 \mathrm{~mm}$ and, respectively, with windings of $L=30 \mathrm{~mm}$ height were also manufactured (these windings could move along the rods to change the distance $H$ ). Direct current $I_{\mathrm{k}}=16$ A was passing in the windings. Induction $B$ was measured by a 


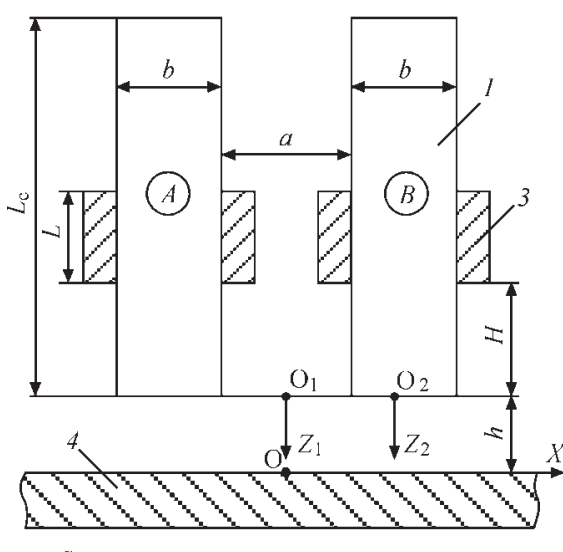

a

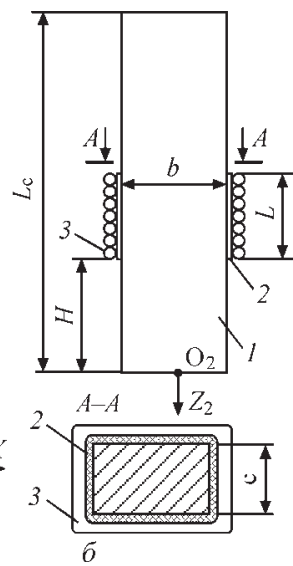

Figure 1. Input device of TMF with two rods $(a)$ and design of rod with winding $(b)$ : 1 — rod; 2 — isolator; 3 — winding; 4 — workpiece

universal teslameter of 43205 type with Hall sensor, having a measurement base of $0.9 \times 0.9 \mathrm{~mm}$.

At first, the specifics of magnetic field (induction) structure for one rod was investigated. It was found that relative values of induction $B_{z} / B_{x \max }$ are distributed along the axis $\mathrm{O}_{2} Z_{2}$ by one and the same dependence in change of $H$ within $H=0-60 \mathrm{~mm}$, i.e. value of $B / B_{x \max }$ parameter under the rod does not almost depend on parameter $H$. Thus, at $H=0$ the winding has no effect by its field of scattering on the resulting field. The field generated is determined completely by the rod magnetizing.

The dependence of $B_{z} / B_{z \max }$ on distance from rod edge to point $z$, being considered, was established. It should be noted that the maximum value of induction component $B_{z \max }$ is observed at the edges of rod of ID of TMF. Rods of ID of TMF have usually a rectangular section. To simplify calculations, the rectangular section of rods was conditionally replaced by a circular section. Moreover, an equivalent radius of turn $r$, which was conditionally located in the rod edge plane $(z=0)$ was calculated by formula $r^{2}=F_{\mathrm{r}} / \pi$. Values $B_{z} / B_{z \max }$ were calculated at change of $z$ (from $z=0$ ) by formula:

$$
B_{z} / B_{z \max }=\frac{r^{2}}{\left(r^{2}+z^{2}\right)^{n}},
$$

where $n$ is the degree index.

Experimental data are well correlated with design data, calculated by formula (1), if the degree index $n=1$ is for all the applied sections of rods, i.e. $26 \times 8 \mathrm{~mm}, 26 \times 16 \mathrm{~mm}, 26 \times 32 \mathrm{~mm}$ and $32 \times 52 \mathrm{~mm}$ $\left(I_{\mathrm{k}}=16 \mathrm{~A}, H=35 \mathrm{~mm}, W=100\right)$.

The relative values of inductions $B_{z} / B_{z \max }$ under the rods (along the axis $\mathrm{O}_{2} \mathrm{Z}_{2}$ in Figure 1, $a$ ), obtained by the experimental data processing, are given in Figure 2. It is shown here, that values $B_{z} / B_{z \max }$ do not almost depend on parameter $a$ (curves $1-4$ ) and are close to values (curve 5), when calculation is made by formula (1).

It was found by measuring the induction $B_{z}$ at the rod edges to winding that with increase in $H$ the induction $B_{z}$ is decreased (at similar values $I_{\mathrm{k}}=16 \mathrm{~A}, W=100$ ).
Induction $B_{z}$ at the edges of rods is governed by relation

$$
\frac{B_{z 2 \max }}{B_{z 1 \max }}=\frac{1}{\left(1+0.04 H_{2}^{2}\right)},
$$

where $\mathrm{H}_{2}$ is the value of size $H$, m, taken in calculations.

During calculations by formula (2) it is necessary first of all to take the value $H_{1}=0$, at which value $B_{z} /$ $B_{z 1 \max }$ is observed. If the distance $H_{2}$ is differed from taken value $H_{1}=0$ (usually in practice $H_{2}>H_{1}$ ), then it is necessary to determine the value $B_{z 2 \text { max }}$ by formula (2), substituting value $H_{2}$ in it. These values $B_{z 2 \text { max }}$ will be observed at the given values $H_{2}$.

If to change value $I W$ up to $I_{2} W_{2}>I_{1} W_{1}$ (or $I_{2} W_{2}<$ $<I_{1} W_{l}$ ), then it is necessary to change $B_{z \max }$ proportionally to change in $I W$ (to increase or to decrease) to obtain the new value $B_{z \max }$, corresponding to the new taken value $I W$ (initially taken that $I W=1600$ ).

It was found experimentally that the absolute values $B_{x \max }$ in point $O_{1}$ at axis $O_{1} Z_{1}$ (Figure $1, a$ ) depend on parameter $a$, which is shown in Figure 2. It should be noted that data about $B_{x \max }$ (in $\mathrm{mT}$ ), given in Figure 2, are initial for further calculations of values $B_{x}$ in points at axis $O_{1} Z_{1}$. Values $B_{x \max }$ refer to the case

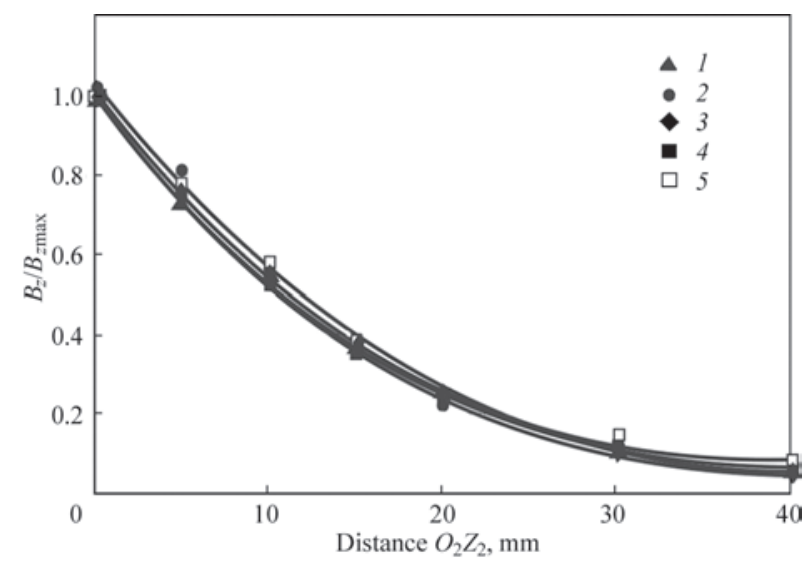

Figure 2. Distribution of values $B_{z} / B_{z \max }$ along the axis $O_{2} Z_{2}$ depending on the parameter $a$ : $1-a=20 ; 2-40 ; 3-60 ; 4-$ $13 \mathrm{~mm} ; 5$ - calculation of $B_{z} / B_{z \max }$ by formula (1) 


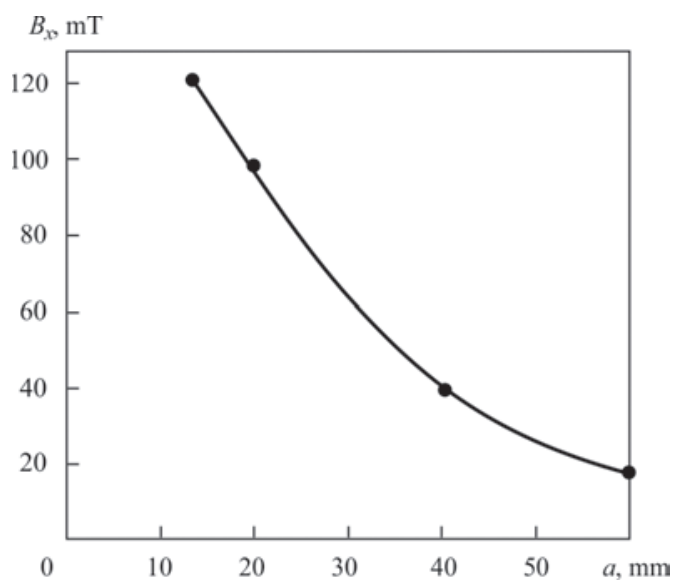

Figure 3. Dependence of component of induction $B_{x}$ on parameter $a$

when $I W=1600, H_{1}=0$, and rods have section $F_{\mathrm{r}}=$ $=26 \times 16 \mathrm{~mm}\left(F_{\mathrm{r}}=416 \mathrm{~mm}^{2)}\right)$. When calculating other absolute values $B_{x}$ in point $0_{1}$ at axis $O_{1} Z_{1}$ (Figure 1, a) at other values $F, H, I W$ which we shall denote by $F_{\mathrm{r} 2}, H_{2},(I W)_{2}$, the calculation is made in the sequence, described above for determination of values of induction $\mathrm{B}_{\mathrm{z}}$ in points at axis $\mathrm{O}_{2} \mathrm{Z}$ by formula (1). It was found by processing the experimental data about induction $B_{x}$ that within $a \leq 20 \mathrm{~mm}$ the formula (1) with value $n=1.0$ is suitable for determination of $B_{x} / B_{x \max }$.

If $a>20 \mathrm{~mm}$, then to determine $B_{x} / B_{x \max }$ it is necessary to apply this formula with changing the values of $n$ degree in it:

- for $a=40 \mathrm{~mm}: n=0.8$;

- for $a=60 \mathrm{~mm}: n=0.5$.

For intermediate values of parameter $a$ within the ranges $a=20-40 \mathrm{~mm}$ it is necessary to apply the intermediate values of $n$ degree in the denominator of formula (1): $n=1.0-0.8$, and similarly, for $a=40$ $60 \mathrm{~mm}: n=0.8-0.5$. To provide their more convenient use in calculation we shall give also their numerical values in point $O_{1}$ at axis $O_{1} Z_{1}$ for $I W=1600$ :

- $a=13 \mathrm{~mm}: B_{x \max }=121 \mathrm{mT}$;

- $a=20 \mathrm{~mm}: B_{x \max }^{x_{\max }}=99.9 \mathrm{mT}$;

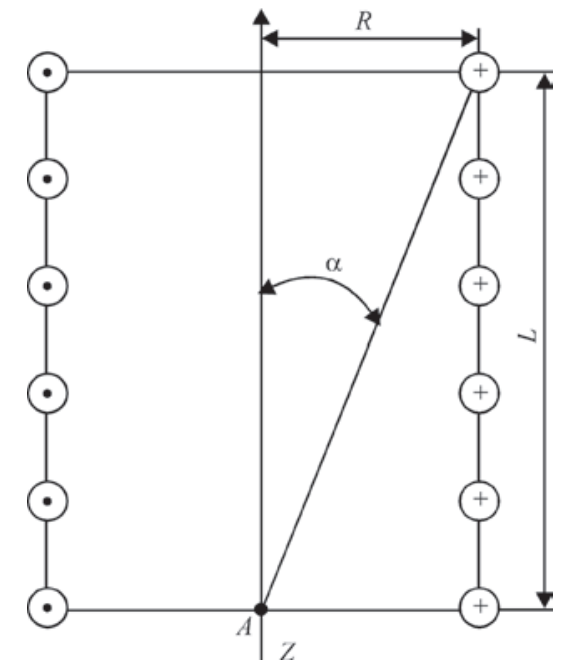

Figure 4. Scheme for calculation of induction $B_{z}$ in point $A$ at the axis $Z: R$ - radius of solenoid windings; $L$ - solenoid length
- $a=40 \mathrm{~mm}: B_{x \max }=37.6 \mathrm{mT}$
- $a=60 \mathrm{~mm}: B_{x \max }=18.5 \mathrm{mT}$.

The checking showed that by using the developed procedure it is possible to determine the numerical values of components of inductions $B_{z}$ and $B_{x}$, respectively, along the axes $O_{2} Z_{2}$ and $O_{1} Z_{1}$ (see Figure 1) at different values of parameters $F ; a ; I W ; H$. As initial parameters (as was noted above) the following parameters were taken: $F_{\mathrm{r}}=26 \times 16 \mathrm{~mm}\left(F_{\mathrm{r}}=416 \mathrm{~mm}^{2}\right)$; $I W=1600 ; H=0$. It should be noted that at the plate surface (weld pool) it is necessary to take the value $z=h$ during calculation of induction $B_{x}$ component by formula (1) (see Figure 1,a).

To realize the suggested procedure it is rational to know the values of induction $B_{z}$ at the edges of rods ID of TMF (and when coils are located near the rod edges, i.e. when $H=0$ ) depending on section of rods and number of ampere-turns of windings arranged on them. For these purposes it is possible to apply the following calculation method.

Induction on longitudinal axis of solenoid of length $L$ (without ferrocore inside it) in point $\mathrm{A}$, which is located at its edge (Figure 4) [6] is:

$$
B_{z}=\mu_{0} \frac{I W}{2 L} \cos \alpha,
$$

where $\mu_{0}$ is the magnetic constant; $\mu_{0}=4 \pi \cdot 10^{-7} \mathrm{H} / \mathrm{m}$; $I W$ is the number of ampere-turns in solenoid;

$$
\cos \alpha=\frac{L}{\sqrt{R^{2}+L^{2}}} .
$$

Here $R$ is the equivalent radius of «window» of coil (solenoid):

$$
R=\sqrt{\frac{F_{\mathrm{r}}}{\pi}}
$$

where $F_{\mathrm{r}}$ is the rod section.

Figure 5 gives the calculation values (curve 2) of induction $B_{z}$ at the coils edges, free of rods of different sections $\left(F_{\mathrm{r}}\right)$. Calculated and experimental (curve 1 ) values $B_{z}$ are close and do not depend on value of «window» section of coils and can be used for calculations. Experimental values $B_{z}$ at the edges of rods (with coils, when $H=0$ ) are much higher, than those in coils (solenoids) without rods (curve 3 in Figure 5) and with increase in $F_{\mathrm{r}}$ they are linearly decreased by relation (for $I W=1600$ ):

$$
B_{z}=90-3.37\left(F_{\mathrm{r}}-2.08\right) \text {. }
$$

For calculations it is possible to use the coefficient $n$, which accounts for the presence of ferromagnetic rod in (solenoid) coil:

$$
n=\frac{B_{z \max }}{B_{z}},
$$

where $B_{z \max }$ is the induction at the rod edge, $\mathrm{mT}$.

The coefficient $n$ is decreased linearly with increase in rod section $F_{r}$. This dependence corresponds to formula (Figure 6): 


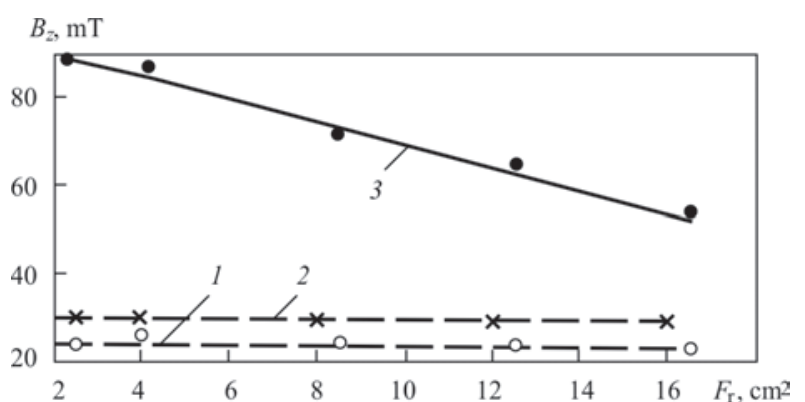

Figure 5. Dependence of induction $B_{z}$ on section of rods $F_{r}$ (IW = = 1600): 1,2 - solenoid without a ferrocore; 1 - experimental data; 2 - calculation data; 3 - solenoid with a ferrocore, experimental data

$$
n=3.75-0.0912\left(F_{\mathrm{r}}-2.08\right) \text {. }
$$

The values of coefficient $n$ did not change for rods of a pack of sheets of electric steel 1521 (E42) and for those of a solid section of steel VMSt.3 (killed) and 09G2S (at equal magnetizing force of windings $I W)$. The values of coefficient $n$ did not also change in passing of direct or alternating current of $50 \mathrm{~Hz}$ frequency and in change of these parameters in coils within the ranges: ampere-turns 800-3200; size $H=$ $=0-70 \mathrm{~mm}$, size $h=15-50 \mathrm{~mm}$.

The developed calculation procedure for determination of induction components can be recommended not only for optimizing the design of ID of TMF, consisting of rods of the rectangular section, but also for rods of a cylindrical section. It should also be noted, that the developed procedure for determination of values of components of induction $B_{x}, B_{z}$ accelerates greatly the determination of optimum sizes of ID of TMF design elements (sizes of rods in sections, distance between rods). The procedure refers to the variant when the base metal (plate) is not a ferromagnetic. The suggested method allows determining the numerical values of induction $B_{x}$ in points at the axis $O_{1} Z_{1}$ and induction $\mathrm{B}_{z}$ in points at the axis $\mathrm{O}_{2} \mathrm{Z}_{2}$.

It is rational to make calculations of inductions in the following sequence. At first, to apply the formulae (3)-(5) and Figure 4, and then to apply the formulae (7), (8). After this, the real values $H$ and $h$ are taken into consideration and calculations are made of numerical values of inductions $B_{x}$ in points at the axis $O_{1} Z_{1}$ and induction $B_{z}$ in points at the axis $O_{2} Z_{2}$ by using formulae (1) and (2), and those at the surface of product-plate $z=h$.

Nature of changing the relative values of components of inductions $B_{x} / B_{x \max }$ and $B_{z} / B_{z \max }$ along the axis $O X$ (Figure 1, a) corresponds to that which was set earlier in work [8]. Using the data of this work about the nature of change of these relative values of induction components along the axis $O X$ according to this procedure it is possible to determine the numerical values of induction components in any point of the

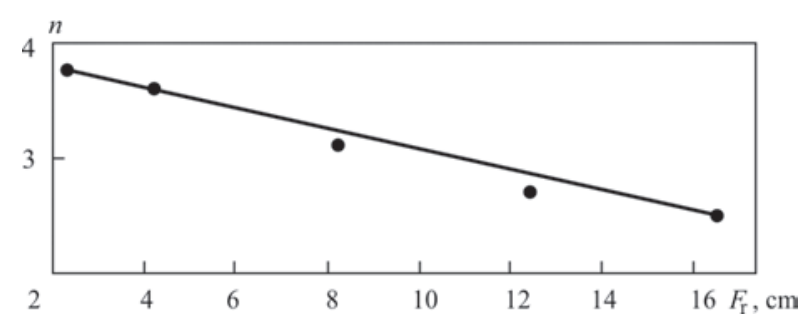

Figure 6. Dependence of coefficient $n$ on $\operatorname{rod}$ section $F_{\mathrm{r}}$

weld pool surface and in the zone of an electrode drop in arc welding and surfacing. If the rods in design of ID of TMF are connected by a crosspiece at the top (made of the same material and the same cross-section as the rods), then the values of components of inductions $B_{x}$ and $B_{z}$, obtained during calculations, should be increased by $20-25 \%$.

\section{Conclusions}

1. The calculation expressions, developed on the basis of experimental data processing, for determination of induction, generated by ID of TMF, in the weld pool zone, provide a fair correlation of calculated data with experimental ones.

2. The calculation procedure allows determining the absolute values of induction in the zone under edges of rods of ID of TMF, if the sizes of their sections are known, or determining their optimum sizes to achieve maximum values of a transverse component of induction at minimum values of a longitudinal component of induction in the weld pool zone.

1. Skipersky, N.A., Rybachuk, A.M. (2000) Weld formation by transverse magnetic field in welding of nonmagnetic materials. Svarochn. Proizvodstvo, 7, 53-55 [in Russian].

2. Iofinov, P.A., Ibragimov, V.S., Dmitrienko, A.K. et al. (1991) Effect of external electromagnetic field on speed of electrode wire melting in automatic submerged-arc welding. Ibid., 1, 34-35 [in Russian].

3. Razmyshlyaev, A.D., Mironova, M.V., Kuzmenko, K.G. et al. (2011) Efficiency of melting of electrode wire in submerged arc surfacing with influence of transverse magnetic field. The Paton Welding J., 5, 39-42.

4. Ryzhov, R.N., Kuznetsov, V.D. (2006) External electromagnetic effects in the processes of arc welding and surfacing (Review). Ibid., 29-35.

5. Andreeva, E.G., Shamets, S.P., Kolmogorov, D.V. (2005) Calculation of stationary magnetic fields and characteristics of electrical devices using program package ANSYS. Electron. Sci. J. Oil and Gas Business, 1. http//ogbus.ru/authors/Andreeva/Andreeva_1.pdf

6. Bessonov, L.A. (2003) Theoretical fundamentals of electrical engineering. Electromagnetic field. Moscow, Gardariki [in Russian].

7. Tozoni, O.V. (1975) Method of secondary sources in electrical engineering. Moscow, Energiya [in Russian].

8. Razmyshlyaev, A.D., Mironova, M.V., Yarmonov, S.V., Vydmysh, P.A. (2013) Structure of transverse magnetic field generated by input devices for arc welding processes. Visnyk Pryazov. DTU: Transact. Mariupol, 26, 135-141 [in Russian]. 


\section{Professor Jan Pilarczyk}

Close longstanding friendly relationships bind the collectives of E.O. Paton Electric Welding Institute of the NAS of Ukraine and Polish Institute of Welding in Gliwice. In many respects it is related with multiple contacts of the specialists of both Institutes as well as personal meetings of Prof. B.E. Paton and Prof. J. Pilarczyk being the head of the Polish Institute for long years. Below is information about many-sided activity of Jan Pilarczyk.

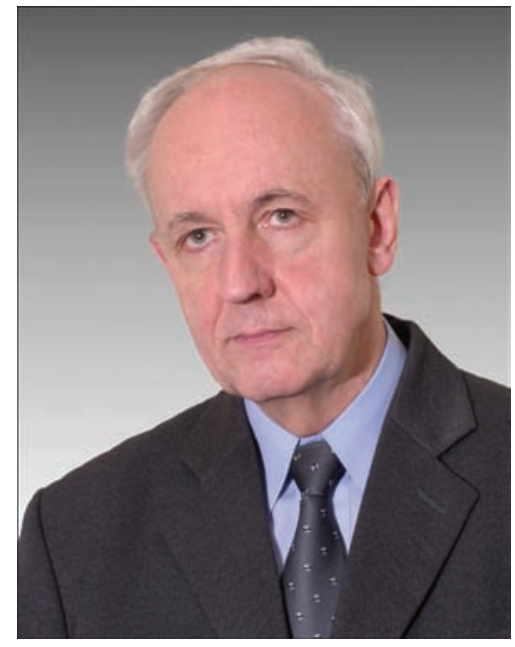

Prof. Jan Pilarczyk

All professional activity of J. Pilarczyk is inseparably linked with the Institute of Welding in Gliwice, which plays fundamental role in Polish industry due to thorough support of many enterprises in the field of application of innovative welding processes and technologies.

Prof. Jan Pilarczyk started his professional life in the Institute on March 1, 1963. His working experience makes 52 years, 25 of which he was a Director of the Institute. After retirement, Professor became a Counselor of the Director on Development of Researches. Professional activity of Prof. Jan Pilarczyk can not be separated from the Institute activity.

He acceded the position of the Director of Institute of Welding in Gliwice in 1990, when the Institute started functioning under conditions of free and competitive market. A decree about the Institutes was published in Poland in this time. This decree provided institutes with higher level of independence, but, at the same time, determined complete self-financing and responsibility for taken decisions. Working under new conditions required quick reorganization, which predetermined radical reformation of the Institute and intensification of search for new directions of activity that would bring income. Search of these directions under conditions of free market was not easy. Production of welded products and structures requires proposals considering current achievements, high professionalism of the staff, rapid task solving, responsible approach and fulfillment of service terms as well as huge flexibility during negotiations with potential customers.

Longstanding productive work of the Institute Director, Prof. Jan Pilarczyk resulted in its step-by-step transformation into a leading central research institute of Polish welding engineering and it as a single organization of such a type plays a role of Polish Welding Center. The result of successfully established European Research Space was granting the Institute with a status of the Polish Welding Center of Excellence approved by a diploma from the Minister of Science. Granting of such a status was also possible due to realization of «Polish Welding Center of Excellence» Project in scope of the $5^{\text {th }}$ Framework Program of European Union.

The Institute having current facilities and apparatuses is at the very good level and is not inferior to that available in similar institutes in the world. At present time the Institute can propose to the potential consumers virtually everything in the

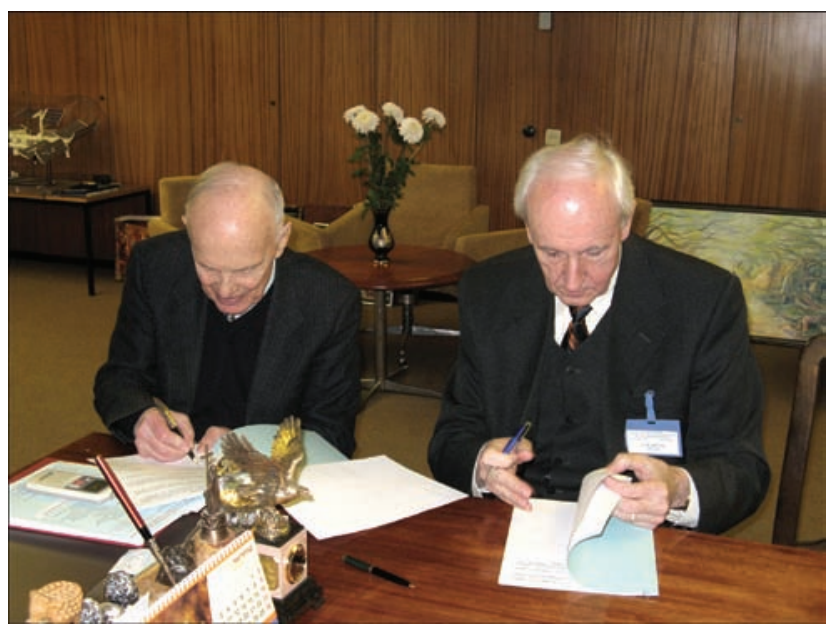

During signing the memorandum on cooperation between PWI and Polish Institute of Welding (on the left — Prof. B.E. Paton, on the right — Prof. Jan Pilarczyk) 
field of welding that is necessary for industry, and the needs are very large, since several thousand of enterprises dealing with joining of metals with the help of welding and related technologies work in Poland.

The problems of welding engineering are not concentrated within one country. Poland also required the connections with welding community of foreign countries. In this situation Prof. Jan Pilarczyk played a significant role. He always had multiple tight personal contacts with the specialists in welding all over the world. After the European Union was established in 1992, Professor brought in the Institute of Welding as a first of welding institutes of Eastern Europe countries in European Welding Federation (EWF). Poland was taken into the European Union only in 2004, whereas the Institute of Welding has had the status of Authorized National Body (ANB) since 1996, and since 1997 a status of a member of the European Welding Federation. A year later the Institute got an approval of its status in the International Institute of Welding (IIW).

Prof. Jan Pilarczyk was a representative of the Institute of Welding in both organizations, namely EWF and IIW. He was also the President of the European Welding Federation and Vice-President of the International Institute of Welding, initiator of implementation in Poland of international harmonized system for training, qualification and certification of welding staff and certification of enterprises dealing with welding engineering.

Separate and very important part of professional activity of Prof. Jan Pilarczyk was establishment of the contacts with E.O. Paton Electric Welding Institute (Kyiv). For the beginning it was participation in the work of group XIX «Weldability of materials», which was one of the 49 groups, functioning in the organization joining welding institutes of the former Council for Mutual Economical Assistance (CMEA). The meetings were held in Kyiv, Sophia, Bratislava, Halle, Berlin, Timisoara and Gliwice from 1957 till 1989. After extinction of CMEA, it was decided to establish new, voluntary organization of countries of Central-Eastern Europe titled the International Association «Welding» (IAW). It took place at the turn of 1990-1991, and Prof. Jan Pilarczyk, at that time already the Director of the Institute of Welding in Gliwice, participated in organizing the activities requiring multiple business trips to Kyiv. Cooperation in scope of the IIW is still in force.

Prof. Jan Pilarczyk also participated in the conferences organized in Kyiv. The conferences related with anniversaries of the Director of E.O. Paton Electric Welding Institute in Kyiv, Prof. B.E. Paton, namely $80^{\text {th }}$ (in 1998) and $90^{\text {th }}$ (in 2008) anniversaries were of particular importance. In turn, Prof. B.E. Paton in 1995 participated in the celebration of 50 years of formation of the Institute of Welding in Gliwice.

Below is a piece of the interview, given by Prof. B.E. Paton to Wroclaw Newspaper Gazeta Poludniowa No. 21/2003 dated 3.12.2003 (re-printed in Krynica Journal published in Ukraine, No. 95-96, 2017, p. 125):

«Particularly close contacts we have with the scientists and specialists from the Institute of Welding in Gliwice, headed by Prof. Jan Pilarczyk — well known scientist in the field of theory of welding processes, especially weldability of materials. Recently, he has become the President of the European Welding Federation. Together with this Institute we have carried out a lot of interesting researches and developments. They are related to the fields such as equipment and consumables for welding and surfacing, systems for automation of technological processes, analysis of weldability of metals using mathematical methods, investigation of strength of welded structures and their workability, diagnostics of their quality. In 1990, the Institute of Welding together with our Institute has founded the International Association «Welding» and makes significant input in its activity in both countries. Scientists 
of Kyiv and Gliwice Institutes actively cooperate during organization of international conferences, seminars, classes, publication of information materials, organization of exhibitions demonstrating achievements of scientists and specialist-welders on problems of welding and related technologies. Polish colleagues write for our journals «Avtomaticheskaya Svarka» («The Paton Welding Journal»), «Svarshchik» and PWI scientists publish their papers in Polish Journals «Biuletyn Instytutu Spawalnictwa» and «Przeglad Spawalnictwa».

Prof. Jan Pilarczyk always by him actively participated in performance of investigations. Many research works have been carried out and headed, and their results have been published in welding journals, booklets and books. He gave lectures in Polytechnic Institute of Silesia and Poznan Polytechnic Institute. He was a head of numerous Ph.D. theses, often acted as an opponent for Ph. D. and Dr. theses as well as participated in evaluation of candidates for a professor position.

He was and still is a member of many committees and organizations including member of Committee of Machine building of the Polish Academy of Sciences and chairman of a section of technologies of this Committee.

In a period from 1989 till 2005 he was a chief editor of Przeglad Spawalnictwa Journal. Currently he is a chairman of the Program Committee of this Journal, chief editor of Biuletyn Instytutu Spawalnictwa Journal, member of editorial board of «Avtomaticheskaya Svarka» («The Paton Welding Journal»).

Prof. Jan Pilarczyk for his longstanding and fruitful work was favored with many state orders, medals and awards. Among the most important are the Knight's Cross of Order of Polonia Restituta and Gold Medal for Long-term Service. Merits of Prof. Jan Pilarczyk were noted by the Ministry of National Economy of Poland - «Honorary award for services on development of national economy of Poland».

The most significant foreign awards are Diploma MERITE DE L'INVENTION (Brussels-1998), Prof. Jozefa Cabelki Medal (Slovakia-2000), AWS — Atlanta 2006 «INTERNATIONAL MERITORIOUS CERTIFICATE AWARD» for services for international welding society (in recognition of their wise counsel, devotion, time and generous contributions in promoting cordial global relations with industry and with other organizations and for their service to the International Welding Community) as well as IIW — the WALTER EDSTROM Medal (2015).

From Editorial board of «The Paton Welding Journal» 


\section{Interview with A.I. Panfilov — Director of Welding Department of «Steel Work» LLC}

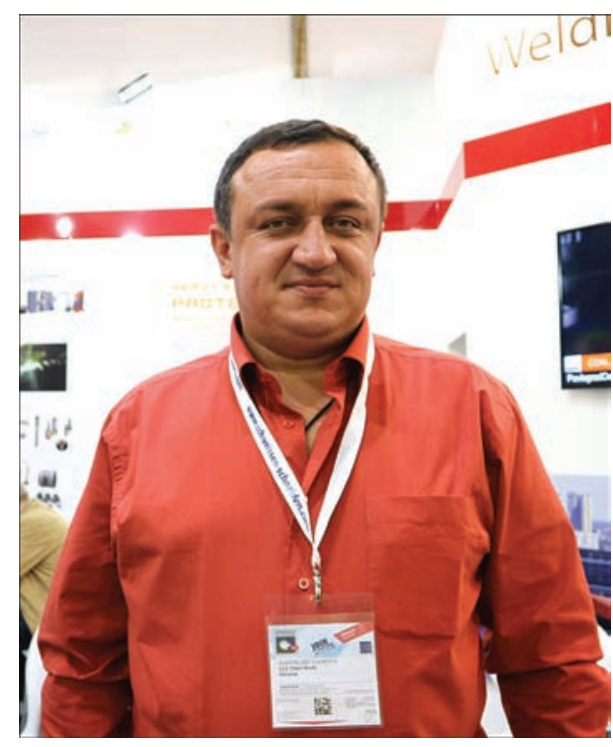

A.I. Panfilov on the joined booth of Ukrainian companies during «Welding and Cutting» Exhibition, September 25-29, 2017.

(Dusseldorf, Germany)

«Steel Work» LLC (Krivoy Rog) produces wear-resistant bimetallic plates and products from them as well as performs reconstruction, hardening and repair of different equipment subjected to abrasive wear.

«Steel Work» Company uses a Quality Management System which is certified by the requirements of International Standard ISO 9001 and Occupational Health and Safety Management System by the requirements of International Standard OHSAS 18001.

The Company supplies products to the preparation, mining and metallurgical enterprises of Ukraine and other countries.

Andrey Ivanovich, what are the origins of your company?

Initially, we created «Best Line» LLC, which dealt with repair of mining equipment with the help of welding and hardfacing as well as increase of wear resistance of components of grinding mills and blowing equipment. An idea of manufacture of bimetal and products from it has appeared in process of work. Such specialists as Panfilov I.I., Peleshko V.N., Panfilov S.A. and other people committed to this were the originators of «Steel Work» LLC.

In recent years, «Steel Work» Company demonstrates successful development and increases output of products, majority of which are bimetallic plates, produced by arc hardfacing. What can explain intensive development of your enterprise under conditions of reduction of Ukrainian market?

The team, successful management and wish to hold leading world market positions play an enormous role in the success.

What are the structures for which technologies of «Steel Work» LLC have been recently realized?

The most indicative were gas cleaning of blast furnace, Tarasov calibrator, drawdown tubes of blast furnace, hopper, chute of bell-less top, inserted cylinder, 13.5 m skip, rotors HP-7500 and HP-9000, shuttle conveyors and many other components.

The enterprise continuously carries out reconstruction of manufacturing capacities. What do you do for output of competitive products?

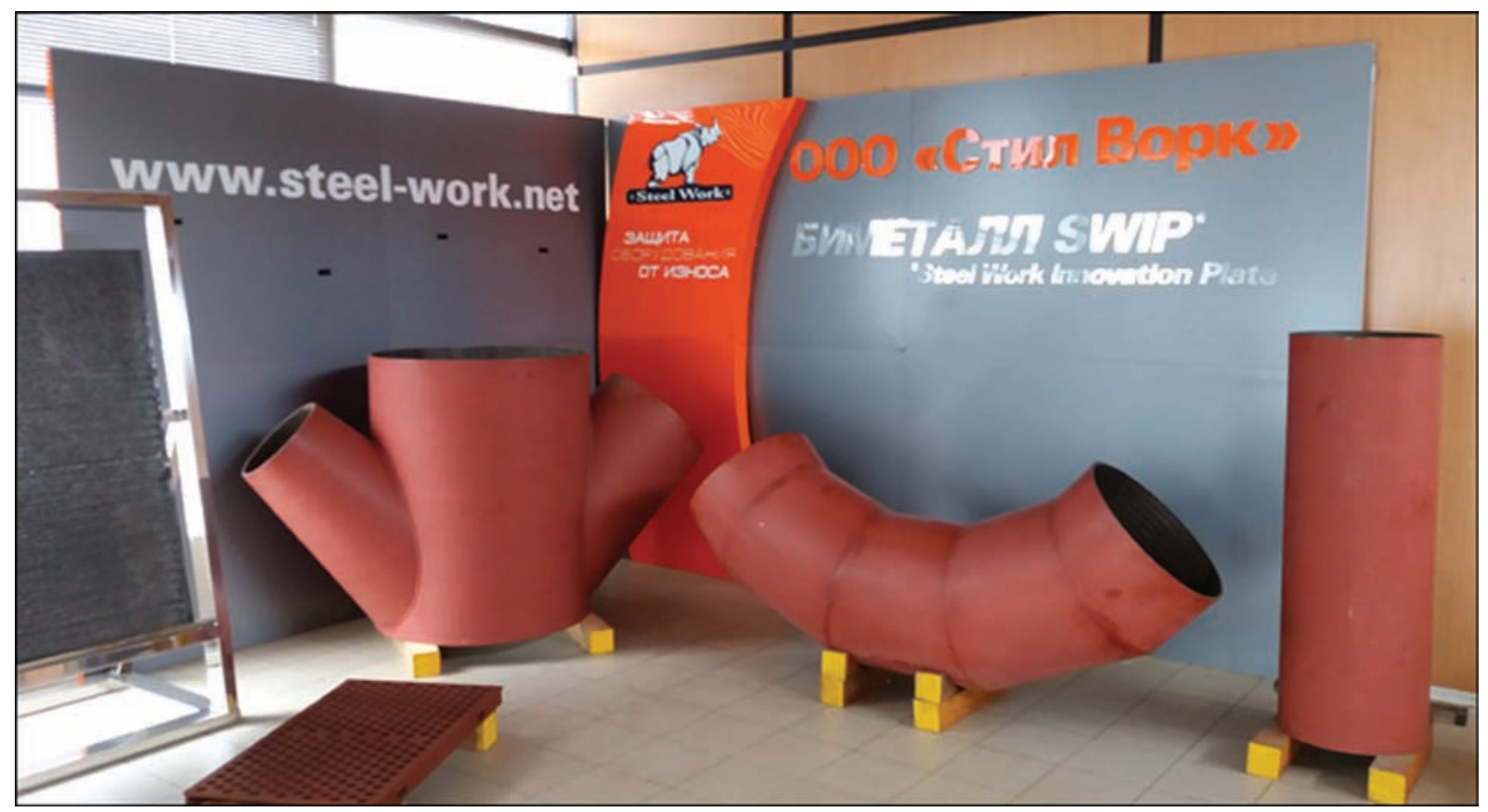




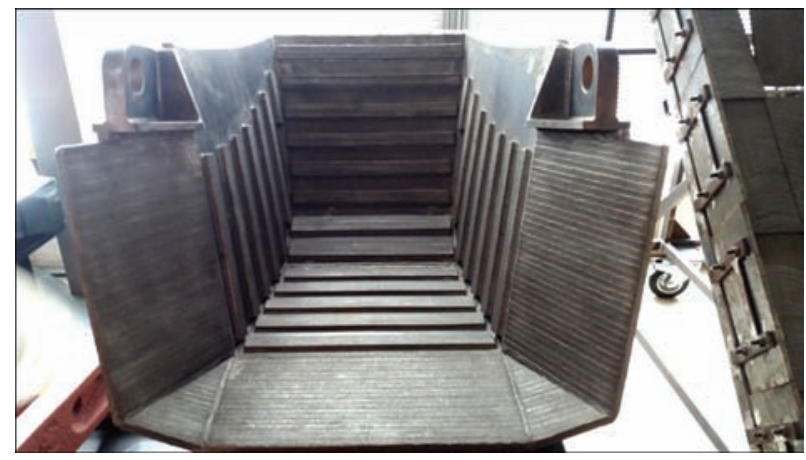

We use quality materials, improve production technologies, including automation and robotization of the production processes. Also, we are in process of implementation of the Quality Management System, in particular, 5S and 6SIGMA.

How does the enterprise solve staff problems, including related with outflow of professionals to Europe?

Due to successful management. We try to increase salary, improve labor conditions. Use other stimulus.

The enterprise has produced more than 10000 bimetallic plates SWIPR. What have changed in the plates

quality from the start of their production till now?

Wear-resistance of products and structures has been increased due to application of quality materials and more modern technologies. Also, we have increased a range of manufactured products.

How can you explain the fact that «Steel Work» has virtually no competitors in Ukraine?

Initially, such a production requires huge investments, payback time of which is more than 15 years. Not everybody is ready to such a risk.

Do you have any benefits from cooperation with the research institutes, including E.O. Paton Electric Welding Institute of the NAS of Ukraine, and what production problems shall be solved together with them?

Cooperation with E.O. Paton Electric Welding Institute of the NAS of Ukraine has provided «Steel Work» Company with a competitive advantage on price and quality of product. This cooperation allows solving the most complex problems at customers' enterprises. Due to joint work, we are getting increase of working efficiency, operation reliability and improvement of quality of released products.

One of the directions of production diversification is explosion welding technology and production of cladded bimetallic plate. What problems should be solved from point of view of production and busi-

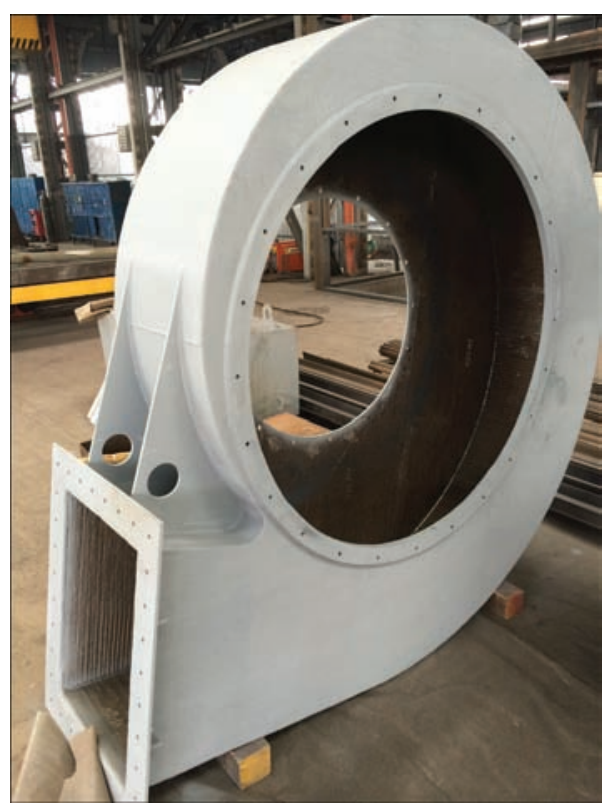
ness?

We work in this direction, but it also requires large investments and special production capacities, i.e. area, workshop and ground for explosion works.

Your enterprise virtually uses technologies of the XX century, and today in the XXI century productions all over the world use digital technologies in the context of «Industry 4.0» concept. What do you do in this direction?

We, like all over the world, try to develop in this direction, and, as I mentioned above, work on robotization and automation of production processes in order to improve product quality.

Andrey Ivanovich, you have proposed to organize a Museum of Welding in Krivoy Rog and made serious preparations. Why the Museum of Welding, not other technology and why in Krivoy Rog?

Krivoy Rog is a big industrial center. Profession of welder is very important in our production. A lot of discoveries have been made in this sphere, and, therefore, my task lies in popularizing this profession. In this connection, I and management of the Company have a great wish to create the Museum of Welding in Krivoy Rog and propose to celebrate the last Friday of May as a professional holiday — Day of Welder.

Thank you Andrey Ivanovich for you readiness to share with the Journal readers the directions of Company activities and wish you success in search and implementation

of innovative welding technologies.

Interview was recorded by A.T. Zelnichenko 